\title{
Industrial Demand-Side Management Programs: What's Happened, What Works, What's Needed
}

Prepared by:

Jennifer A. Jordan and Steven M. Nadel

American Council for an Energy-Efficient Economy

Prepared for:

Pacific Northwest Laboratories of

U.S. Dupartment of Energy

March 1993 


\section{TABLE OF CONTENTS}

\section{Page}

Executive Summary 1

Introduction 6

Methodology 10

Caveats 13

Results

Description of Successful Programs

Other Notable Efforts in Industrial DSM 37

Successful Programs: Common Traits

Steps to Help Advance Industrial DSM

Conclusions

References

69

Appendix: Industrial DSM Program Data 


\section{ACKNOWLEDGEMENTS}

The authors would like to acknowledge and thank a number of individuals and organizations who provided assistance during the course of this study. This project was funded by Pacific Northwest Laboratories of the U.S. Department of Energy, supplemented with a grant from the Energy Foundation. Michael Warwick of the Battelle/Pacific Northwest Laboratories and Diane Pirkey of the U.S. Department of Energy filled an important role in conceiving and overseeing the study.

Extensive assistance was provided by the utilities who provided detailed information on their industrial demand-side management programs. Without their cooperation and help, preparation of this report would not have been possible.

The following individuals provided helpful comments on a draft version of the report: Bruce Appelbaum and Ken Stern, Chem Systems; Diane DeVaul, Northeast-Midwest Institute; Neal Elliott, formerly of the North Carolina Alternative Energy Corporation (now with ACEEE); Nikhil Gandhi, XENERGY; Howard Geller, ACEEE; Fred Gordon, Pacific Energy Associates; Andrew MacMullen, Linhoff March; Bill Nicholson, Potlatch; Jane Peters, Barakat and Chamberlin; Marc Ross, University of Michigan, Ann Arbor; and Dick Rusk, Iowa State University Energy Analysis and Diagnostic Center.

Finally, thanks go to ACEEE staff member Micia Burgard for assistance producing the report.

Neither the individuals nor the organizations acknowledged here necessarily endorse the analysis or the conclusions expressed in this report. The authors assume full responsibility for all information presented. 


\section{EXECUTIVE SUMMARY}

\section{INTRODUCTION}

There is considerable room for improving the efficiency of industries in the United States. Studies have shown that the energy savings potential in the U.S. industrial sector in the years 2010 and 2015 range from $11-37 \%$ relative to a business-as-usual scenario. Several other studies have estimated the electricity savings potential in the industrial sector as between 9-38\%.

There are many reasons why the majority of industrial firms do not capture the energy savings still available in the industrial sector. Energy costs are generally a small fraction of total industrial costs, which means that the typical firm pays only limited attention to their energy bills. Additionally, for most firms, capital is scarce. Because the links between improvement in energy efficiency and higher priority goals such as improvements in plant productivity, product quality, environmental emission requirements, and labor and materials efficiency are generally not understood, energy-efficiency projects are considered non-strategic and take low priority when industrial firms allocate capital. A one- to three-year payback is often required for cost-saving investments such as energy-efficiency projects. Capital rationing, a common budgeting approach, further hinders energy-efficiency investments, since fewer investments are undertaken than would be justified by more conventional budgeting analysis.

Many industrial firms also have concerns about the long-term persistence of savings of energy-efficiency measures, the amount of downtime that will result from measure installation and maintenance, and the effect of process changes on productivity and ongoing operations. For some firms, there are doubts as to whether the technologies even save energy. The lack of easily accessible information on the availability and/or economic and technical viability of energy-efficiency measures under full-scale, actual usage conditions amplifies the skepticism. Smaller-sized firms in particular often do not even know about the specific technologies that are available. In addition, many small- to medium-sized industrial firms do not have the expertise 
on their staff nor the time to address energy efficiency in isolation from more strategic concerns.

Due to these barriers, there is justification for outside parties, such as utilities, to step in and encourage adoption of cost-effective energy-efficiency technologies. The field of utility demand-side management (DSM) has evolved to the point where utilities now have both the resources and the interest to play an important role in improving the energy efficiency of the U.S. industrial sector. In response to the growing interest in industrial DSM, this report documents utility experience with industrial DSM programs and provides recommendations to utilities and other key players on steps that could be taken to advance the field of industrial DSM.

\section{ANALYSIS OF INCENTIVE-BASED INDUSTRIAL DSM PROGRAMS}

In order to analyze experience to date with industrial DSM, a survey of utilities was conducted and a database of industrial DSM programs was prepared. More than eighty utilities and third-party organizations were interviewed. Data were collected via phone, fax, and/or mail from the utilities and entered into a database. In order to limit the scope of this study, the database contains incentive-based, energy-saving programs and not load management or information-only programs (including technical assistance programs).

Programs in the database were divided into four categories: two "prescriptive rebate" categories and two "custom rebate" categories. Prescriptive rebate programs are those programs which offer fixed financial incentives to participants who install utility-defined energy-efficiency measures (i.e. specific lighting or motor-related measures). Custom rebate programs are those DSM programs which offer a financial incentive to encourage the design and implementation of site-specific energy-efficiency projects within a participant's facility. Incentives are typically paid for each $\mathrm{kW}$ or $\mathrm{kWh}$ of svings.

The primary measures of program sliccess adopted for this study of industrial efficiency programs are high participation rates and/or high electricity savings as a percent of 1989 
industrial electricity sales, at levelized costs below the avoided costs of most utilities.

\section{Caveats}

There are a number of important caveats associated with the data. Perhaps most importantly, there is significant variation in the quality of the industrial program data and the methods with which different utilities track data. Additionally, for about one-third of the programs in the database, the energy savings results are highly approximate because, for many of the joint commercial and industrial (C\&I) programs in the database, a formal delineation of industrial versus commercial savings has not been performed. Other key issues include the fact that the number of participants, free riders, indirect costs, and customer costs are frequently not tracked.

\section{Database Results}

The database contains 31 incentive-based, energy-saving industrial DSM programs offered by 17 utilities. The appendix to this report summarizes the results approximately 60 industrial DSM programs. Most of the programs included in the appendix, but not in the database, are either C\&I programs for which commercial and industrial data were not disaggregated or new industrial DSM programs for which data are not yet available. One-half of the programs in the database offer custom incentives, one-third offer prescriptive rebates, and one-fifth offer both custom and prescriptive rebates. The average industrial program for which quantitative results were available (based on average database values and excluding remote outliers) has been offered for 4 years, has annually saved $0.2 \%$ of a utility's industrial 1989 electricity sales, has a $4 \%$ participation rate, and has a levelized utility cost of $\$ 0.019 / \mathrm{kWh}$ saved.

A total of 12 "successful" programs were identified in the database. These programs meet one or more of the following four criteria and cost the utility no more than $\$ 0.045 / \mathrm{kWh}$ saved: (a) annual participation rate of at least 8\%; (b) annual savings as a percent of 1989 industrial sales of at least $0.5 \%$; (c) cumulative participation rate of at least $12 \%$; and/or (d) 
cumulative savings as a percent of industrial sales of at least $0.7 \%$. The average annual savings as a percent of 1989 industrial sales for these "successful" programs are $1.1 \%$, the average annual participation rate is $9 \%$, and the levelized utility cost is $\$ 0.014 / \mathrm{kWh}$ saved. The successful programs have therefore achieved roughly six times the savings and two times the participation of the average program in the database, at lower cost. Features that appear to distinguish these twelve programs from others include addressing the industrial customer's perspective, using effective marketing strategies, offering a flexible program package, offering financial incentives, and performing extensive marketing research and program evaluations.

\section{STEPS TO ADVANCE INDUSTRIAL DSM}

There are a number of important steps which can be taken by particular parties to improve the field of industrial demand-side management. These include the following:

1. Utilities should improve industrial DSM program design by addressing customer concerns, improving marketing techniques, focusing on program flexibility, and offering financial incentives;

2. Utilities should improve data tracking methods and program evaluation techniques;

3. There should be improved information exchange among utilities through industrial DSM workshops and an industrial DSM conference;

4. Adjoining electric utilities should coordinate industrial DSM efforts to reduce customer and vendor confusion, and electric and gas utilities should coordinate joint industrial energy audits;

5. Utilities should establish better links with industries by attending industrial energy conferences and coordinating with industrial trade associations and state industrial 
efficiency programs;

6. Utility industrial DSM staff should receive education and training on industrial process materials and energy flows, the budgeting cycles of different industries, the general perspective of the industrial customer, and the links between improved energy efficiency and increased productivity and reduced environmental emissions;

7. The quality and quantity of data on industrial energy use patterns should be improver;

8. State-of-the-art energy-efficient industrial technologies should be demonstrated and monitored more widely; and

9. Links should be forged between energy efficiency and important industrial concerns.

\section{CONCLUSIONS}

Studies have shown enormous energy-savings potential in the U.S. industrial sector; ihe savings potential by the year 2010 relative to a business-as-usual scenario has been estimated as between $11-27 \%$, and up to $37 \%$ by the year 2015 . We cannot afford to leave this potential untapped. It is time for utilities, regulators, and other key parties to move forward and actively pursue the large energy-saving opportunities in the industrial sector. Although past experience in industrial DSM is not extensive, experience to date shows that successful programs can be designed and indicates ways to design even more successful programs in the future. 


\section{INTRODUCTION}

\section{Energy Use and Savings Opportunities in the Industrial Sector}

The industrial sector is responsible for $37 \%$ of U.S. energy consumption, considerably greater than any other sector. Industrial natural gas and electricity consumption are respectively $45 \%$ and $35 \%$ of total national consumption.

There is considerable room for improving the efficiency of industries; studies have shown that the energy-savings potential in the U.S. industrial sector in the years 2010 and 2015 range from $11-37 \%$ relative to a business-as-usual scenario. A study by four public interest research groups estimates that industrial sector energy-savings potential in the year 2010 is between 12 19\% (Alliance to Save Energy, et al. 1991). The U.S. Department of Energy (DOE) has estimated that the technical and achievable industrial energy-savings potentials in the year 2010 are $27 \%$ and $13 \%$ respectively (DOE 1988). The U.S. Congress' Office of Technology Assessment (OTA) estimates the potential industrial energy savings in the year 2015 as between 11-37\% (OTA 1991). And an Oak Ridge National Laboratory report estimates that the costeffective industrial fuel (non-electric) savings potential is $11 \%$ in the year 2010 (Carlsmith, et al. 1990).

Several other studies estimate the electricity savings potential in the industrial sector as between $9-38 \%$. The Electric Power Research Institute (EPRI) estimates that the maximum technical electricity savings potential in the industrial sector is between $24-38 \%$ in the year 2000 relative to a business-as-usual scenario (Faruqui, et al. 1990). Synergic Resources Corporation (SRC) has conducted studies for several utilities on the amount of savings that can be achieved over a 10-year period from cost-effective DSM measures in the industrial sector; depending on the utility, "conservative" estimates of potential savings range from 9-15\% (Heidell and King 1990). Another study has analyzed three years of data from an industrial DSM program offered at a major New England utility and estimates the potential savings per participant due to DSM programs at $13 \%$ of total facility electricity costs (Fuller 1992). A technical potential study 
performed for the state of New York estimates the cost-effective electric savings potential in the industrial sector, from application of motor and lighting measures (but not process measures), at $17 \%$ (Miller, et al. 1989).

\section{Barriers to Energy-Efficiency Investments in Industries}

There are many reasons why the majority of industrial firms do not capture the energy savings still available in the industrial sector. These reasons differ among the various industries and regions of the country. For example, there are notable differences between the most energyintensive and least energy-interisive industries and between larger and smaller-sized firms. Highlighted below are the most commonly cited barriers to pursuit of improved energy efficiency in the industrial sector. The barriers cited come primarily from existing literature on the subject (Alliance to Save Energy 1983; Carlsmith, et al. 1990; Fuller 1992; Jeffress 1992; Martucci and Sassone 1984; Reddy 1991). In a few cases, we supplemented this section with information obtained through interviews conducted with environmental managers at industrial firms, industrial program managers at utilities, and utility and industry experts.

\section{Energy Costs are Generally a Small Fraction of Total Industrial Costs}

Energy costs are generally between 3 to $5 \%$ of total industrial production costs (Appelbaum 1992, Elliott 1992; Steinmeyer 1992). ${ }^{1}$ A particular process modification, energyefficiency measure, or package of rneasures might reduce total energy use in a facility by a few percent, but this often results in a negligible reduction in the total cost of production. The small economic benefit from an individual retrofit or process modification is viewed as not being worth the "hassle".

\section{Investment Priorities}

Often energy efficiency takes low priority when industrial firms allocate capital. For

1 There are exceptions to this trend, such as the aluminum and chlorine industries, where energy costs are typically $25 \%$ of total production costs. 
most firms, capital is scarce, particularly in regions or industries hit hardest by recessions or low business cycles where even financial loans may be difficult to obtain. A firm's first priority is generally to get a quality product out the door as soon as possible, and available capital will usually be channelled to this end. Many firms discriminate between investments that increase market share and those that reduce costs, with preference given to the former. Investments in energy efficiency are cost-saving investments, whereas investments in improved product quality and plant productivity are viewed as increasing market share (Carlsmith, et al. 1990). Among many industrial firms, the links between improvement in energy efficiency and higher priority goals such as improvements in plant productivity, product quality, environmental emission requirements, and labor and materials efficiency are generally not understood. As a result, energy-efficiency investments are considered non-strategic and often lose out to investments in these other priorities (Jeffress 1992, Steinmeyer 1992).

A one- to three-year payback is often required for cost-saving investments (Fuller 1992; Hughes 1992; Carlsmith, et al. 1990). Payback requirements can fluctuate depending on the economic health of the firm; one industrial expert's experience has shown that large firms in good economic condition are often willing to accept up to a 5-year payback for efficiency measures, whereas in bad economic conditions these same firms might only be willing to accept a measure with a 6-month payback (Peters 1992).

Capital rationing, a common budgeting approach for larger industrial firms, further hinders energy-efficiency investments, since fewer investments are undertaken than would be justified by more conventional budgeting analysis (Alliance to Save Energy 1983). Under capital rationing, top management allocates capital separately to each division, or facility, within the firm. Since certain projects are often favored by top management, remaining allocations are less, and generally much less, than the profitable opportunities within most divisions or industrial facilities. Therefore, profitable projects compete against each other. Much of the available funds are spent on the top strategic projects favored by upper management and not on the projects favored by managers within each individual manufacturing plant (Ross 1992). 
Perceived Riskiness of Energy-Efficiency Investments

Industrial firms are concerned about the long-term persistence of energy savings, the amount of downtime that will result from measure installation and maintenance, and the effect of the changes on productivity and ongoing operations (Carlsmith, et al. 1990, Metz 1992). For some firms, there are doubts as to whether the technologies even save energy. These concerns often translate into a perception that the risks of energy-efficiency investments are too great to take.

\section{Lack of Information on Technologies}

There is a lack of easily-accessible information on the availability and/or economic and technical viability of energy-efficiency measures under full-scale, actual usage conditions (Carlsmith, et al. 1990, Metz 1992, Price 1992, Sullivan 1992). Smaller-sized firms in particular often do not even know about the specific technologies that are available. Lack of accessible current information is of particular concern for energy options that are relatively new or that are still evolving.

\section{Inadequate Staff and Time}

Many firms, particularly small- to medium-sized industrial firms, do not have the expertise on staff nor the time to address energy efficiency in isolation from more strategic concern; (Gordon 1992, Johnston 1992, Ross 1992). In addition, the time required to install energy-efficiency measures might be considered burdensome by some firms when implementation necessitates shutting down a process line. Most firms prefer to use scheduled downtimes, but only so much can be done at times of planned shutdown and maintenance work. Since there is generally no immediate time frame in which a firm must complete a conservation project, such projects generally receive minimal attention and are put off -- often indefinitely.

Due to these barriers, there is justification for outside parties, such as utilities, to step in and encourage adoption of cost-effective energy-efficiency technologies. The field of utility 
demand-side management (DSM) has evolved to the point where utilities now have both the resources and the interest to play an important role in improving the energy efficiency of the U.S. industrial sector. The savings potential summarized earlier, linked with the fact that energy use in the industrial sector is often concentrated in a relatively small number of customers, makes the industrial sector attractive to utilities pursuing DSM.

In response to the growing interest in industrial DSM, this report documents utility experience with industrial DSM programs. A survey of utilities was conducted and a database on industrial DSM programs was prepared in order to analyze program experience and the lessons learned. The report concludes with recommended steps particular parties can take to advance the field of industrial demand-side management.

\section{METHODOLOGY}

To develop a database of industrial DSM programs, contact was made via phone, fax, and/or mail with over 80 utilities and third-party organizations identified through iiterature review (particularly EPRI 1991, Nadel 1990) and word-of-mouth. Telephone interviews were conducted with all leads. Those utilities indicating that data were available were mailed or faxed a letter describing the project and a data request sheet. Specific data requested from utilities included the annual and cumulative ${ }^{2}$ values for the following: number of program participants, electricity or gas savings, direct utility expenditures (i.e., money directly paid to customers in the form of financial incentives), and indirect utility expenditures (i.e., administrative program costs incurred by the utility). Annual data were collected for 1991 when available (in a few cases 1990 data were collected). It is important to emphasize that for C\&I programs, data were collected only for the industrial portion of each program. Data on 1989 electric utility sales to industrial customers was taken from a document prepared by the U.S. Department of Energy (DOE 1991a, DOE 1991b).

\footnotetext{
2 "Cumulative" refers to the incremental annualized results of a program since its inception.
} 
Due to the need to limit the scope of this report, certain restrictions were placed on the types of programs which were included in the industrial DSM database. Information-only or audit-only programs were not included in the database, since for the most part, their overall impact has been relatively small compared to other DSM programs (Nadel 1990). In addition, we have focused on those DSM programs which reduce energy use and have not considered load management programs which shift energy use from. one time period to another without saving energy. Therefore, interruptible rate, load control, stand-by generation, and other load management programs were not examined. To be included in the database, utilities had to provide program data which allowed for the calculation of at least two of the three following indices: a program's industrial customer participation rate, industrial energy savings as a percent of the utility's industrial sales, and the levelized program cost to the utility. Furthermore, if a utility offered a joint commercial and industrial (C\&I) incentive-based DSM program, to be included in the database, program data had to be available which disaggregates between commercial sector and industrial sector results.

In order to evaluate the results of the database, certain measures of success were defined. The primary measures of success are high annual participation rates and/or high annual electricity savings as a percent of 1989 industrial electricity sales, at or below a threshold levelized cost which indicates a program is likely to be cost-effective to the sponsoring utility. In addition to data on participation rates and savings, qualitative information obtained through telephone interviews was also taken into consideration.

Participation rate is the number of customers participating in a program divided by the number of customers eligible for the program. Participation rates indicate the effectiveness of a program in reaching the eligible customer base.

Electricity savings are reported as a percent of a utility's total industrial sales. Savings as a percent of sales indicate the effectiveness of the program in significantly lowering a utility's electricity demand.

Program costs per $k$ Wh saved are based on levelized utility costs (including indirect costs 
such as staff and marketing) and do not include costs borne by the customer. Costs per $\mathrm{kWh}$ are levelized using the California Standard Practice Approach (CPUC 1987) over an assumed ten-year measure life and using a $6 \%$ real discount rate. ${ }^{3}$ A ten-year measure life is assumed since industrial equipment is often removed before the end of its useful life during changes to production processes (Gordon 1989; Nadel 1990). The 6\% discount rate is based on the average real cost of capital for a typical utility (Nadel 1990).

For the purposes of the ensuing analysis, programs in the database were divided into four somervhat arbitrary categories: Prescriptive Programs - Motors; Prescriptive Programs - Other; Custom Programs; and Joint Custom/Prescriptive Programs.

Prescriptive programs in the database are those programs which offer fixed financial incentives to participants who install specific, utility-defined energy-efficiency measures, such as the replacement of failed motors with motors exceeding specific efficiency ratings or the installation of a steam trap maintenance system. The Prescriptive Programs - Motors category includes prescriptive motor rebate programs, which generally offer incentives for the installation of energy-efficient motors in industrial facilities. The Prescriptive Programs - Other category consists of those prescriptive programs offering incentives either for one specific measure unrelated to motors or for a range of specific measures which may include motor-related measures.

Custom programs in the database are those DSM programs which offer a financial incentive to encourage the design and implementation of site-specific energy-efficiency projects, generally customer-designed, within a participant's facility. With customs programs the utility does not limit project eligibility to a predetermined list of efficiency measures.

To date, industrial DSM programs, like commercial programs, are focused primarily on equipment upgrades such as motors, lighting, and ventilation system upgrades. Even the custom

${ }^{3}$ For the few programs in the database which offer incentive payments over a measure's lifetime, calculations of levelized utility costs include only savings and payments to date, and not future savings and payments. 
programs generally focus on customer-designed versions of these "prescriptive" measures. Few existing DSM programs focus on improving the efficiency of individual manufacturing processes which account for the bulk of the energy used in industrial facilities. ${ }^{4}$ In choosing programs for inclusion in the database, we have particularly sought out those programs that address the efficiency of industrial processes. However, many of these programs have only just begun and program results are not available yet.

\section{CAVEATS}

Before results of the database analysis are presented, a number of important caveats should be noted.

Data were obtained from the individual utilities conducting the programs. There is significant variation in the quality of the industrial program data and the methods with which utilities track data. For example, some utilities track participation by the number of rebates given or the number of projects completed, whereas others track the participation of individual customers even if a single customer completes several projects. For this study, efforts were made to directly reflect the number of industrial customers in the participation rates. In order to supply us with comparable data, many utilities who only track the number of rebates given (rather than the number of rebated customers) made rough guesses of the ratio of rebates given to customers participating in a particular program.

For about one-third of the programs in the database, the energy savings results are highly approximate. This is due to the fact that, for many of the joint C\&I programs in the database, a formal delineation of industrial versus commercial savings has not been performed. Instead, managers of these programs made rough estimates of the percentage of total savings attributable

${ }^{4}$ Although electric motors typically account for between $60-90 \%$ of an industrial facility's electric consumption, only limited savings are available from changes to the motor itself -- much larger savings are available when the motor systems (motors, drives, gears, belts, etc.) are optimized for specific processes (Nadel, et al. 1991; Ross 1992). 
to the industrial sector.

Another significant caveat lies in the differing definitions utilities have for what constitutes an "industrial customer". Whereas most utilities base their definition on the Standard Industrial Classification (SIC) code system, some utilities base it on customer load requirements. To the extent possible, we have attempted to limit the information to programs serving customers falling within SIC codes 20 through $39 .^{5}$

The cost-effectiveness analyses employed in this study are from the utility perspective, rather than from the societal or participant perspectives, since data on customer costs were rarely available. In calculating levelized utility costs, for one-third of the programs, only direct utility expenditures (i.e. rebates) were available rather than the total indirect and direct costs which would include administrative expenditures. In these cases, we have assumed that the indirect utility program expenditures were $30 \%$ of the direct expenditures (Berry 1989; Nadel 1990).

Since approximately one-third of the program results include free riders (customers who participate in a program but would have implemented a conservation measure even if a program was not offered), average participation and savings results for the database probably exaggerate the effectiveness of the programs in acquiring additional electricity savings.

Due to the limitations outlined above, figures reported in this study are best used for scoping purposes only, rather than for detailed program evaluation.

5 SIC 20: Food \& kindred products; SIC 21: Tobacco products; SIC 22: Textile mill products; SIC 23: Apparel \& other textile products; SIC 24: Lumber \& wood products; SIC 25: Furniture \& fixtures; SIC 26: Paper \& allied products; SIC 27: Printing \& publishing; SIC 28: Chemicals \& allied products; SIC 29: Petroleum \& coal products; SIC 30: Rubber \& miscellaneous plastics; SIC 31: Leather \& leather products; SIC 32: Stone, clay, \& glass products; SIC 33: Primary metals industries; SIC 34-38: Metal durables; SIC 39: Miscellaneous manufacturing industries. 


\section{RESULTS}

Although there are hundreds of existing utility industrial DSM programs, in contacting utilities it became apparent that many programs either did not fall into the category of an incentive-based energy-efficiency program or had only just begun and program results were not yet available. The final database was narrowed down to 31 programs offered by 17 utilities (see Table 1). The database is therefore not an exhaustive list of all utility DSM programs offered to industrial customers, but is instead a small subset consisting of incentive-based programs for which the required data were available.

The appendix to this report summarizes approximately 60 industrial DSM programs, including the 31 programs in the report's database. Most of the programs included in the appendix, but not in the database, are either C\&I DSM programs for which commercial and industrial data were not disaggregated or new industrial DSM programs for which data are not available yet.

\section{Basic Description of Programs}

The majority of the programs in the database are offered jointly to C\&I customers, with less than one-fourth of the programs offered only to industrial customers. One industrial DSM program in the database is offered by a gas local distribution company; the rest of the programs are offered by electric or dual-fuel utilities. One-half of the programs (16) offer custom incentives, 9 offer prescriptive rebates, and 6 offer both custom and prescriptive rebates.

Prescriptive programs in the database generally offer direct rebates for the installation of energy-efficient measures related to the following: motors; lighting; heating, ventilation and air conditioning (HVAC) systems; steam traps; adjustable speed drives (ASDs); and compressed air systems. Rebates are typically based either on a dollar amount per unit energy saved, the incremental costs of installing efficient equipment, or a percentage of project costs.

The custom programs in the database offer incentives based on either a dollar amount per 


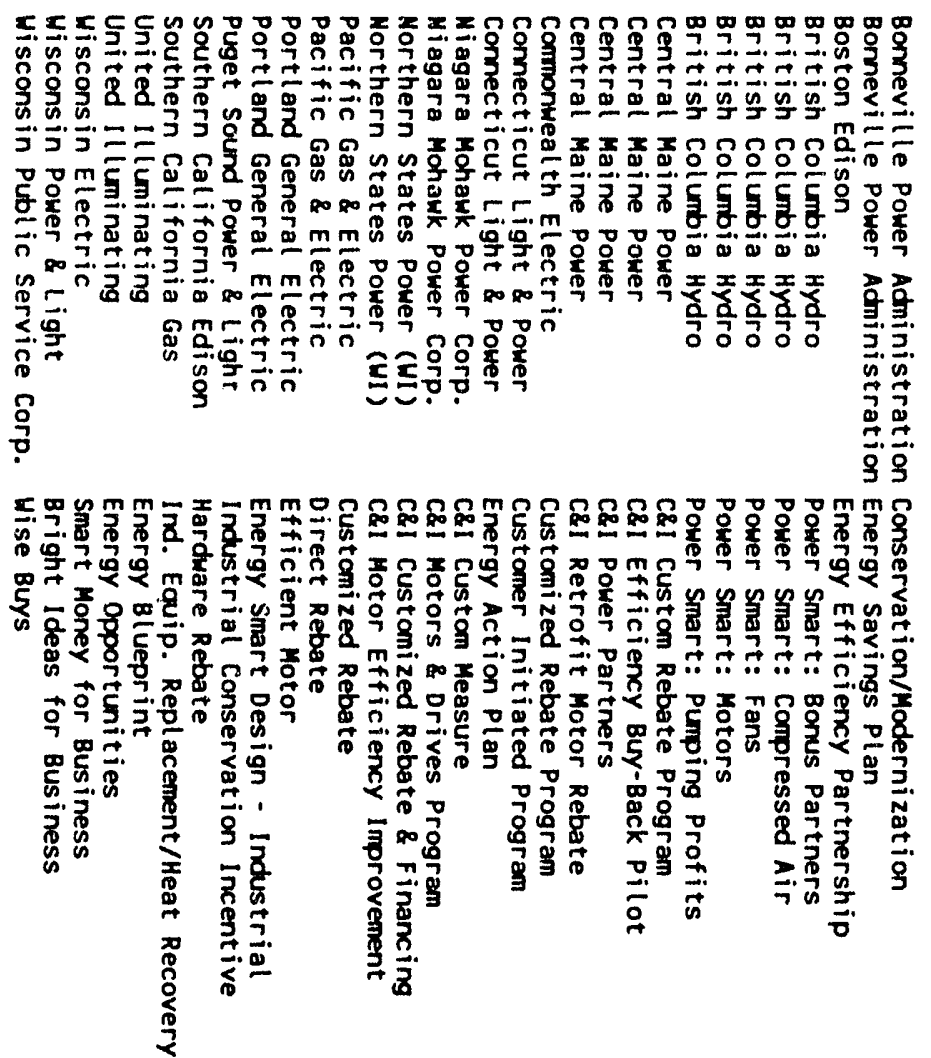

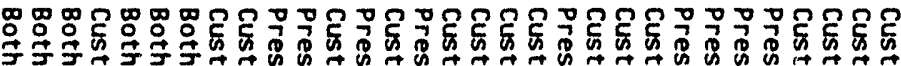

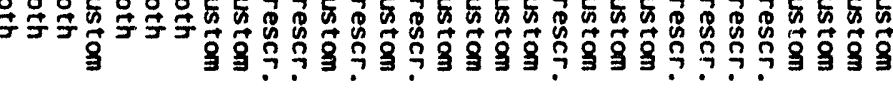

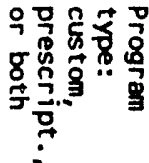

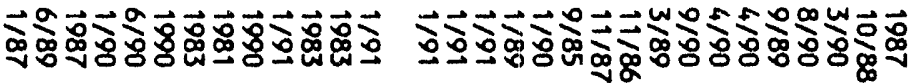

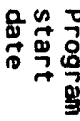

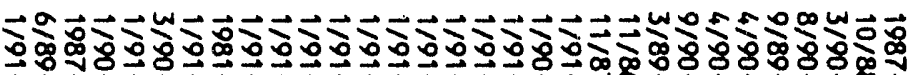

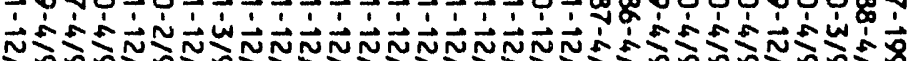

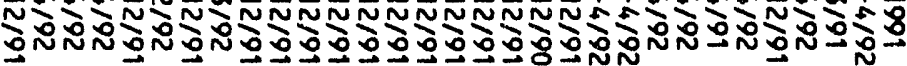

$\frac{2}{2}$

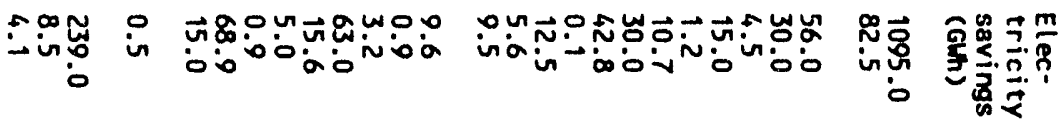

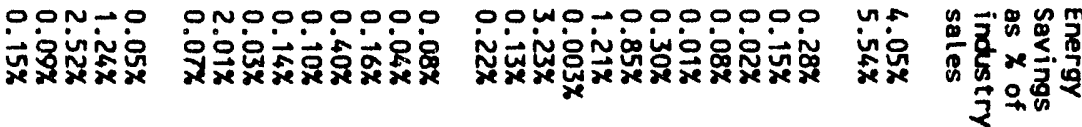

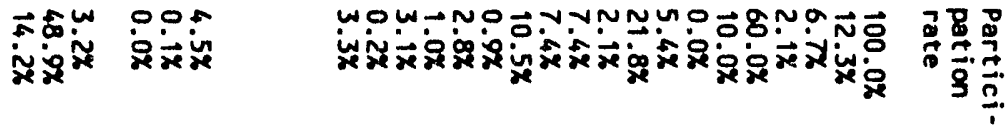

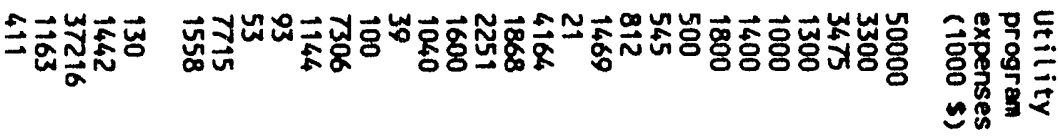

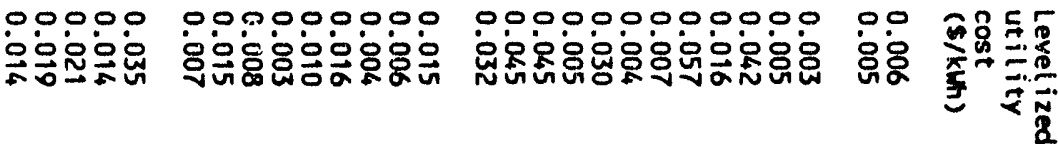


unit energy saved, the incremental costs of installing efficient equipment, a percentage of project costs, low-to-no-interesi loans, and/or payback period buy-down incentives (a utility offers a financial incentive to a program participant in order to reduce the participant's simple payback to a designated level, say two years). The custom rebate programs are generally structured so that an energy survey is performed first to identify energy-saving opportunities. Some utilities allow the customer to choose their own contractor to perform the initial survey, whereas other utilities have their own industrial engineers or contractors perform the survey. The measures most often installed in the custom programs are process heating and cooling system modifications, refrigeration improvements, and lighting and motor upgrades.

For approximately two-thirds of the programs in the database, estimates of free riders were made by the utilities and savings and participation data are net results. Varying methods of post-project on-site verification of savings (such as verifying that installed measures are still on-line, measuring the hours of equipment operation, and -- less frequently -- metering of equipment) have been performed for slightly less than one-half of the programs in the database. Since cumulative results (from the start of the program) were only available for less than half of the programs in the database, the data analysis focuses on annual data. Cumulative results are noted; however, due to the small sample size, these results are less robust.

\section{Average Results from Incentive-Based Industrial DSM Programs}

The average industrial program for which quantitative results are available (based on average database values and excluding remote outliers) has been offered for 4 years, has annually saved $0.2 \%$ of a utility's industrial 1989 electricity sales, has seen annual participation from roughly 1 of every 25 targeted industrial customers (a $4 \%$ participation rate), and has a levelized utility cost of $\$ 0.019 / \mathrm{kWh}$ saved. The average savings as a percent of sales since the start of the programs are $0.7 \%$, and the average cumulative participation rate is $9 \%$. Tables 2 and 3 highlight annual and cumulative results respectively. The median annual results in the database are close in value to the average annual results and are as follows: $0.2 \%$ savings as a percent of industrial electricity sales, $3 \%$ participation rate, and a levelized utility cost of $\$ 0.016 / \mathrm{kWh}$ saved. 
Table 2. Average Annual Results for Different Categories in the Database.

\begin{tabular}{||l|l|l|l|l||}
\hline & $\begin{array}{l}\text { Partici- } \\
\text { pation } \\
\text { rate }\end{array}$ & $\begin{array}{l}\text { Savings } \\
\text { as } \% \text { of } \\
1989 \\
\text { industrial } \\
\text { sales }\end{array}$ & $\begin{array}{l}\text { Levelized } \\
\text { utility } \\
\text { costs } \\
(\$ / \mathrm{kWh})\end{array}$ & $\begin{array}{l}\text { Number } \\
\text { of } \\
\text { programs } \\
\text { in } \\
\text { category }\end{array}$ \\
\hline All programs & $4.0 \%$ & $0.18 \%$ & 0.019 & 31 \\
\hline Prescriptive - Motors & $4.6 \%$ & $0.09 \%$ & 0.012 & 6 \\
\hline Prescriptive - Other & $5.0 \%$ & $0.06 \%$ & 0.026 & 3 \\
\hline Custom & $3.5 \%$ & $0.74 \%$ & 0.022 & 16 \\
\hline Custom \& Prescriptive & $4.5 \%$ & $0.14 \%$ & 0.016 & 6 \\
\hline "Successful" Programs & $9.0 \%$ & $1.11 \%$ & 0.014 & 12 \\
\hline
\end{tabular}

Table 3. Average Cumulative Results for Different Categories in the Database.

\begin{tabular}{||l|l|l|l||}
\hline & $\begin{array}{l}\text { Participation } \\
\text { rate }\end{array}$ & $\begin{array}{l}\text { Savings as } \\
\% \text { of 1989 } \\
\text { industrial } \\
\text { sales }\end{array}$ & $\begin{array}{l}\text { Number of } \\
\text { programs in } \\
\text { category }\end{array}$ \\
\hline All programs & $9.4 \%$ & $0.65 \%$ & 31 \\
\hline Prescriptive - Motors & $\mathrm{n} / \mathrm{a}$ & $0.16 \%$ & 6 \\
\hline Prescriptive - Other & $\mathrm{n} / \mathrm{a}$ & $0.06 \%$ & 3 \\
\hline Custom & $8.0 \%$ & $1.34 \%$ & 16 \\
\hline Custom \& Prescriptive & $14.2 \%$ & $0.31 \%$ & 6 \\
\hline "Successful" Programs & $20.3 \%$ & $1.33 \%$ & 12 \\
\hline
\end{tabular}


It should be noted that there is wide variation in the results of the 31 programs. More than half of the programs in the database have values that are either more than twice or less than one-half the average values highlighted above. This is most pronounced with the savings data, where more than two-thirds of the programs have savings percentages that are either more than twice or less than half of the average savings in the database.

\section{Successful Industrial DSM Programs}

While the average industrial program has had limited impact, there are a few programs which have achieved significantly higher savings and participation. "Successful" programs have been somewhat arbitrarily defined based on thresholds for annual and cumulative participation, savings, and levelized cost. These thresholds were arrived at after examining both the average values and the range of values in the database. A program, in order to be deemed successful, had to meet at least one of the following four criteria and cost the utility no more than $\$ 0.045 / \mathrm{kWh}$ saved: (a) annual participation rate of at least $8 \%$; (b) annual savings as a percent of 1989 industrial sales of at least $0.5 \%$; (c) cumulative participation rate of at least $12 \%$; or (d) cumulative savings as a percent of industrial sales of at least $0.7 \%$. A total of 12 programs meet these criteria.

Relative to the average program in the database, the successful programs have achieved more than two times the participation and roughly six times the electricity savings as a percent of industrial sales at lower cost. The average age of the successful programs is the same as that of the average program in the database. The average annual savings as a percent of 1989 industrial sales for these programs are $1.1 \%$, the average annual participation rate is $9 \%$, and the levelized utility cost is $\$ 0.014 / \mathrm{kWh}$ saved. The average cumulative results for the successful programs are $1.3 \%$ savings as percent of sales and $20 \%$ participation.

The custom programs account for three-fourths of the "successful" industrial DSM programs, although they account for only one-half of the programs in the database. In contrast, although motor programs account for almost one in every five programs in the database, no motor program met the criteria for successful programs. Prescriptive -- Other and 
Custom/Prescriptive programs are represented in the successful program category in approximate proportion to their fraction of the entire database.

An informal analysis of the financial incentives offered by the programs in the database was performed to compare the size of an incentive payment for the "average overall" program with that of the "successful" program in the database. Although it must be noted that this was not a rigorous analysis and that the sample size is small, a preliminary analysis shows that incentive payments appear higher for the successful programs. With a few exceptions, the successful programs offer incentives which generally cover between $50-100 \%$ of the total cost of industrial projects. Although less detailed data were available for the rest of the database, it appears that the average incentive payments for the less successful programs average between $30-60 \%$ of total project costs, with a few exceptions which offer higher incentives.

\section{Analysis by Program Type}

Differences among prescriptive and custom programs in the database arise when savings and participation rates are considered separately. Prescriptive programs tend to reach a larger number of customers, whereas custom programs appear to result in greater energy savings, both overall and per participant. The results from Tables 2 and 3 generally support this conclusion. Analysis of both annual and cumulative participation rates and energy savings showed that roughly $30 \%$ of the custom programs and $70 \%$ of the prescriptive programs are above the average and median participation rates of the database, and $60 \%$ of the custom programs and $20 \%$ of the prescriptive programs are above the average and median values for savings as a percent of industrial sales. Of the joint custom/prescriptive programs, $75 \%$ are above the average and median participation rates for the database, and $60 \%$ are above the average and median values for savings as a percent of industrial sales.

Since about two-thirds of industrial electricity use flows through motors, it is of no surprise that utilities have often opted to offer motor rebate programs over other types of prescriptive rebate programs (Nadel, et al. 1991). However, as noted earlier, there are a few prescriptive rebate programs in the database which target other end-uses such as industrial 
lighting, HVAC systems, steam traps, and compressed air systems. As shown in Tables 2 and 3 , these programs have resulted in savings and participation rates similar to the industrial motor rebate programs, but at more than twice the cost. This cost discrepancy may be partially due to the greater wealth of experience with and information on energy-efficient motor systems relative to many other prescriptive measures in industry.

There are seven programs in the database which are offered only to industrial customers (rather than to both commercial and industrial customers). It is of interest to note that all of these programs are offered by public utilities, suggesting that public utilities may have progressed further in industrial DSM. Of these seven programs, five are within the "successful program" category.

\section{DESCRIPTIONS OF SUCCESSFUL PROGRAMS}

This section highlights the 12 programs deemed "successful" by the criteria of this study. This is not a comprehensive list of all of the best DSM programs for industrial customers; rather, it is limited to the scope of this study and to those programs for which we obtained the necessary data. Custom, prescriptive, and joint custom/prescriptive programs are grouped together. Within each category, programs are listed alphabetically by utility. Levelized utility costs are based on cumulative data when possible and annual data otherwise.

\section{Custom Programs}

Bonneville Power Administration's Aluminum Smelter Conservation/Modernization Program

Bonneville Power Administration (BPA), a federal wholesaler of electricity in the Northwest, has been administering its Aluminum Smelter Conservation/Modernization (Con/Mod) program since 1987. The original purpose of this program was to retain load through improving the energy efficiency of the aluminum smelters in the region. The 10 primary smelters in BPA's service territory purchase approximately one-third of all BPA's 
power, or roughly $15 \%$ of the total electricity use in the region (sold by BPA and other utilities). The program was introduced at a time when BPA had an electricity surplus and when the aluminum industry was just emerging from: one of the longest economic slumps in recent history. Two plants had closed in the region, and there was the threat of more closures in the near future. The most vulnerable plants were of World War II vintage. Aluminum production is a highly electricity-intensive industry with electricity purchases responsible for approximately $25 \%$ of production costs. The short-term objective of the Con/Mod program was designed to encourage the region's 10 primary aluminum smelters to make additional investments in plant modernization so that they could become economically viable in the highly competitive world aluminum market. The long-term objective of the program from BPA's perspective was to purchase low-cost power from the smelters through efficiency improvements (Mortenson 1992).

All of the primary aluminum smelters participated in the planning and design of the program. Initial measurements of the baseline efficiency of the smelters, in $\mathrm{kWh}$ per pound of aluminum produced, were made in 1987. Since then, the smelters have reported their electricity use per pound to BPA on a quarterly basis. The incentive payment to the smelters is linked to improvements in this baseline efficiency and equals $\$ 0.005 / \mathrm{kWh}(1987 \$)$ saved over a ten-year period, or roughly one-third of the costs of efficiency improvements. Although the deadline for completion of modernization projects was mid-1991, BPA will continue making incentive payments to the smelters over the life of the measures. The customers are under no obligation to explain to the utility how they reduce their electricity consumption due to proprietary concerns. According to utility staff, as a result of this stipulation and the fact that many of the smelters need to make some of the improvements in order to survive, the financial incentive offered to the customer is fairly small (Kusaka 1992).

Since the start of the program, Con/Mod has achieved electricity savings of $4.1 \%$ of total industrial sales ${ }^{6}$ and a $100 \%$ participation rate (Mortenson 1992; Reiwer 1992). Although BPA has not estimated the free-ridership of this program, staff notes that some of the measures would

${ }^{6}$ Industrial electricity sales included in these calculations are both sales directly from BPA to the smelters and sales made by BPA's utility customers to their respective industrial customers. 
have been installed regardless of the program due to the smelters' need to remain competitive and electricity's high contribution to total aluminum production costs (Johnson 1992; Kusaka 1992). The levelized cost to the utility has been $\$ 0.006 / \mathrm{kWh}$ saved. According to the utility, the low cost of the program is partly due to the minimal administrative requirements of the program, since the smelters do not allow utility staff to enter their facilities. The smelters keep all the recorded data and report results to BPA.

BPA suspects that some smelters have made "real" energy savings as a result of the program, and others have made less genuine savings, meaning that the methods for reducing the $\mathrm{kWh}$ usage per unit of aluminum produced were not necessarily due to pure energy-efficiency improvements but rather to more questionable methods. For example, the amount of savings achieved in the smelter projects depended on the assumed baseline efficiency, which was regotiated jointly by BPA and the smelters. Since the program was initiated during an economic slump in the U.S. aluminum industry, the efficiency of many of the smelters was lower than normal when baseline efficiencies were calculated, according to utility staff. Soon after the program began, the industry began to recover as aluminum prices escalated. Smelters resumed their "noriral" operations, the efficiencies of the plants improved, and BPA has reason to believe that the resulting reluctions in $\mathrm{kWh}$ per pound of aluminum were claimed as savings under the Con/Mod program. Although BPA notes that this suspicion can not been proved, staff noted that the utility has seen only $50 \%$ of the savings "paid for" through this program, and increases in aluminum production do not fully account for the discrepancy (Kusaka 1992). "Real" energy savings generally came from installing process control measures and measures controlling the magnetic field of the pot within which aluminum is produced.

The program has been deemed successful by the utility, although there has been some concern about free riders and the fact that in late 1990 one of the ten smelters shut down. No official impact evaluation of the program has been performed because the aluminum smelters will not allow BPA into their facilities (Kusaka 1992). 


\section{BPA's Energy Savings Plan}

BPA's Energy Savings Plan (ESP) was initiated in early 1988 as a custom pilot program to promote energy efficiency in industries. According to utility staff, for the first 18 months of the program, participation was disappointing (Tawney 1992). As a result, when BPA redesigned the program to a full-scale version in mid-1990, it decentralized the program and altered the marketing techniques. Whereas the earlier version of ESP was designed and administered only by BPA, the revised program gives administering control to the utilities who distribute BPA's power in order to reduce the paperwork and increase the flexibility of the program. The new version brings together vendors, contractors, utility customers, industrial customers, and others to help plan, design, and participate in the on-going evaluation of the new program structure. As part of this evaluation, these parties contribute to the annual modification of a list of flexible "program principles" which the administering utilities use as the basis for designing their own version of ESP. BPA staff noted that flexible program principles were chosen over program rules in order to give the individual utilities the ability to design the program around the needs of their particular industrial customers. The on-going revision of the principles allows BPA to incorporate lessons learned and changing conditions into the program design in a timely manner (Rose 1992).

The utilities administering the program generally negotiate incentives with industrial participants based on the individual customer's needs; other benefits, such as changes in labor requirements and/or non-electric savings, are taken into account. On average, however, the customer receives -- upon completion of a project -- $\$ 0.15 / \mathrm{kWh}$ saved in the first year or $80 \%$ of the project costs, whichever is smaller. It was noted that as long as a project's payback can be reduced to less than three years, most industrial firms are interested in participating. Since, as with most industrial DSM programs, the customer receives an financial incentive after installing a project, the biggest barrier to participation is the difficulty industrial firms face when trying to locate the capital for initially financing a project (Reiwer 1992).

Increased emphasis has been placed on equipment vendors since the re-design of ESP in mid-1990. Utility marketing staff attend trade shows and offer vendor seminars in order to 
educate vendors on how ESP works and on effective methods for marketing their products by marketing the ESP program. Vendors have since played a central role in "selling" the program to industrial customers, and BPA staff cite this as largely contributing to the increased success of the program in attracting participants and savings (Peters 1992, Tawney 1992).

The past $11 / 2$ years of the program have seen a four-fold increase in the number of participants compared to the first $11 / 2$ years. If industrial electricity sales to primary aluminum smelters are excluded (since they are not eligible for the program and account for $95 \%$ of BPA electricity sales to industrial customers), the 1991 savings as a percent of industrial sales were $2.2 \%$. The 1991 participation rate was $4 \%$. Cumulative savings as a percent of sales are $5.5 \%$ and the cumulative participation rate is $12 \%$. ESP's low levelized utility cost of $\$ 0.005 / \mathrm{kWh}$ saved indicates its cost-effectiveness.

\section{Boston Edison's Energy Efficiency Partnership Program}

The Energy Efficiency Partnership program, offered by Boston Edison since 1990, provides commercial and industrial customers incentives to install energy-efficient measures in new and existing facilities. Incentives for customers constructing new facilities, or extensively renovating existing facilities, cover the incremental cost of efficient equipment. Incentives for retrofit measures generally buy down the payback period to one year, with the typical incentive covering approximately $80 \%$ of an industrial project's total costs. The retrofit incentives are received by the participant in quarterly payments over a two-year period, contingent upon verification of savings through end-use metering of a sample of installations within a facility.

If a participant wishes to receive an energy audit, two choices are available; either the customer can receive a free "mini" audit which covers lighting and motor systems, or the customer can receive a more comprehensive audit which the customer pays for up-front. The participant will be reimbursed a portion or all of the comprehensive audit costs depending on the percentage of recommendations that are adopted.

According to the utility, few new construction projects have been completed. Little 
direct marketing of the program has been done; the program is marketed via word-of-mouth. The utility generally tells industrial customers interested in the retrofit portion of the program that by participating in the program, their electricity bill can be reduced by $20 \%$ on average (Noell 1992).

The program has seen an annual participation rate of $7 \%$ and cumulative savings as a percent of sales of $0.7 \%$ (cumulative participation and annual savings were not available). The estimated levelized program cost is $\$ 0.035 / \mathrm{kWh}$. One industry expert who has followed Energy Efficiency Partnership noted that the program has been successful in acquiring process-related savings (Gordon 1992). Participation has been somewhat hindered by the fact that customers must finance the retrofits themselves; payments from the utility are received slowly over time and are given only if certain levels of savings are achieved. In an attempt to address these concerns, the utility is currently re-designing the way incentives are paid (Noell 1992).

Boston Edison has an interesting arrangement with the Massachusetts State Energy Office (SEO) with regard to industrial energy audits that is worth noting. For the past seven years, the SEO has been offering industrial firms in Massachusetts comprehensive audits covering electricity, fuel, and water use in their facilities. Called the Energy Advisor Service (EAS), this program is designed as a joint economic development and energy conservation service. EAS offers technical audits and analyses focusing on industrial processes performed by private engineering companies chosen for their knowledge of industrial processes. Almost 500 manufacturing facilities have been audited through the service. Until two years ago, industrial participants paid, on average, $\$ 100$ per day for the comprehensive audits and the SEO covered the rest of the service's costs, or roughly $\$ 700$ per day. When Boston Edison began offering its Energy Efficiency Partnership program, the SEO entered into an agreement with the utility. The EAS now provides the technical auditing services for the program, and the utility pays the SEO a percentage of the total costs of the service based on the number of recommendations which industrial participants ultimately decide to implement. The minimum percentage of the EAS costs paid by Boston Edison is $50 \%$ and the maximum is $70 \%$, based on the SEO's estimate that roughly $70 \%$ of their auditing time is spent on a facility's electricity use and $30 \%$ on thermal and water use. According to the utility and the SEO, the EAS audits have gained 
the general confidence of local industries due to their non-biased and comprehensive nature (Noell 1992, Sullivan 1992). The SEO noted that the audits have, on average, revealed that industrial firms can reduce their energy use by $15-20 \%$ through implementing energy-efficiency measures with a payback of under three years (Sullivan 1992). In the near future, the SEO plans to include environmental waste management opportunities in its auditing process.

\section{Central Maine Power's C\&I Custom Rebate and Efficiency Buy-Back Programs}

The commercial and industrial Custom Rebate program at Central Maine Power (CMP) encourages customers to install energy-efficient equipment not covered by the utility's prescriptive lighting or motor rebate programs. Incentives are available for both new and existing facilities. The majority of activity in the industrial sector has been in the retrofit category and not in new construction. Until recently, upon completion of a pre-approved conservation project, participants received $\$ 0.01$ per $\mathrm{kWh}$ expected to be saved over the lifetime of the measures. The incentive was capped at $90 \%$ of the project's material costs (not labor). This cap was recently changed to $80 \%$ of the total project costs because, according to the utility, vendors performing engineering analyses and measure installations were often rolling labor and engineering costs into the measure's "material" costs. Therefore, under the old incentive, the utility was paying for more than they bargained for (Littlefield 1992). The utility has also begun negotiating incentive amounts with customers on a trial basis. Measures frequently installed in industrial facilities include ASDs, sensors, and energy management systems. Some processspecific measures were installed as well. CMP's primary industrial customers are paper mills, wood products companies, and electronics manufacturers.

The Custom Rebate program has seen annual and cumulative participation rates of $6 \%$ and $22 \%$, respectively. Annual and cumulative savings as a percent of industrial electricity sales are $0.1 \%$ and $0.3 \%$, respectively. The levelized program cost to the utility is approximately $\$ 0.007 / \mathrm{kWh}$ saved. The utility has recently begun savings verification tests. The utility randomly inspects $10 \%$ of the projects one to two years after installation in order to verify that savings are still occurring, relying on both metering of equipment and questioning of the equipment operators. The program manager attributes much of the success of the program in 
attracting participants to the marketing of the program. The program is marketed largely through vendors and also through one-on-one meetings with industrial customers. Based on informal interviews with program participants and utility field staff, CMP estimates little to no free ridership within this program (Gervais 1993).

The precursor to the Custom Rebate program was CMP's Efficiency Buy-Back program. Initiated in 1986, Efficiency Buy-Back allowed large industrial and commercial customers to competitively bid for conservation incentives. Proposed projects had to save at least $500 \mathrm{MWh}$ per year. The program manager noted that the program was not entirely based on requests for proposals (RFPs), and that applications were accepted at other times as well (Carter 1992). Over time, the functions of the Custom Rebate and Efficiency Buy-Back programs began to overlap. Therefore, as of mid-1992, the utility absorbed the Efficiency Buy-Back into the Custom Rebate program.

The incentive under the Efficiency Buy-Back program brought a project's simple payback down to two years, with a maximum incentive equal to $50 \%$ of project costs. On average, customers received incentives close to the maximum allowable amount. The most commonly installed measures included process-related improvements in paper mills and lighting and space conditioning improvements.

As of December 1991, the program achieved a cumulative participation rate of $2 \%$, savings as a percent of 1989 industrial sales of $0.9 \%$, and a levelized utility cost of $\$ 0.004 / \mathrm{kWh}$ saved. The program's success, according to the utility, lies primarily in the flexibility of the program and in the fact that large energy-saving projects were targeted (Linn 1992). As with the custom rebate program, the utility estimates little to no free ridership in the program (Gervais 1993).

\section{CMP's Power Partners Program}

CMP's Power Partners program is an all-source bidding program in which C\&I customers or energy service companies (ESCOs) submit energy management project bids in 
response to RFPs issued by the utility for specific blocks of power. The applicants propose a payment level for a projected amount of electricity savings. Although bids have not been solicited for almost three years due to adequate power availability, savings from existing projects are still coming in, including savings from industrial projects. Measures often installed in the industrial projects include process-related improvements and lighting retrofits. Incentive payments are made over the lifetime of the measures, with the sum of the payments made over the years generally covering more than $100 \%$ of the initial project costs (Carter 1992). To date, ESCOs have generally managed the industrial projects in the program.

As of early 1992, the industrial projects within this bidding program have saved the equivalent of $1.2 \%$ of CMP's industrial electricity sales. Approximately $7 \%$ of CMP's industrial customers are involved in the Power Partners program. The levelized utility cost is $\$ 0.030 / \mathrm{kWh}$ saved. This cost takes into account all savings and costs accrued through 1991, and does not include future savings and costs since these were not available from the utility (projects typically receive payments for 15 years). Thus, the program is a cost-effective resource for CMP, even though the utility payment may be large compared to the initial cost of the efficiency projects. The utility monitors all projects within this program to determine if the savings are persisting over time. Staff noted the program's flexibility as a key component contributing to its success (Linn 1992). No estimates of the free ridership for this program have been made (Gervais 1993).

Commonwealth Electric's Custom Rebate Program

Commonwealth Electric (COM/Electric), located in Massachusetts, administered a Custom Rebate program to commercial and industrial customers between 1987 and 1991. The program offered a free comprehensive energy audit that resulted in recommendations of energysaving projects. Recommended measures were those whose cost fell below COM/Electric's avoided costs, which are high relative to other utilities. The customer then either chose a contractor or solicited bids from contractors to install the measures. The incentive covered up to $100 \%$ of the project's costs, including auditing, engineering studies, equipment, and installation costs. 
There was no need for the utility to market the program, since contractors eagerly played this role. Actually, according to the utility, the customer response to the program was too great and, in the interest of controlling costs, the program was terminated in mid-1991 so that $\mathrm{COM} /$ Electric could reassess the program design. A process evaluation was subsequently performed, revealing that, although the program had been designed to capture process-related energy savings, this goal had not been achieved (Casey 1992). The program did not require comprehensive retrofits; lighting measures dominated while few process-related retrofits were performed. In addition to lighting measures, air compressor, HVAC, and motor/ASD-related measures and enerigy management systems were frequently installed. According to utility staff, audits revealed that many of the potential process changes were gas-saving rather than electricity-saving (Carvalho 1992).

In spite of the lack of process improvements, in 1991 alone, the Custom $F$ jate program achieved a $10.5 \%$ participation rate and savings of $3.2 \%$ of industrial electricity sales. It is important to note that the savings estimates are under question and are being revisited by the utility, and the savings data could change significantly as a result (Casey 1992). Nevertheless, the savings results will most likely still be above average compared to the average industrial DSM program. However, the program comes at a cost. The levelized utility cost for the program in 1991 was $\$ 0.045 / \mathrm{kWh}$ saved, just under the cost-effectiveness limit set for "successful" programs. The success of the program in attracting participants, according to the utility, was largely due to the size of the financial incentives. Because of the high cost and lack of measure comprehensiveness, COM/Electric is in the process of re-designing this program.

\section{Puget Power's Industrial Conservation Incentive Program}

Puget Power, located in Washington State, has administered its Industrial Conservation Incentive program since 1981. Utility staff work with program participants and consultants to perform analyses of entire industrial systems, identify where the electricity savings and greatest overall customer benefits lie, oversee project bidding, assist in project design, and perform savings verification tests. Seminars on commonly-applied measures, such as ASDs or compressed air-related measures, are available to customers. Energy audits are performed by 
both utility staff as well as consultants chosen by either the utility or the customer. Three-tofive-year plans are developed with participants to coordinate which measures will be installed and when. Initially, although the program was open to all industrial customers, Puget targeted its marketing toward the 100 largest industrial customers. In the last few years they have begun to market to small- and medium-sized customers as well. The customer incentive usually covers approximately $75 \%$ of materials and installation costs of a project. Puget staff noted that due to the intensive labor requirements of this program, the availability of staff to broadly market the program is limited. The program is marketed simply by word-of-mouth (Banister 1992).

The utility divides the measures performed into three categories: process, HVAC, and lighting. According to the program manager, $80 \%$ of the measures performed are in the process category, which includes pumping, motor/ASD, compressed air, and refrigeration-related measures as well as other site-specific measures. Of these, pumping, motor/ASD, and compressed air-related measures are the most commonly installed process measures (Banister 1992).

The utility performs savings verification on every project one year after project completion, including metering and monitoring of installed equipment. In addition, for some of the projects, the utility will return to the facility in latter years to see if the equipment is still on-line. Although the utility has not yet formally estimated the number of free riders in the program, a preliminary draft evaluation by a consultant indicates that the percent of participants who are free riders may be approximately 10-20\% (Peters 1992).

The program achieved a participation rate of $1 \%$ in 1991 and 5\% cumulatively. According to the utility, low electric rates reduced the participation in the earlier years (Banister 1992). The electricity savings as a percent of industrial sales were $0.7 \%$ in 1991 and $2.0 \%$ since the beginning of the program. The savings have increased by a factor of four over the past three years. For 1992 and beyond, the utility has a goal of saving $1 \%$ of industrial sales annually through this program. The levelized utility cost in 1991 was $\$ 0.026 / \mathrm{kWh}$ saved.

The utility attributes the program's success to a number of factors, including the 
following: (1) the program is part of a package of energy services, and is marketed as such (industrial customers generally do not want to be part of a program, according to the utility, but would rather receive energy services); (2) contractors involved in the projects generally have extensive technical expertise in the participating industries; and (3) the audits and recommendations target process-related improvements.

\section{United Illuminating's Energy Opportunities Program}

United Illuminating (UI) in Connecticut is now into the second year of its commercial and industrial custom program, Energy Opportunities. The utility offers eligible customers free energy audits to determine electricity-saving opportunities. Customers have the choice of developing their own projects and presenting them to the utility or working with the utility in designing projects. The utility will co-fund, with the participant, engineering studies for measures related to advanced process, energy management, cogeneration, and heat recovery. The customer can choose its own vendors and contractors to carry out project implementation or ask for the utility's assistance. Until recently, financial incentives of $\$ 0.15 /$ first year $\mathrm{kWh}$ saved were offered for measures with payback periods greater than five years. Measures with shorter payback periods receive rebates as a percent of project cost; rebates decrease as the payback period decreases. Incentives have generally covered approximately $40 \%$ of the total project costs.

After its second year of a three-year DSM program planning cycle, UI had still not used a large portion of the program budget. As a result, in 1992 UI doubled the incentive for measures with paybacks greater than five years to $\$ 0.30$ /first year $\mathrm{kWh}$ saved for manufacturing customers. This change has led to a very large increase in participation in 1992 and a shift from prescriptive measures (generally lighting) to process-related measures (Mills 1992).

In the first two years of operation, Energy Opportunities cumulatively achieved a participation rate of $3 \%$ and savings as a percent of industrial sales of $1.2 \%$. The levelized utility cost was $\$ 0.014 / \mathrm{kWh}$ saved. Annual data are not available. Despite the fact that this program is relatively new and participation has been below expectations, UI has achieved high 
savings without large program start-up costs. The utility attributes the moderate success of the program partly to the flexible nature of the program. In addition, the program manager noted that during the first two years of the program, UI focused more attention on the quality of the engineering consultants and the audit than on the size of the incentives (Mills 1992).

\section{Prescriptive Programs}

British Columbia Hydro's Power Smart: Efficient Compressed Air Systems Program

British Columbia Hydro (BC Hydro) has estimated that up to $50 \%$ of the energy used in an industrial compressed air system can be lost through leaks. These losses are particularly great in pulp and paper mills, whose facilities often occupy acres of land and have an extensive network of distribution piping. In its Efficient Compressed Air Systems program, BC Hydro performs free leak tests on the compressed air systems of its industrial customers, targeting pulp and paper customers. The test identifies the general location of leaks, estimates how much they are costing the customer, and suggests a leak reduction target (generally down to $15 \%$ leakage of air volume). Either the customer repairs its own leaks (generally at very low cost) and the utility performs a follow-up leakage test three to six months later, or -- if the customer agrees to do quarterly leak testing for $21 / 2$ years -- the customer and the utility split the cost of leak testing equipment. If the leak reduction targets are being met, the utility will refund the customer's payment for the leak testing unit.

The program reached $27 \%$ of the eligible customers in 1991 alone and $60 \%$ since the program's inception $21 / 2$ years ago. Electricity savings as a percent of industrial sales were $0.07 \%$ in 1991 and $0.15 \%$ cumulatively. The levelized utility cost is $\$ 0.005 / \mathrm{kWh}$ saved. Some of the reasons for the program's success in recruiting participants were noted by the program manager: (1) the utility set an internal mandate to achieve $100 \%$ participation over a three-year time span; (2) an extensive marketing effort was made, including seminars and computer software packages; and (3) little time and effort is required by the customer to participate in the program (Merrill 1992). 


\section{Joint Custom/Prescriptive Programs}

\section{Wisconsin Electric's Smart Money for Business Program}

Wisconsin Electric's (WEPCo) C\&I Smart Money for Business program is a combination custom and prescriptive program offering commercial and industrial customers zero-to-low interest loans or cash rebates for installing qualifying energy-efficient measures. Special incentives are also provided to encourage energy-efficient design and new construction. Prescriptive rebates are available for lighting, HVAC, energy management controls, and refrigeration measures. Custom incentives are available for motor and process-related improvements and are negotiated with the customer on a case-by-case basis (even prescriptive rebates are sometimes negotiated). According to the program manager, this keeps program costs down since the lowest required incentive is generally offered. Between $20-50 \%$ of a custom project's total costs are typically covered by the incentive (Hawley 1992). If a project requires a feasibility study, WEPCo will pay up to $50 \%$ of the costs of a comprehensive audit.

After administering the program for over three years and studying the managerial structure of its industrial customers, WEPCo refined its marketing approach to reflect what had been learned. A two-pronged strategy is now taken: utility engineers communicate with and market the program to process-level plant personnel, such as plant engineers and maintenance operators. Simultaneously, utility account executives interact with and market the program to industrial vice presidents. Generally, smaller projects can be handled by the process-level employees, whereas larger projects must be dealt with at a senior management level.

Over the past five years, almost half of all WEPCo's industrial customers have received rebates or loans through the Smart Money program. The majority of participants have focused on prescriptive measures, with approximately $70-80 \%$ of rebates being prescriptive. More than half of the industrial energy savings have been due to lighting measures, while process-oriented measures are responsible for approximately $30 \%$ of the savings. The program manager noted that it has taken time to gain the trust of the industrial customers with regard to DSM, especially in moving from lighting and HVAC measures to process measures. According to the utility, 
industrial customers have shown great concern and caution in altering their processes (Hawley 1992).

The industrial portion of Smart Money for Business experienced a 12\% participation rate in 1991 and a $49 \%$ participation rate since the start of the program. Electricity savings as a percent of industrial electricity sales were $0.4 \%$ for projects installed in 1991, and $2.5 \%$ for projects implemented since the program began. The levelized utility cost is $\$ 0.021 / \mathrm{kWh}$ saved. The program manager noted that the program's success in recruiting a large proportion of the eligible industrial customer base and acquiring significant savings as a percent of sales is primarily due to the utility's focus on understanding the customer's perspective, making personal one-on-one customer contact, utilizing effective marketing techniques, simplifying the program while still offering a comprehensive package, and securing technical expertise necessary to do a good job (Hawley 1992).

The program manager noted that the utility is experimenting with a new component to the program: the utility will arrange contract agreements between customers and ESCOs with technical expertise in particular industries. The utility will assist in an initial audit, but beyond this the utility will primarily act as a facilitator. The ESCOs will guarantee the savings to the customer and sell the savings back to the utility (Hawley 1992).

\section{Wisconsin Power \& Light's Bright Ideas for Business}

Wisconsin Power \& Light, a dual-fuel utility, has offered its Bright Ideas for Business program since 1987. The program was initially designed as a shared-savings conservation program targeted at the company's largest C\&I customers. Under this arrangement, participants are paid the full cost of a pre-approved electricity and/or gas-saving project upon completion of measure installation and the customer and the utility sign a contract guaranteeing the savings, guaranteeing that the customer will have a positive cash flow, and stating that the customer agrees to pay back the utility for the cost of the project based on a monthly surcharge on their electric bill. During the first two years of the program, the utility experienced high administrative costs in its small shared-savings projects. To deal with this problem, in 1989 the 
utility added the option of prescriptive and custom rebates which are paid upon completion of the project. Prescriptive rebates are offered for energy-efficient lighting and motor retrofits. Custom rebates are offered for customer-designed, utility-approved projects. The custom incentive buys the project's simple payback down to two years, with a maximum incentive of $50 \%$ of the project's installation costs.

To date, roughly two-thirds of the program savings have come from lighting improvements. Installation of efficient motors, refrigeration systems, and energy rnanagement systems are relatively common. Utility staff noted that a shift is already underway toward more custom, process-related measures (Osterholz 1992). Most of the industrial projects during the past three years have been shared-savings projects; most of the smaller industrial projects received rebates. The utility is presently studying methods for reducing the administrative costs of the shared-savings option for smaller projects, since many small industrial customers cannot afford to make the up-front costs required under the rebate option (Greb 1993).

Marketing of the program has generally been by word-of-mouth and through field representatives. The utility plans to start an aggressive advertising campaign in 1993; according to staff, the "cream" of the energy savings has already been skimmed, the simple efficiency improvements within industries have generally been captured, and efforts need to be made to capture process-related savings. To date, the field representatives have been skilled in nonprocess-related energy-saving opportunities. In the coming year, the utility expects to rely more heavily on engineering consultants to help evaluate additional savings opportunities within industrial facilities.

The cumulative participation rate for the Bright Ideas for Business program (since 1989) is $14 \%$ and cumulative electricity savings as a percent of industrial sales are $0.1 \%$. The levelized utility cost is $\$ 0.019 / \mathrm{kWh}$ saved. ${ }^{7}$ These results are net of free riders. The utility has performed impact and process evaluations of the program. The high participation rate has been partially attributed to the commitment of many of the field representatives to conservation

${ }^{7}$ Although this program offers incentives for both gas and electricity savings, only electricity-related data were available. 
(Osterholz 1992). The savings as a percent of sales are not as high as savings from most of the other "successful" programs, and this is probably due to the fact that the majority of the measures installed were lighting measures which generally do not save a large percentage of overall industrial electricity use.

A few years ago, as part of this program, Wisconsin Power \& Light wrote a letter to motor vendors -- which was signed by a large portion of its industrial customers -- stating that the customers and the utility wanted energy-efficient motors stocked on a regular basis. According to the utility, the letter helped catalyze a market shift toward more efficient motors. To encourage a further shift, the utility has begun offering a promotional weekend vacation package to motor vendors for e isry 100 horsepower of ficient motors sold to customers.

\section{OTHER NOTABLE EFFORTS IN INDUSTRIAL DSM}

As noted earlier, although 70 programs are included in the appendix to this report, less than half of these programs were included in the data analysis. There are programs not listed in Table 1 that are worth highlighting due to their innovative design. In addition, a few programs in Table 1 which did not meet the "successful program" criteria have irteresting design features which are worth highlighting as well. Some of these more interesting efforts are summarized below. The following programs are not a comprehensive list of notable efforts, but are rather a further indication of the breadth of activity in industrial DSM program design.

BC Hydro's Power Smart: Bonus Partners Program

BC Hydro's Bonus Partners program, a custom nrogram for BC Hydro's industrial clismers, was initiated in mid-1990. The program is unique in its incentive design and marketing approach. Under Bonus Partners, industrial customers propose energy-conserving, process-related projects to $\mathrm{BC}$ Hydro; either financing options or cash grants are offered for qualifying projects. If an approved project yields savings of less than $200 \mathrm{MWh}$ per year, the participant generally receives an incentive which brings the project's payback period down to 
no less than two years. For larger projects, the utility meets with the customer and negotiates the investment criteria that the industrial customer would need in order to proceed with the project. In determining the incentive payment for projects of any size, other factors beyond the energy savings are considered; the utility works with the customer in determining the effects the project will have on maintenance costs, productivity, product quality, equipment reliability and other important industrial concerns. The utility and the participant jointly assign monetary values to these effects and factor these values into the incentive calculation. Pointing out the other benefits of the efficiency projects generally enhances participation in the program; the program manager noted that although this approach takes longer than a more traditional incentive arrangement, it is worth the effort. Incentives generally cover between $20-50 \%$ of the project costs; with BC Hydro's incentive design, the utility noted that an incentive covering 80-100\% of project costs is not needed (Hesson 1992). It is important to note, however, that customers participating in the larger Bonus Partners projects are generally energy-intensive industries, such as paper and pulp, mining, and food processing industries, and are more interested in improving the energy efficiency of their facilities than the average industrial firm. It is therefore unclear whether this trend of lower incentive requirements would apply to the typical industrial customer in other utility service territories.

In marketing Bonus Partners, as with many of its DSM programs, BC Hydro makes available to prospective participants a variety of literature on efficient technologies and case studies. One primary way in which BC Hydro has marketed this program is by co-sponsoring energy forums. The utility contacts staff at industrial associations who have an active interest in energy efficiency and offers to provide materials, partial financing, and marketing for a seminar on a particular topic of interest related to energy efficiency within the industry. BC Hydro's experience has been that the associations are generally very interested in going forward with such seminars. In the past 18 months, the utility has initiated a forum on industrial refrigeration and a forum for the foundry industry. An additional forum is currently being planned for the pulp and paper industry on distribution control systems. The key to the success, according to BC Hydro, is that the industry associations, and not the utility, are "up front" leading the forum. The industrial customer perceives their electric utility as an expert in one field, the production and delivery of electric power, and does not perceive the utility as 
knowledgeable in industrial technologies and processes (Hesson 1992).

\section{BC Hydro's Power Smart: Efficient Fan Program}

The Power Smart: Efficient Fan program narrowly missed the "successful program" designation of this report. The program was introduced in the spring of 1990 . Prior to the program, a utility-sponsored market survey was conducted to pinpoint the industrial application with the largest fan-related energy-savings potential. Lumber-drying kilns in the region's sawmills were noted as having the largest savings potential (50-60 GWh), and thus the program initially targeted the 400 lumber-drying kilns. According to the utility, electricity costs for the typical sawmill in the region are approximately 5-6\% of total production costs, slightly higher than the average percentage for industries. Free energy audits are offered to eligible customers to identify energy savings from installing fan speed controls (ASDs) and a few other fan-related efficiency measures. Approximately $85 \%$ of the region's lumber-drying kilns have been audited under the program. The marketing strategy for the program has emphasized multi-level contacts with the customer (i.e., marketing to both industrial financial executives and plant managers). ASD software and literature on case studies of electricity-saving fan-related projects are made available to interested customers. The program manager emphasized the importance of marketing the program first to the plant manager (in order to get the initial "buy-in") and then to the person running or managing the facility for final approval (Donnelly 1992).

Financial incentives are offered to participants based on energy savings and are designed to provide the customer with a one-year simple payback. Generally, the incentives cover between $65-75 \%$ of the project costs. ASDs are the primary measures installed. Since early 1992, the utility has begun marketing the program to other industrial customers besides sawmills, although the incentive to these customers is capped at a two-year rather than a oneyear payback. The program manager noted that industrial customers are very cautious when it comes to changing a process, since the potential financial repercussions are perceived to be great if something goes wrong. Installing fan speed controls in lumber drying-kilns is a processrelated measure, whereas in most other industrial applications it is not, and this is why the utility offers a payback buydown to one year with the kilns and not with other customers. 
The fan program achieved a participation rate of $6 \%$ in 1991 and $10 \%$ since initiation. Annual and cumulative savings as a percent of BC Hydro's industrial electricity sales are $0.01 \%$ and $0.02 \%$ respectively. The levelized utility cost is $\$ 0.042 / \mathrm{kWh}$ saved. Although the savings appear small, it should be noted that the targeted customers represent a relatively small proportion of total industrial sales. A savings verification evaluation performed in early 1992 indicated that the savings have been slightly less than projected, and in a few isolated cases no savings are being achieved because the energy-saving equipment has not been used. The nosavings cases were in situations where the project had only been "sold" at the management level and not at the plant level.

The utility has estimated that the potential electricity savings due to fan-related improvements in its industrial customers' facilities represent approximately $17 \%$ of BC Hydro's total potential industrial DSM savings. For the typical sawmill, fan-related improvements may reduce the customer's electricity bill by $2-3 \%$. Although this appears small, for many sawmills in the region the annual electricity bill is $\$ 1$ million per year, and the savings can be significant enough to capture the customer's attention. Typical savings from participating projects are approximately $\$ 5000$ per year per kiln (Donnelly 1993).

The program manager noted that a group of Canadian utilities have recently joined together in order to increase the effectiveness and minimize the costs of demand-side management programs for industrial fans, pumps, and blowers. The group is in the process of deciding how to promote more efficient fans, pumps, and blowers through manufacturers within the U.S. and Canada (Donnelly 1992).

\section{BC Hydro's Power Smart: Motor Rebate Program}

Relative to other motor rebate programs in the database, BC Hydro's Power Smart: Motor Rebate program has fared well. The utility offers industrial customers an incentive of $\$ 400 / \mathrm{kW}$ and $\$ 600 / \mathrm{kW}$ saved for new and replacement motors respectively. A vendor incentive is additionally offered and is equivalent to $20 \%$ of the customer incentive. 
Since the start of the program, BC Hydro has seen roughly $4 \%$ of its industrial customers participate and has experienced savings of $0.3 \%$ of industrial electricity sales. These savings are significantly higher than most motor rebate programs in the database. Annual data were not available. BC Hydro's levelized cost of $\$ 0.016 / \mathrm{kWh}$ saved is typical of other motor rebate programs.

Although the participation rate appears small, before the program began, high-efficiency motors accounted for only $5 \%$ of the motor horsepower sold in BC Hydro's service territory; as of early 1992 this figure has increased to $60 \%$. Largely due to the motor rebate program, many dealers have begun routinely stocking and selling high-efficiency motors; thus the program has been successful in transforming the motor market in British Columbia (McLelland 1992). Since the majority of motors rebated are large motors, it is not surprising that the percentage of horsepower sold in the form of high-efficiency motors is large even though the percentage of customers participating in the program is small. BC Hydro's program manager cited a number of reasons for the program's success: the presentation of a broad Power Smart package to industries, the close relationship established with customers, comprehensive educational materials (i.e., educational booklets for customers, computer software for dealers and large customers, and a motors database), and the vendor incentive.

\section{BC Hydro's Power Smart: Power Plays Pilot Program}

BC Hydro ran the Power Plays pilot program in 1991 as a test for a new and innovative approach to achieving industrial energy savings. The utility's aim in offering this program was to acquire low-cost savings by offering an incentive to employees who operate equipment in industrial customers' facilities. Employees at seven industrial facilities were encouraged to submit suggestions on electricity-saving measures. Employees whose ideas were finally implemented received $\$ 0.005 / \mathrm{kWh}$ saved from BC Hydro. Most of the viable ideas fall within the guidelines of another Power Smart program, and therefore the utility is also eligible for an incentive. According to the program manager, the industrial customers implemented and paid for more than two-thirds of the proposed projects themselves without applying for additional incentives (Venneman 1992). Within each participating facility, BC Hydro promoted the 
program for six months; workshops were held and ideas were solicited. The pilot program had a good response, according to the program manager, and $2.5 \mathrm{GW}$ of load reduction were achieved. The retrofit most commonly performed was the installation of sensors and timers for motors, lights, fans, and pumps.

The utility is in the process of designing a full-scale version of the program which will be presented to customers in early 1993. An evaluation of the pilot program indicated that the six-month promotional period within each industrial facility was unnecessarily long, so the new version of the program will promote the program for only two months. After the two-month period is over, the utility plans to do an initial survey of the technical feasibility of the proposed projects. Then a meeting will be held with the key decision makers in the industrial firm to decide which of the options are the most viable based on a number of factors, including the project's effect on safety and production. The utility is also considering offering a "two-tiered" incentive. With this approach, the utility will offer -- in addition to the reward for the employee whose idea is implemented -- a more comprehensive point-based incentive system in which managers and other employees who contribute to the success of the program are awarded points which are redeemable for prizes (Venneman 1992).

\section{Carolina Power \& Light's Industrial Audit Program}

Carolina Power \& Light in North Carolina has offered an intensive industrial audit program since 1983. The program is seen as both a method for maintaining the economic viability of industrial firms as well as a method for improving power quality, moving load offpeak, and achieving energy savings. Free audits are offered for existing and new industrial facilities. Audits can last from one day to two months, depending on the customer's size and needs. Surveys of electricity, water, gas, and other fuel savings are performed. According to the program manager, this comprehensive approach significantly enhances customer respect for the program (Castellow 1992). In recommending measures for implementation, the utility takes into account both energy savings and optimizing loads to available rate structures. The auditors generally recommend measures with a two-year payback or less because experience has shown that these are the measures that get implemented; however, in a few cases, measures with up 
to a 7-year payback have been recommended and implemented due to either a unique situation or to the fact that the customer will not survive economically without implementing the measures (Pendleton 1992).

The dominant industries in Carolina Power \& Light's service territory are textiles, paper and pulp, wood products, and chemicals. The measures most frequently installed as a result of utility recommendations are the optimization of chillers, boilers, and lighting systems. In addition, process-related energy-saving measures are often installed, such as infrared and microwave drying. Installation of energy-efficient motors has also brought large savings in the industrial audit program. For customers who have motors which run for long periods of time, auditors perform a motor survey, including spot metering of motor $\mathrm{kW}$ use, and focus on units that upon failure should be replaced with high-efficiency motors. They often recommend that customers mark motors which have high operating hours and/or are improperly sized with yellow paint. Instead of repairing failed "yellow dot" motors, staff are instructed to replace these units with energy-efficient models. Follow-up surveys have shown that this system has worked well in practice.

Although the reduction in customer electricity costs varies widely, typically if all the recommended measures are implemented, customer electricity costs are reduced by $10-15 \%$ and sometimes even by 30-40\% (Castellow 1992; Pendleton 1992). Between 1983 and 1989, approximately 200 customers received audits, resulting in demand reductions of about $75 \mathrm{MW}$ (Nadel, et al. 1991). Between 1989 and early 1992, roughly 100 additional customers were audited (Welker 1992). The utility noted that the program has been very cost-effective. Carolina Power \& Light has not offered, and does not plan to offer, financial incentives to encourage participants to install recommended measures. Staff noted that the free comprehensive audits are a significant incentive and a large proportion of the recommendations are implemented; therefore, a financial incentive is not deemed necessary.

Connecticut Light \& Power's Energy Action and Customer-Initiated Programs

Connecticut Light \& Power has offered two customized programs for commercial and 
industrial customers, the Energy Action Program (EAP) and the Customer-Initiated Program (CIP). Under the EAP, which began in 1987, the utility's contractor performs an audit on a customer's facility. If the customer wishes to go further, a detailed energy study of the facility is performed for which the customer and the utility split the cost. The customer's payment is refunded if the customer decides to go ahead with implementation of a measure(s) which cost more than the energy study. To date, all participants who received a detailed energy study have implemented at least a portion of the utility's recommendations. More than half of the projects performed under the EAP are lighting-related projects, one-fourth of the projects are processrelated, and the remainder are mainly refrigeration and motor-related projects (Sayko 1992).

Initially, the incentive for industrial customers brought down the cost of qualifying conservation measures to a three-year payback. However, this incentive did not attract sufficient participants. Therefore, starting in 1990, the utility began offering industrial customers an incentive which buys down the cost of measures to a one-year payback, up to a maximum of $90 \%$ of the total project costs (except for lighting projects which are still based on a three-year payback). According to the program manager, most industrial projects to date have received incentives covering approximately $80 \%$ of the total project costs. Another change in the program design relates to the method with which the participant recovers the energy study costs. To promote comprehensive retrofits, the utility recently altered the format and now requires that, in order for the customer to recover the energy study costs, measures accounting for at least $80 \%$ of the recommended energy savings must be installed.

The Customer-Initiated Program (CIP), which got underway in 1989, was a response to some industrial customers' hesitation at allowing the utility to enter their facilities for proprietary reasons. This program is similar to EAP with the main difference being that under CIP the utility does not provide a comprehensive analysis of participants' facilities nor a contractor to provide technical assistance. In addition, participants in the CIP can perform single conservation retrofits rather than larger projects. The utility encourages customers to enroll in the EAP over the CIP, but there has been enough demand for the CIP to justify operating both programs.

The EAP just missed passing the "successful" program criteria, with a 1991 participation 
rate of $3 \%$ and savings as a percent of industrial sales of $0.2 \%$. In 1991, the CIP achieved a participation rate of $1 \%$ and savings as a percent of industrial sales of $0.1 \%$. According to the

program manager, although engineering analyses are used to estimate savings, an impact evaluation of the two programs is presently underway. The preliminary findings of the evaluation indicate that, on the aggregate, savings estimates have been accurate (Sayko 1992).

\section{New England Electric System's Energy Initiative and Design 2000 Programs}

New England Electric System (NEES) offers two commercial and industrial conservation programs: the Energy Initiative program for existing facilities and the Design 2000 program for new construction (new construction in the industrial sector includes major facility re-design and replacement of equipment at the end of its useful life as well as new facility construction). Technical assistance is provided for both of these programs. These programs are notable for their relatively high energy savings. In 1991, Energy Initiative saved approximately $1.1 \%$ of commercial and industrial electricity sales. In 1992, Design 2000 saved $0.4 \%$ of commercial and industrial electricity sales (McAteer 1993). Since the utility does not separate commercial results from industrial results, these programs could not be included in the database.

The two programs offer a variety of incentives covering both prescriptive measures (i.e. motors, lighting, HVAC, and prescriptive process measures) and custom measures. Special incentives are offered for certain plastics industry and jewelry industry measures (NEES serves a large number of plastics and jewelry factories). The Design 2000 incentives generally cover $100 \%$ of the incremental costs of installed measures, with 30 percent of the costs available upfront. The utility verifies savings through metered analyses, case studies, and billing analyses.

In 1991, the Energy Initiative incentives generally covered $100 \%$ of the full cost of measures. Due to the large incentive, Energy Initiative program was oversubscribed and went over budget in 1991 (more than $\$ 12$ million in ASD incentives were paid). As a result, incentive levels were lowered in 1992 to approximately 60-80\% of project costs (lighting projects were brought down to a $11 / 2$ year payback, and non-lighting projects to a one year payback). Even so, the program still faced oversubscription within the first few days of 
operation in 1992. In order to stay within the program's budget, the utility negotiated incentives and the scope of projects with new participants. In 1993, NEES is offering incentives which cover approximately $30-50 \%$ of total measure costs. In addition, the utility's marketing strategy has changed significantly. Whereas in the past NEES relied heavily on vendor marketing, now utility representatives are more actively involved with the customers, offering a number of services including technical assistance and detailed measure implementation planning. The intention is to have utility staff work more directly with the customer in order to plan long-term DSM strategies for each customer that, it is hoped, will result in a more even flow of work under the program. The utility plans to monitor the effects of the lower incentives and the new program approach on program participation (Panacoast 1993).

In 1992, NEES ran a pilot program in which detailed technical studies were performed on the facilities of seven C\&I customers. Although NEES has offered technical studies to all its C\&I customers for the past two years, studies performed under the pilot program were of greater scope and depth. The intent of the pilot was not only to gain greater knowledge of the energy-efficiency opportunities in different types of commercial and industrial facilities and incorporate this knowledge into existing programs, but to also gain greater understanding of the interactions between different efficiency measures (i.e. how the installation of various lighting measures affects electricity use in HVAC systems). The results of the pilot program are presently being compiled by the utility (Campbell 1993).

\section{Niagara Mohawk's C\&I Motors and Drives Program}

Niagara Mohawk Power Corporation, located in New York, has offered a C\&I Motors and Drives Program since January 1991. Under this program, financial incentives are offered for the installation of energy-efficient motors and drives. The incentives are fixed and are based on the nominal motor efficiency and horsepower. Generally, the ASD incentives pay for 50$75 \%$ of the drive installation costs. More drives than motors are installed under this program. The marketing staff is trained to demonstrate the advantages of ASDs and efficient motors from the customer's perspective. According to the program manager, substantial funds are spent on marketing to and working with equipment vendors (Stapleton 1992). The utility organizes 
numerous breakfast meetings with trade allies and assists them in marketing the program at industrial shows. Now that word has spread about the program, the utility plans a lower-key marketing approach for 1993.

In its first year, this program exceeded the utility's savings goal by $500 \%$. The program's industrial savings were $0.1 \%$ of industrial electricity sales. The participation rate was $3 \%$, and the levelized utility cost was $\$ 0.015 / \mathrm{kWh}$ saved. Niagara Mohawk credits its marketing approach and the large ASD incentive for the program's success.

\section{Southern California Gas' Industrial Equipment Replacement/Heat Recovery Program}

Since 1990, Southern California Gas has offered incentives to industrial customers to install or replace efficient equipment through its High Efficiency Industrial Equipment Replacement and Industrial Heat Recovery programs. This program is notable since it is the only industrial programs in the database offered by a gas utility. The measures most commonly installed are high-efficiency boilers, burners, economizers, and recuperators. The program achieved a $2 \%$ annual participation rate and $0.2 \%$ savings as a percent of 1991 industrial gas sales. The levelized utility cost was $\$ 0.04$ per therm saved (compared to a typical marginal cost of $\$ 0.30 /$ therm). Cumulative savings were $0.3 \%$ of industrial retail sales. According to utility staff, some customers are meeting new air quality standards in California by participating in the program. Customers who operate industrial process waste heat boilers can receive a rebate for adding "super-efficient" heat recovery devices to these boilers. The devices can increase the efficiency of the boilers to at least $92.5 \%$, according to the utility, and this helps participants meet air quality regulations (Maynard 1993).

\section{Yankee Gas' Industrial Conservation Fund}

Another industrial DSM program offered by a gas utility is Yankee Gas' Industrial Conservation Fund. Although this program is summarized in the appendix, insufficient data were available to include it in the database. Yankee Gas, based in Connecticut, established the program in August, 1991. The Industrial Conservation Fund offers grants to manufacturing 
customers who are financially distressed to install gas conservation measures. Grants buy down the payback periods of conservation measures to 18-24 months. Free audits of the customer's facilities are performed. Customers compete for grants by submitting proposals during "rounds" which are held approximately twice a year. The proposals must outline cost estimates, energy savings, engineering analyses, environmental benefits, and economic development opportunities associated with the projects.

The first round of grants, totaling $\$ 500,000$, were awarded in August 1992. Twenty-two customers filed applications, and all were offered grants of varying amounts; the projects with ingher savings-to-cost ratios received larger grants. Twenty-one customers accepted the grants and one customer refused, stating that the grant was too small. The utility pays the grant to the customer upon completion of the project. One project has been completed to date. The types of industries participating and projects involved in the program vary, according to the program manager. Brass forges have participated in the greatest numbers; there are many improvements that can be made in the old and inefficient annealing furnaces of these facilities that reap large gas savings (Toth 1992).

\section{SUCCESSFUL PROGRAMS: COMMON TRAITS}

There are several traits which appear among the relatively successful programs -programs with above-average participation and savings. Outlined below are some of the primary features which appear to distinguish more successful programs from less successful programs. Given the small number of programs analyzed, the limited data available, and the recent start of many of the programs, these findings should be considered preliminary and not definitive.

\section{Addressing Customer Concerns}

Addressing customer concerns is particularly important when it comes to industrial firms. To date, industries have been skeptical about the quality and intent of utility DSM programs (Metz 1992, Nicholson 1992, Price 1992, Steinmeyer 1992). A survey conducted in 1991 by 
the Washington State Energy Office (WSEO) concluded that industries do not generally perceive utilities and government as credible sources of information (Hamilton and Rudeen 1991). This is primarily due to insufficient attention on the part of utilities to the perspective and priorities of industrial customers.

Issues of concern for industries include power quality and reliability, waste minimization and disposal, environmental regulations, and competitiveness. In order to operate successful industrial energy-efficiency programs, it is essential for utilities to understand the interconnectedness of these factors with industrial process energy flows and to design and market programs with such links in mind. As one long-time industry observer aptly put it, an industrial DSM program "can't be meringue, it's got to be a pretty solid pie" (Hamilton and Rudeen 1991).

In particular, productivity and environmental concerns are more important to industries than are energy costs. Not only must industrial firms remain competitive in order to survive, they must comply with a growing number of environmental and health regulations. In addition, many industries want to be viewed as "green". Capital budgeting cycles of industrial firms often reflect these concerns; according to one industrial manager, the first capital expenditures for large industrial firms in the U.S. are generally related to OSHA and environmental regulations, and the second expenditures are usually for new or improved product development (Price 1992). Various utilities with at least five years of industrial DSM experience behind them, such as BC Hydro, Puget Power, and Wisconsin Electric, indicated that they have had to "prove their value to the industrial customer" and that it has been important for them to find ways to increase the productivity and/or reduce the environmental impact of a customer's facility while also reducing energy consumption (Banister 1992, Hawley 1992, Hesson 1992).

Whereas industrial plant managers may be keen about the idea of improving the efficiency of non-process systems (such as lighting and space heating and cooling), they may be unwilling to change their process due to the perceived high technical and financial risk associated with process changes. Putting such a risk in the hands of a utility company is often considered an unwise decision. As a result, a number of utilities, such as United Illuminating, Wisconsin 
Electric, and Wisconsin Power and Light, allow the industrial participant the option of either performing the energy-efficiency analyses and retrofits themselves, choosing their own vendor and/or engineering contractors to help design and install energy-efficiency measures, or using engineering contractors chosen by the utility for their expertise in particular industries and processes. Wisconsin Power \& Light, after administering its C\&I Bright Ideas for Business custom program for three years, recently began hiring consultants with specific industrial process experience to perform the detailed industrial energy analyses; according to the utility, hiring the average DSM consultant to assist in detailed industrial process energy audits has not been effective, both from a technical and a marketing standpoint (Greb 1992).

Since "time is money" for an industrial customer, an industrial conservation program must be user-friendly to be widely acceptable to a diverse industrial base; it needs to be welladministered and minimize the paperwork, bureaucracy, and customer time requirements often associated with utility programs. One drawback associated with many custom measure programs, as they are currently administered, is the long wait between initial customer enrollment in the program and actual receipt of an incentive payment. A few industrial DSM program managers noted that it is worthwhile for utilities to follow large industrial customers' capital budgeting cycles closely. The utility should present the program to the customer well in advance of the start of a new cycle (i.e. offer a free audit and indicate the energy-saving opportunities) in order to increase the likelihood for implementation. Planning a marketing approach around the customer's capital appropriations can also shorten the length of time between initial customer contact and final measure implementation. Industries have a limited attention span; if the bureaucratic process drags on too long, their attention tends to shift away from the program and its merits and back to more urgent concerns within their facilities.

\section{Marketing Techniques}

The marketing techniques employed by the utility can make the crucial difference between an industrial program's success and failure. Industrial programs can not be run out of an office. Bill stuffers and other direct mail alone will rarely succeed in marketing a conservation program to the appropriate people in a large industrial facility. The utility needs 
to make continual personal contact with the customer and target the marketing efforts to the customer's appropriate decision makers. One utility program manager indicated that utilities often will market their programs through utility staff who have had no previous contact with the industrial customer, whereas elsewhere in the utility -- most likely in the customer relations department -- close relationships have developed over years of interaction (Hawley 1992). It is worthwhile to utilize existing contacts with industrial customers so that utility staff do not waste time competing with equipment vendors and other salespersons for the attention of the industrial firm.

Some utilities, such as BPA, BC Hydro, and Niagara Mohawk, have focused on trade allies (i.e., motor and ASD manufacturers) for marketing a program. BC Hydro, for example, provides an incentive to equipment vendors equal to $20 \%$ of the customer rebate. Marketing a rrogram through the use of trade allies not only reduces the administrative costs for the utility, but can also reduce the participant paperwork required. As a program administrator at BC Hydro noted, wade allies and manufacturers can indirectly act as utility marketing staff and thus reduce the utility manpower required to market a program (McLelland 1992).

\section{Program Flexibility}

Generally, the more program flexibility offered the industrial customer the more successful the utility has been in recruiting participants. A custom program is inherently more flexible compared to a prescriptive program and is therefore generally attractive to industrial customers (Barkovich 1992). However, even custom programs can be too rigid for industrial customers, as was demonstraled in the earlier version of BPA's Energy Savings Plan. The fa:lure of the program to recruit participants was partly due to the concrete, restrictive deadlines for submitting project proposals which had no relationship to capital budgeting cycles of industrial facilities (Nadel 1990; Tawney 1992).

Ultimately, both custom and prescriptive programs can play important roles in securing industrial energy-efficiency improvements. If the two types of programs are offered in conjunction with each other, more customers will most likely be reached and greater savings 
achieved than if only one type of program is offered. By offering prescriptive rebates for particular measures, utilities can achieve high participation rates and get a large number of customers accustomed to working with the utility. Several utilities have found that success with prescriptive rebates increases customer receptivity to custom rebates for process-related measures (Hawley 1992, Ilic 1992, Osterholz 1992).

\section{Financial Incentives}

Customer financial incentives are offered by all the programs in the database. A few programs offer the option of low-to-no-interest loans instead of or in addition to a cash rebate. Generally, the programs offering larger financial incentives have above-average participation and savings, such as Commonwealth Electric's Custom Rebate Program. In addition, a few utilities offering relatively successful industrial conservation programs have noted that vendor incentives can streamline and improve the effectiveness of program marketing.

However, as the program manager of BC Hydro's Bonus Partners program noted, high incentives do not guarantee program success and neither are they always needed. Tailoring a comprehensive range of energy-related services (including DSM) to the needs of the industrial customer may mean that an incentive equaling, for example, $20-50 \%$ of a project's total cost may be sufficient, rather than $80 \%$ of a project's total cost (Hesson 1992).

\section{Program Analysis and Evaluation}

Two-thirds of the utilities offering the successful prigrams in the database have performed extensive market research of their industrial customer base and/or have performed impact and process evaluations. For example, Wisconsin Electric altered its industrial marketing strategy for the Smart Money program after studying the managerial structure of its industrial customers for over three years. BPA, BC Hydro, Puget Power, Wisconsin Electric, and Wisconsin Power and Light -- all utilities offering successful programs in the database -- have performed process and/or impact evaluations of their programs. All of these activities provide utilities with a wealth of information on how to improve the design of their programs and 
thereby increase participation and savings.

\section{STEPS TO HELP ADVANCE INDUSTRIAL DSM}

The above summary of program activity reflects the progress that is being made in the field of industrial DSM. However, as indicated in the introduction to this report, significant barriers still inhibit industries and utilities from making a concerted shift toward improved industrial energy efficiency. The following sections recommend ways to overcome these barriers and improve the effectiveness of industrial DSM programs.

\section{Improve Utility Program Design}

The typical industrial DSM program, as reflected in this report's database, has seen an annual participation rate of $9 \%$ and annual electricity savings as a percent of a utility's industrial electricity sales of $0.2 \%$. The 12 most "successful" programs have achieved an average annual participation rate of $20 \%$ and annual electricity savings as a percent of industrial sales of $1.1 \%$. The potential cost-effective savings and participation from industrial DSM programs are most likely much greater than even those achieved by the better existing programs. For example, a recent examination of a sampling of detailed industrial energy studies performed over a threeyear period as part of an industrial DSM program of a major New England utility concluded that the typical industrial customer could reduce its electricity consumption by $13 \%$ if all costeffective measures identified in an audit are implemented (Fuller 1992). Current shortcomings in industrial DSM program design are important contributors to the large gap between the DSM potential and the DSM reality. Program design recommendations are outlined below. Utilities should experiment with different industrial DSM program designs, possibly through first offering pilot programs.

Addressing Customer Concerns

As reflected in the average participation rate of programs in the database, to date, utility 
DSM programs offered to industrial firms generally have not been designed in a manner which captures the attention of a large portion of the eligible customer base. One important reason is that current programs do not adequately address the concerns of the industrial customer. Programs are often offered jointly to commercial and industrial customers and are generally designed with the commercial sector's perspective in mind and not the industrial sector's perspective. One significant difference in the two sectors is the fact that energy consumption in industrial facilities is generally process-oriented, whereas HVAC and lighting systems consume the bulk of energy in commercial buildings. Not only is the breakdown of end-use energy consumption significantly different for the commercial versus industrial sectors, the two sectors exhibit considerably different decision-making behavior when dealing with the issue of facility energy consumption. Examples of the differences include the following: (1) generally speaking, industrial facilities are owner-occupied and commercial buildings are not; (2) installation of efficiency measures may be more disruptive of operations in an industrial facility than in a commercial building; and (3) industrial customers generally require shorter payback horizons for energy-efficiency projects than commercial customers.

For many utilities, particular industries dominate their industrial customer base. It may be worthwhile for these utilities to focus DSM programs on such industries, especially the most energy-intensive industries. In the process of operating programs designed to target particular industries, utilities can gain an increased understanding of special technical features and financial priorities of these customers, an understanding which is crucial for operating successful industrial DSM programs.

To improve the quality and attractiveness of their industrial DSM programs, a few utilities offering the better programs analyzed in the database (such as United Illuminating and Wisconsin Electric) hired engineering consultants with extensive technical experience within the major industries in their service territories.

\section{Improve Marketing Techniques}

When selling DSM to industries, it is important that utilities market programs with the 
industrial customer's perspective in mind. For example, marketing the multiple benefits of improved energy efficiency, which may include increased plant productivity and reduced environmental impacts, is usually more effective in capturing the attention of firms than simply marketing energy efficiency alone (Ross 1992). Additionally, marketing efforts should be directed at the appropriate decision makers in industrial firms. Some of the more successful programs highlighted in this report, including Wisconsin Electric's Smart Money for Business program, target marketing efforts at multiple levels within an industrial firm simultaneously, such as the facility technical staff as well as senior management. Furthermore, utilities should not rely on bill stuffers to market an industrial DSM program; consistent personal contact with decision makers is important. Utilities should build on contacts already established (for example, by including major account representatives in the marketing strategy). Finally, industrial DSM programs should be packaged in ways that are clear and easy to understand. Decision makers will shy away from programs that appear complex and/or time intensive.

In order to effectively market DSM programs to industrial customers, it is important for utilities to understand the economic climate and the budgeting and decision-making processes within the relevant industries in their service territories. One way utilities can improve their understanding of the decision-making processes within local industries is by directly interviewing the key decision makers within industrial firms, gaining first-hand knowledge of their perspective.

\section{Maximize Program Flexibility}

Utilities should take advantage of existing internal contacts with industrial customers (i.e.,

large account executives) and approach the customer with a comprehensive, flexible, and coordinated package that brings together all available energy services such as technical assistance, training, and financial and informational services. The comprehensive package should address important industrial concerns. One way to do this could be to offer custom as well as prescriptive programs, as has been done with six programs in this report's database. Prescriptive programs help initiate the customer's interest in DSM. Once successful prescriptive projects have been implemented, customers are more receptive to custom-designed projects 
which offer larger savings.

The utility can also give the industrial firm the option of either doing its own audit and/or retrofit or using the utility's contractor. Offering multiple incentive options (i.e., rebate, loans, and/or shared savings agreements) -- either within one program or within a package of programs for industries -- has proven successful for some of the utilities in the database, such as BC Hydro and Central Maine Power.

\section{Offer Significant Incentives}

Offering substantial incentives, both financial and service-related, to industries for pursuit of energy conservation measures is important in overcoming the barriers that industries face when considering energy-efficiency improvements. As at least one DSM program impact evaluation has revealed, if only a small fraction of the cost of an energy-efficient measure is offered to industrial customers, the utility may be wasting its time since participating customers are often free riders (Peters 1992). The successful programs in the database generally offer incentives which cover between $50-100 \%$ of the equipment and installation costs. In 1992 , United Illuminating doubled the incentive offered to manufacturing customers under its Energy Opportunities program. The program manager reports that the increase in the number of program applications has been phenomenal; he also noted that the types of proposed projects have shifted away from prescriptive measures and to process-related measures. However, as one industrial DSM program manager at a leading utility noted, if an industrial DSM program is designed well, and provides many other benefits to the customer besides energy savings, somewhat lower incentives may be acceptable (Hesson 1992).

By better understanding the economic climate of industrial customers, as well as the links between issues of primary concern to industries (i.e. plant productivity and environmental emission control) and issues of secondary concern (i.e. improved energy efficiency), utilities can begin to discern when a substantial financial incentive is needed and when a smaller incentive may be acceptable due to multiple benefits of a proposed project. Negotiation-based incentives, generally for large customers, have been adopted by some of the utilities offering successful 
programs, such as BC Hydro, Puget Power, and Wisconsin Electric.

\section{Improve Utility Data Tracking Methods and Program Evaluation}

\section{Improve Data Tracking Methods}

As reflected in this report, little data are currently available to assess the performance of different types of industrial DSM programs in a highly accurate manner. It appears that for even the better industrial DSM programs, data are not being tracked in an efficient and systematic manner. Such data are needed if utilities wish to accurately analyze lessons learned from past DSM program experience. An obvious first step in making the necessary data available is for those utilities still offering C\&I programs to begin tracking their commercial and industrial program results separately. This data will help utilities in analyzing how industrial customers have responded to their DSM programs and what program designs best fit their customers' needs. Better yet, utilities should offer DSM programs which target industrial customers only, rather than both industrial and commercial customers. In so doing, utilities will be able to address the industrial sector in a more comprehensive manner and gain greater understanding of their industrial customers as a result. BC Hydro, within its DSM department, not only has separate divisions for both residential and commercial DSM, but also has an entire division focused on industrial DSM.

In order for utilities to further understand the industrial sector response to DSM programs, the definition of what constitutes an "industrial customer" should be based on the SIC system rather than on the size of the customer's load. In tracking participation in DSM programs, utilities should not only track the number of rebates issued in a program, but also the number of program participants in order to better understand the penetration of the program. Furthermore, many utilities do not closely track the indirect costs associated with their programs, such as administrative and evaluation costs. These costs are important and should be tracked more closely if a utility wishes to evaluate the overall cost-effectiveness of DSM programs. 


\section{Thoroughly Evaluate Program Results}

Verification of energy savings has been performed to varying degrees for less than onehalf of the programs in the database. It is important for utilities to be more aggressive in their evaluation of DSM programs. Improving the accuracy of industrial DSM program savings data through savings verification helps the industrial customer, the utility, and the DSM field in a variety of ways. Industrial customers will have greater confidence in, and will be more likely to participate in, their utility's DSM programs if they know that energy savings clains have been verified. Utilities will benefit from improving the accuracy of industrial DSM savings data for a number of reasons. Utilities need evaluation data in order to accurately assess the costeffectiveness of the program. Incentive payments paid by utilities to industrial participants in DSM programs are based on energy savings. Accurate savings figures are needed in order to pay the proper incentive; through impact and process evaluations, utilities can improve the accuracy of the data and thus the incentive payment. In addition, by conducting evaluations, utilities can improve upon their programs as they incorporate the lessons learned from the past and gain the much-needed credibility of their industrial customers. Persistence of savings needs to be addressed in these evaluations, as does the number of free riders. Better industrial program evaluation will help the DSM field by providing an improved understanding as to how different industrial energy-efficiency measures affect industrial facilities and how different program designs have fared.

\section{Improved Information Exchange and Coordination Among Utilities}

Based on interviews conducted for this report, there appears to be a need for both improved exchange of information among utilities on what is happening at the "forefront" of industrial DSM and increased coordination among adjoining utilities and among electric and gas utilities in offering DSM services to industrial customers.

Hold Industrial DSM Workshops and Conference

One step toward increased information exchange among utilities is to offer more 
opportunities for information sharing on industrial DSM at existing utility DSM conferences. At these conferences, industrial issues are typically covered in only one or two sessions. If the barriers to successful industrial DSM are to be overcome, more attention to the topic is needed at these national conferences, with equal attention given to the industrial sector as is given to the commercial and residential sectors.

Another important step would be the creation of a major industrial energy-efficiency conference. Such a conference would be useful in bringing together utility DSM program managers, industrial plant managers, equipment manufacturers, industrial firms and utility experts, and others to discuss issues related to program design and recent research in the area of industrial energy use. The conference could possibly be organized by DOE, EPRI, GRI, the Association of Energy Engineers (AEE), and/or ACEEE.

During interviews, at least one industrial representative and one industrial observer suggested that, in addition to a major national conference, smaller regional workshops be held which specifically focus on particular industries (Nicholson 1992, Peters 1992). These workshops could be sponsored both by the appropriate industry associations and by utilities who have many customers in the relevant industrial categories. Local equipment manufacturers, engineering consulting firms, state energy offices, industrial customers, and utilities are some of the parties who could attend the workshops. Topics addressed could include energy-related issues important to the industries in each particular region. The semi-annual Northwest Industrial Energy Forum sponsored by the Washington State Energy Office, which brings together utilities, consultants, industrial customers, and vendors to discuss industrial DSM, is an example of such a regional effort.

\section{Coordination Between Adjoining Utilities to Reduce Customer and Vendor Confusion}

Both industrial customers with facilities powered by more than one utility and equipment vendors are often faced with differing eligibility levels and participation guidelines from adjoining utilities. These differences tend to lower the effectiveness of the individual utilities' programs (Donnelly 1992). In order to surmount these problems, utilities and utility 
commissions should consider coordinating prescriptive rebate programs among adjoining utilities, or on a state-wide basis as is currently being done with motor rebate programs in Wisconsin (Kay 1992). In addition, a group of Canadian utilities have joined together to coordinate energyefficient equipment performance testing and to strategize on ways to break down market barriers and lower costs of energy-efficient motors, fans, pumps, and blowers (Donnelly 1992).

\section{Coordinate Joint Electric and Gas Utility Energy Audits for Industrial Firms}

Most industrial customers of single-fuel utilities are currently approached separately by gas and electric utilities. Electric utilities will generally only audit their industrial customers' electric equipment. A few gas utilities offer their industrial customers separate audits of gas equipment. Little coordination among the utilities exists. Usually, some degree of financial incentives are offered to implement the electric-saving measures. Since gas DSM is still in its infancy, few gas utilities presently offer financial incentives to industries for implementation of gas-saving measures. During interviews, some industrial firms, utilities, and third-party affiliates noted that many opportunities for improved energy efficiency within industrial facilities are overlooked by this piecemeal approach by utilities (MacMullen 1992, Nicholson 1992, Price 1992, Rose 1992).

As a first step in dealing with these overlooked opportunities (which can contribute to the often-noted low confidence industrial customers have in utility's technical understanding of industrial facilities), electric utilities should consider coordinating industrial DSM programs with gas utilities. Fuel-blind audits are a good start and may significantly increase industries' trust in DSM. Ultimately, each utility could help pay for the energy savings of "their" fuel. These efforts could possibly be coordinated with state energy offices, as is done in Massachusetts where the Massachusetts State Energy Office and Boston Edison jointly sponsor an energy audit program for industrial customers. As noted earlier in this report, Carolina Power \& Light has been offering fuel-blind audits for ten years. The utility has found that the fuel-blind nature of the audits is a key feature leading to the program's success. The auditors have been trained to conduct unbiased energy surveys. Although the utility reported that initially customers were surprised at, and even skeptical of, the utility's approach, as utility auditors performed more and 
more surveys, industrial customers were impressed with the comprehensive and informative nature of the audits and word spread about the program (Castellow 1992).

\section{Develop Better Links with Industrial Customers}

In order to improve the quality of industrial DSM programs, utilities could benefit from developing a better understanding of industrial customer concerns and needs. One way for utilities to do this is by taking advantage of existing industrial conferences. These conferences, at which utilities are generally under-represented, offer an opportunity for utilities and industrial customers to constructively discuss DSM-related issues (Peters 1992, Steinmeyer 1992). An example of one such conference is the Industrial Energy Technology Conference held annually in Houston and sponsored by a number of parties, including EPRI, DOE, and the Texas Governor's Energy Office. This conference focuses primarily on energy use in industrial processes. Additionally, the AEE holds a number of conferences every year that address industrial energy issues. Two of these conferences are the annual World Energy Engineering Congress and the annual Energy and the Environment conference.

Further coordination between industry trade associations, utilities, and state governments on DSM-related issues would provide another useful avenue for developing better links between utilities and industries. Provisions in the Federal Energy Policy Act of 1992 encourage industrial associations to work with their members to develop and promote voluntary energy efficiency targets, and encourage utilities and states to work together on energy-efficiency programs for industry (U.S. Congress 1992). With the help of DOE, EPRI, and GRI, industry associations can help to further promote utility energy-efficiency programs among their members and to promote their members' views to utilities. State energy offices (SEOs) can act as moderators between industries and utilities within their states by assisting, advising, and/or facilitating in the development of relationships between local industries and utilities. The Washington State Energy Office has recently begun taking such a role in the Northwest. While only some SEO's have sufficient links with industries for these efforts to be useful, where these links exist, they should be used. 


\section{Increase Education and Training}

Education and training of industrial plant personnel on industrial energy use and efficiency is already available through a few successful regional programs such as those offered by the North Carolina State University Industrial Extension Service (IES). The IES offers industries in North Carolina technical and educational services which focus on improving plant efficiency and productivity. Among the services which IES offers are a series of on-going seminars for industrial employees on a wide range of topics, including process energy flows, equipment maintenance, waste heat recovery, machinery energy use, anci auditing techniques (Johnston 1992).

As was noted during some interviews with industrial firms and industrial and utility experts, utility staff must also be educated and trained on industrial energy issues before they can operate effective industrial sector efficiency programs (Harding 1992; Gordon 1992; Johnston 1992). Regional programs similar to the North Carolina IES, but targeting utility conservation program staff rather than industrial plant personnel, would be useful. Among the topics this training could cover include the process and energy flows within dominant industries in the region (particularly energy-intensive industries), case studies of successes -- and failures - of regional industrial energy-efficiency projects, an overview of the typical budgeting cycles of industries, a review of the issues that are of greatest concern to different regional industries, and the links between these concerns and energy efficiency.

In addition, in looking toward the future, utility research institutes, industrial associations, and DOE can offer support to those undergraduate and graduate industrial engineering programs to include energy efficiency and DSM issues in their programs. This will ensure the future availability of knowledgeable engineers with extensive technical understanding of both industrial process design, industrial energy flows, energy efficiency, and demand-side management. DOE's 18 Energy Analysis and Diagnostic Centers (EADCs), located at different universities across the country, offer students a chance to participate in energy audits of smallto medium-sized industrial firms and to analyze the energy data (Rusk 1992). The level of activity and budget of the existing EADC centers could be expanded, and additional centers 
could be established.

\section{Improve Quality and Quantity of Data on Industrial Energy Use Patterns}

One way to disaggregate U.S. industries is by the commonly-used standard industrial classification (SIC) system developed by the U.S. Office of Management and Budget (OMB 1982). This system classifies industries based on two-digit, three-digit, and four-digit SIC codes. The four-digit codes reflect the greatest disaggregation, and the two-digit codes reflect minimal disaggregation of industries. SIC 33 (Primary Metals Industries) demonstrates the broad range of industries falling within the lower-digit SIC codes. Two subcategories within SIC 33 are Blast Furnace and Basic Steel Products (SIC 331) and Primary Nonferrous Metals (SIC 333). One four-digit code within SIC 333 is Primary Aluminum (SIC 3334).

At the present time, only limited industrial energy data is collected at the four-digit SIC code level. $^{8}$ A coordinated effort by utility research institutes, national laboratories, and/or DOE to obtain and organize energy-related information, including end-use allocations, at the three- and/or four-digit SIC level would greatly expand the possibilities for understanding and studying energy use patterns in the industrial sector. This would also allow utilities to develop better end-use profiles for their service territories based on the three- and four-digit classifications of their industrial customers.

\section{Demonstrate State-of-the-Art Energy-Efricient Industrial Technologies}

A joint effort between DOE, EPRI, utilities, and industrial customers to demonstrate and monitor state-of-the-art process-oriented energy-efficient technologies (rather than "run-of-themill" technologies), in as close to plant conditions as possible, could provide useful information to both industries and utilities on the performance of these technologies. In some cases,

${ }^{8}$ The Manufacturing Energy Consumption Surveys published by the U.S. DOE's Energy Information Administration (EIA), as well as the Census of Manufactures and Annual Survey of Manufactures published by the U.S. Department of Commerce's Bureau of the Census, publish limited data on four-digit SIC codes. 
industrial plant engineers, vendors, and utilities could visit the demonstration facilities, provided equipment can be observed without revealing proprietary information about the facilities' operations. Among other things, these demonstration centers could help answer some of the questions that industrial customers have regarding the performance as well as the operation and maintenance requirements of energy-efficient technologies.

Furthermore, efforts should be coordinated between state energy offices, industrial associations, utility research institutes, and DOE to develop case studies of the energy savings and environmental and productivity benefits of energy-efficiency measures installed by participants in industrial DSM programs. Case studies should cover a range of industries, industrial firm sizes, geographic regions, and industrial DSM program types. These case studies could be made available to both utilities and industries as examples of "success stories" in industrial DSM and as examples of the potential multiple benefits of energy-efficiency projects.

\section{Forge Link Between Energy Efficiency and Important Industrial Concerns}

Further research into the links between energy efficiency, product quality, plant productivity, economic competitiveness, environmental emissions, materials end-use efficiency, and other industrial concerns is needed. To the extent energy-efficiency investments can be demonstrated to further these other important objectives, industrial customers will be more likely to undertake energy-efficiency investments. For example, EPRI's new Partnership for Industrial Competitiveness program plans in part to address the linkages between these concerns. The U.S. Environmental Protection Agency's Green Lights program is an example of selling energy efficiency through marketing it as pollution prevention.

Local government, state energy offices, utilities, and knowledgeable third parties could develop programs that aim at improving the economic competitiveness as well as the energy efficiency of local industries, as has been done, for example, by a few utilities in Pennsylvania, Iowa, Ohio, Oregon, and Washington (DeVaul 1992, Meadows 1992). In Pennsylvania, Iowa, and Ohio, the Northeast-Midwest Institute, in collaboration with local government, has helped utilities establish process-oriented industrial DSM programs which assess opportunities for 
energy-efficiency improvements in conjunction with waste stream reduction and product quality and productivity improvements. Some industrial customers participating in the initial pilot programs experienced up to a $200 \%$ increase in production while energy consumption dropped as much as $30 \%$ (DeVaul 1992).

BPA's Aluminum Smelter Conservation/Modernization Program, described earlier, is a good example of a program which focuses on improving the economic viability of a major ind'stry within the utility's "ervice territory by improving the efficiency of the energy use within the industry. This program could serve as a model for other utilities to use in developing industry-specific DSM programs.

\section{Recommended Roles for Particuler Farties}

Implementation of the re ommendations made in the previous sections will require actions by man, arties. Table 4 lists the many parties who need to be involved and the steps that each party should take. Steps number 1-8 in the table refer to the eight general recommendations summarized above. A large ' $\mathrm{X}$ ' indicates that the party should take a leading role in carrying out a recommendation, and a small ' $x$ ' indicates that the party should take a supporting role.

\section{CONCLUSIONS}

Increased international competition, fluctuating economic cycles, and growing environmental awareness and regulations contribute to the pressures on our manufacturing base. By providing the necessary incentives for industrial firms to pursue energy-efficiency

improvements, utility DSM programs can play an important role in improving industrial efficiency as weil as increasing the productivity and decreasing the environmental impact of the industrial sector.

It may seem surprising that there are relatively few demand-side management programs offered by utilities that focus on the industrial sector. To date, utilities generally have stayed 
Table 4. Recommended Roles for Particular Parties in Advancing Industrial DSM.

\begin{tabular}{||l|l|l|l|l|l|l|l|l||}
\hline \multirow{2}{*}{ Party } & \multicolumn{7}{|c|}{ Recommended Steps (\#1-8 from above) } \\
\cline { 2 - 10 } & $\# 1$ & $\# 2$ & $\# 3$ & $\# 4$ & $\# 5$ & $\# 6$ & $\# 7$ & $\# 8$ \\
\hline Electric and Gas Utilities & $\mathrm{X}$ & $\mathrm{X}$ & $\mathrm{X}$ & $\mathrm{X}$ & $\mathrm{x}$ & $\mathrm{X}$ & $\mathrm{X}$ & $\mathrm{X}$ \\
\hline Utility Research Institutes & $\mathrm{x}$ & $\mathrm{x}$ & $\mathrm{X}$ & $\mathrm{x}$ & $\mathrm{X}$ & $\mathrm{X}$ & $\mathrm{X}$ & $\mathrm{X}$ \\
\hline Industrial Firms & $\mathrm{x}$ & & & $\mathrm{x}$ & $\mathrm{x}$ & & $\mathrm{X}$ & $\mathrm{x}$ \\
\hline Industrial Associations & $\mathrm{x}$ & & & $\mathrm{X}$ & $\mathrm{X}$ & $\mathrm{X}$ & $\mathrm{X}$ & $\mathrm{x}$ \\
\hline SEOs \& Research Institutes & $\mathrm{x}$ & $\mathrm{x}$ & $\mathrm{x}$ & $\mathrm{x}$ & $\mathrm{X}$ & $\mathrm{x}$ & $\mathrm{X}$ & $\mathrm{X}$ \\
\hline U.S. DOE \& National Labs & $\mathrm{x}$ & $\mathrm{x}$ & $\mathrm{x}$ & $\mathrm{x}$ & $\mathrm{X}$ & $\mathrm{X}$ & $\mathrm{X}$ & $\mathrm{X}$ \\
\hline U.S. EPA & & & & & & & $\mathrm{x}$ & $\mathrm{X}$ \\
\hline
\end{tabular}

* The recommended steps are as follows:

\#1: Improve utility program design

\#2: Improve utility data tracking methods and program evaluation

\#3: Improve information exchange and coordination among utilities

\#4: Develop better links between utilities and industrial customers

\#5: Increase education and training

\#6: Improve quality and quantity of data on industrial energy use patterns

\#7: Demonstrate and monitor state-of-the-art energy-efficient industrial technologies

\#8: Forge link between energy efficiency and important industrial concerns

away from offering purely industrial programs due to the highly diversified nature of the sector, as well as the general lack of understanding of industrial customers' operations and needs. To the extent attention has been given to industrial customers, it is more often than not within a program that targets both commercial and industrial customers. The driving forces behind industrial decision-making are significantly different than those in the commercial sector. C\&I programs are often designed around the structure of the commercial sector and therefore have 
had limited application to industries.

Although many DSM programs presently available to industrial firms have not been particularly "successful" (using the definition in this study), there are a number of good programs currently being offered which could act as models for further development of industrial DSM programs. Of the incentive-based industrial DSM programs analyzed in this report, the most successful programs have achieved more than two times the participation and roughly six times the electricity savings as a percent of industrial sales at less cost than the average program analyzed. For the 12 successful programs in the database to this report, the average annual savings as a percent of industrial sales is $1.1 \%$, the average annual participation rate is $9 \%$, and the levelized utility cost is $\$ 0.014 / \mathrm{kWh}$ saved. Lessons learned from these more successful programs, as well as information obtained from interviews and literature, are summarized below.

Industrial customers want to know how to improve the productivity of their facilities, not simply how to improve their energy efficiency. Therefore, utilities need to understand the industrial processes of their customers and their associated efficiencies in order to begin to find the links between increased efficiency and increased productivity. By hiring contractors and/or staff who have specific expertise with different types of industrial customers, the utility will more likely succeed in identifying appropriate measures and in assuring the confidence of the industrial customer.

The marketing methods of industrial programs can have considerable impact on the effectiveness of attracting participants. Efforts to remain in regular personal contact with both customers and dealers can pay off in large participation rates and energy savings.

Through offering a flexible package to an industrial customer, the utility will be working with the diverse nature of industries rather than against it. Offering joint custom and prescriptive rebate programs helps to address the need for achieving long-term impacts through high customer participation and significant energy savings per customer. In addition, offering higher financial incentives and comprehensive technical assistance to customers are often helpful tools for encouraging participation. Consistently tracking industrial program results provides 
an invaluable tool for learning lessons from past DSM efforts. Moreover, better analysis and verification of energy-savings claims from industrial DSM programs is important; such evaluation is crucial to understanding the true impact of the programs and how best to structure programs to maximize cost-effective savings.

One important step now is for utilities to simply get started and begin experimenting with industrial program design, using the lessons learned from other utilities as a guide. Other steps that can be taken to advance the quality and quantity of industrial DSM programs include improving information exchange and coordination among utilities (i.e. through industrial DSM conferences and workshops), developing better links with industrial firms, increasing the availability of education and training for utility staff, improving the quality and quantity of data on industrial energy use patterns, demonstrating and monitoring state-of-the-art energy-efficient industrial technologies, and forging links between energy efficiency and other important industrial concerns.

Studies have shown enormous energy-savings potential in the U.S. industrial sector; the savings potential by the year 2010 relative to a business-as-usual scenario has been estimated as between $11-27 \%$, and up to $37 \%$ by the year 2015 . We cannot afford to leave this potential untapped. It is time for utilities, regulators, and other key parties to move forward and actively pursue the large energy-saving opportunities in the industrial sector. Although past experience in industrial DSM is not extensive, experience to date shows that successful programs can be designed and indicates ways to design even more successful programs in the future. 


\section{REFERENCES}

Alliance to Save Energy, 1983, Industrial Investment in Energy Efficiency: Opportunities, Management Practices, and Tax Incentives, Washington, D.C.

Alliance to Save Energy, American Council for an Energy-Efficient Economy, Natural Resources Defense Council, and Union of Concerned Scientists, 1991, America's Energy Choices: Investing in a Strong Economy and a Clean Environment, Technical Appendixes, Cambridge, MA.

Appelbaum, Bruce, 1992, personal communication, Tarrytown, NY: Chem Systems, 914-6312828.

Banister, Bob, 1992, personal communication, Bellevue, WA: Puget Sound Power \& Light, 206462-3726.

Barkovich, Barbara, 1992, personal communication, Berkeley, CA: Barkovich and Yap, 510486-8040.

Berry, Linda, 1989, The Administrative Costs of Energy Conservation Programs (ORNL/CON294), Oak Ridge, TN: Oak Ridge National Laboratory.

California Public Utilities Commission, 1987, Standard Practice Manual for Cost-Benefit Analysis of Demand-Side Management Programs, Sacramento, CA: California Public Utilities Commission.

Campbell, Margaret, 1993, personal communication, Westborough, MA: New England Electric Systems, 508-366-9011.

Carlsmith, R., Chandler, W., McMahon, J., and D. Santini, 1990, Energy Efficiency: How Far Can We Go (ORNL/TM-11441), Oak Ridge, TN: Oak Ridge National Laboratory.

Carter, Ann, 1992, personal communication, Augusta, ME: Central Maine Power, 207-6233521 .

Carvalho, Jerry, 1992, personal communication, Wareham, MA: Commonwealth Electric, 5082S1-0950.

Casey, Brian, 1992, personal communication, Wareham, MA: Commonwealth Electric, 508291-0950.

Castellow, Carl, 1992, personal communication, Raleigh, NC: Carolina Power \& Light, 919546-7078.

CPUC 1987. See California Public Utilities Commission. 
DeVaul, Diane, 1992, personal communication, Washington, D.C.: Northeast-Midwest Institute, 202-544-5200.

DOE. See U.S. Department of Energy.

Donnelly, Brian, 1992, personal communication, British Columbia, Canada: British Columbia Hydro, 604-663-3969.

Electric Power Research Institute, 1991, 1990 Survey of Industrial-Sector Demand-Side Management Programs (CU-7089), Palo Alto, CA.

Elliott, Neal, 1992, personal communication, Research Triangle Park, NC: North Carolina Alternative Energy Corporation, 919-361-8000.

EPRI 1991. See Electric Power Research Institute.

Faruqui, A., Gellings, C., Mauldin, M., Schick, S., Seiden, K. and G. Wikler, 1990, Efficient Electricity Use: Estimates of Maximum Energy Savings (CU-6746), Palo Alto, CA: Electric Power Research Institute.

Fuller, W. H., 1992, "Industrial DSM -- What Works and What Doesn't", Proceedings ACEEE 1992 Summer Study on Energy Efficiency in Buildings, Berkeley, CA: American Council for an Energy-Efficient Economy.

Gervais, Edward, 1993, personal communication, Augusta, ME: Central Maine Power, 207-6233521.

Gordon, Fred, 1989, Memo to David Wolcott, Portland, OR: Pacific Energy Associates.

Gordon, Fred, 1992, personal communication, Portland, OR: Pacific Energy Associates, 503233-6543.

Greb, Frank, 1992 and 1993, personal communication, Madison, WI: Wisconsin Power \& Light, 608-252-3311.

Hamilton, Mark and Shelley Kirk Rudeen, 1991, "Industrial Energy Efficiency Programs: A Scoping Study for the Washington State Energy Office Industrial Section, Draft", Olympia, WA: Washington State Energy Office.

Harding, William, 1992, personal communication, Bethlehem, PA: Bethlehem Steel, 215-6942424.

Hawley, Thomas, 1992, personal communication, Milwaukee, WI: Wisconsin Electric Power Co., 414-221-3887.

Heidell, J. and M. King, 1990, "The Industrial Sector: A Conservation Gold Mine or a Quagmire", Proceedings ACEEE 1990 Summer Study on Energy Efficiency in Buildings, 
Berkeley, CA: American Council for an Energy-Efficient Economy.

Hesson, John, 1992, personal communication, British Columbia, Canada: British Columbia Hydro, 604-685-2206.

Hughes, John, 1992, "The Anticompetitive Effects of Industrial DSM Programs", Proceedings Fourth National Conference on Integrated Resource Planning, Burlington, VT: National Association of Regulatory Utility Commissioners.

Ilic, Grad, 1992, personal communication, British Columbia, Canada: British Columbia Hydro, 604-663-3290.

Jeffress, Robert, 1992, personal communication, Palo Alto, CA: Electric Power Research Institute, 415-855-2101.

Johnson, Mark, 1992, personal communication, Portland, OR: Bonneville Power Administration, 503-230-7669.

Johnston, Walter, 1992, personal communication, Raleigh, NC: North Carolina State University Industrial Extension Service, 919-515-5439.

Kusaka, Stanley, 1992, personal communication, Portland, OR: Bonneville Power Administration, 503-230-3657.

Linn, Jonathan, 1992, personal communication, Augusta, ME: Central Maine Power, 207-6233521 .

Littlefield, Daniel, 1992, personal communication, Augusta, ME: Central Maine Power, 207623-3521.

MacMullen, Andrew, 1992, personal communication, Leesburg, VA: Linhoff March, 703-7771118.

Martucci, M. and P. Sassone, 1984, "Industrial Energy Conservation: the Reasons Behind the Decisions", Energy, Vol. 9, No. 5, pp. 427-437.

Maynard, Gordon, 1993, personal communication, Los Angeles, CA: Southern California Gas Company, 213-244-3688.

McAteer, Michael, 1993, personal communication, Westborough, MA: New England Electric Systems, 508-366-9011.

McLelland, Lyle, 1992, personal communication, British Columbia, Canada: British Columbia Hydro, 604-623-4305.

Meadows, Karen, 1992, personal communication, Olympia, WA: Washington State Energy Office, 206-956-2000. 
Merrill, Andrew, 1992, personal communication, British Columbia, Canada: British Columbia Hydro, 604-663-3143.

Metz, Jeremy, 1992, personal communication, New York, NY: American Paper Institute, 212340-0667.

Miller, P., Eto, J., Geller, H., 1989, The Potential for Electricity Conservation in New York State, Washington, D.C.: American Council for an Energy-Efficient Economy.

Mills, Robert, 1992, personal communication, New Haven, CT: United Illuminating, 203-7776176.

Mortensen, Wendy, 1992, personal communication, Portland, OR: Bonneville Power Administration, 503-230-3983.

Nadel, S., M. Shepard, S. Greenberg, G. Katz, and A.T. de Almeida, 1991, Energy-Efficient Motor Systems, Washington, D.C.: American Council for an Energy-Efficient Economy.

Nadel, Steven, 1990, Lessons Learned: A Review of Utility Experience with Conservation and Load Management Programs for Commercial and Industrial Customers, Albany, NY: New York State Energy Research and Development Authority.

Nicholson, Bill, 1992, personal communication, San Francisco, CA: Potlatch, 415-956-2973.

Noell, Sandy, 1992, personal communication, Boston, MA: Boston Edison, 617-424-3885.

Office of Management and Budget, 1982, Standard Industrial Classification Manual, 1972, Office of Management and Budget, Washington D.C.

Office of Technology Assessment, U.S. Congress, 1991, Changing by Degrees: Steps to Reduce Greenhouse Gases (OTA-O-482), Washington, D.C.

OMB 1972. See Office of Management and Budget.

Osterholz, Jill, 1992, personal communication, Madison, WI: Wisconsin Power \& Light, 608252-3311.

OTA 1991. See Office of Technology Assessment.

Panacoast, Ed, 1993, personal communication, Westborough, MA: New England Electric Systems, 508-366-9011.

Pendleton, Len, 1992, personal communication, Raleigh, NC: Carolina Power \& Light, 919546-7078.

Peters, Jane, 1992, personal communication, Portland, OR: Barakat \& Chamberlin, 503-224- 
3666.

Price, A., 1992, personal communication, Dearborn, MI: Ford Corporation, 313-594-4835.

Reddy, Amulya, 1991, "Barriers to improvements in energy efficiency", Energy Policy, December 1991, pp. 953-961.

Riewer, Sheila, 1992, personal communication, Portland, OR: Bonneville Power Administration, 503-230-5473.

Rose, Michael, 1992, personal communication, Portland, OR: Bonneville Power Administration, 503-230-3601.

Ross, Marc, 1986, "Capital Budgeting Practices of Twelve Large Manufacturers", Financial Management, Winter 1986, pp. 15-22.

Ross, Marc, 1992, personal communication, Ann Arbor, MI: University of Michigan, 313-7644459.

Rusk, Dick, 1992, personal communication, Ames, IA: Iowa State University Energy Analysis and Diagnostic Center, 515-294-3080.

Sayko, Jan, 1992, personal communication, Hartford, CT: Northeast Utilities, 203-665-2721.

Stapleton, James, 1992, personal communication, Syracuse, NY: Niagara Mohawk Power Corporation, 315-428-5382.

Steinmeyer, Daniel, 1992, personal communication, , MI: Monsanto Company, 313-694-6646.

Sullivan, Cliff, 1992, personal communication, Boston, MA: Massachusetts State Energy Office, 617-727-4732.

Tawney, Pat, 1992, personal communication, Portland, OR: Bonneville Power Administration, 503-230-3973.

Toth, Brenda, 1992, personal communication, Meriden, CT: Yankee Gas, 203-639-4482.

U.S. Congress, 1992, Federal Energy Policy Act of 1992, U.S. Government Printing Office, Washington, D.C.

U.S. Department of Energy, Energy Information Administration, 1991a, Financial Statistics of Selected Investor-Owned Electric Utilities 1989 (DOE/EIA-0437(89)/1), Washington, D.C.

U.S. Department of Energy, Energy Information Administration, 1991b, Financial Statistics of Selected Publicly-Owned Electric Utilities 1989 (DOE/EIA-0437(89)/2), Washington, D.C. 
U.S. Department of Energy, Office of Conservation, 1988, Energy Conservation Multi-Year Plan 1990-1994, Washington, D.C.

Venneman, Mary, 1992, personal communication, British Columbia, Canada: British Columbia Hydro, 604-663-4069.

Welker, Skip, 1992, personal communication, Raleigh, NC: Carolina Power \& Light, 919-5466311. 


\section{APPENDIX}

INDUSTRIAL DSM PROGRAMS:

PROGRAM RESULTS AND DESCRIPTIONS 


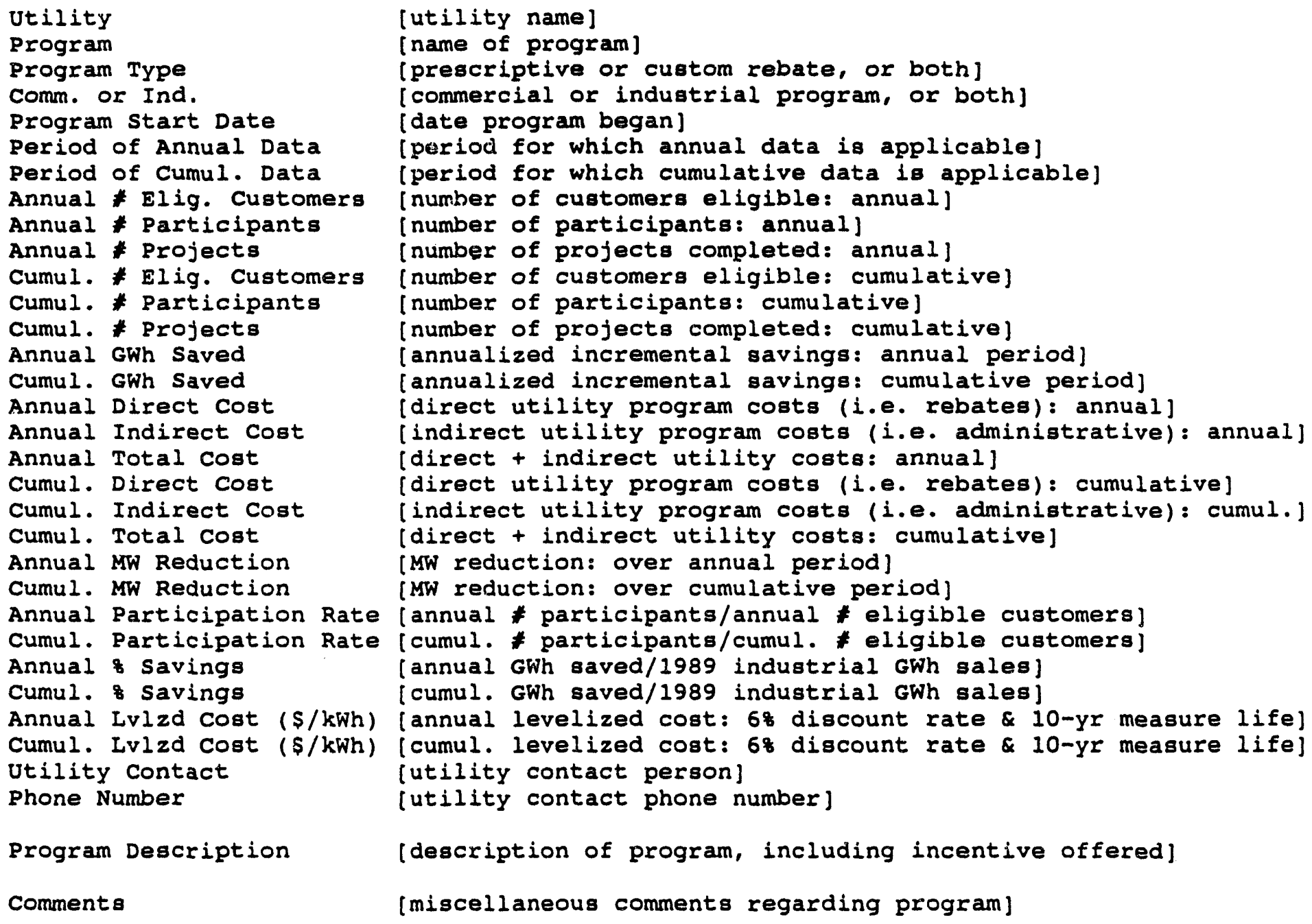




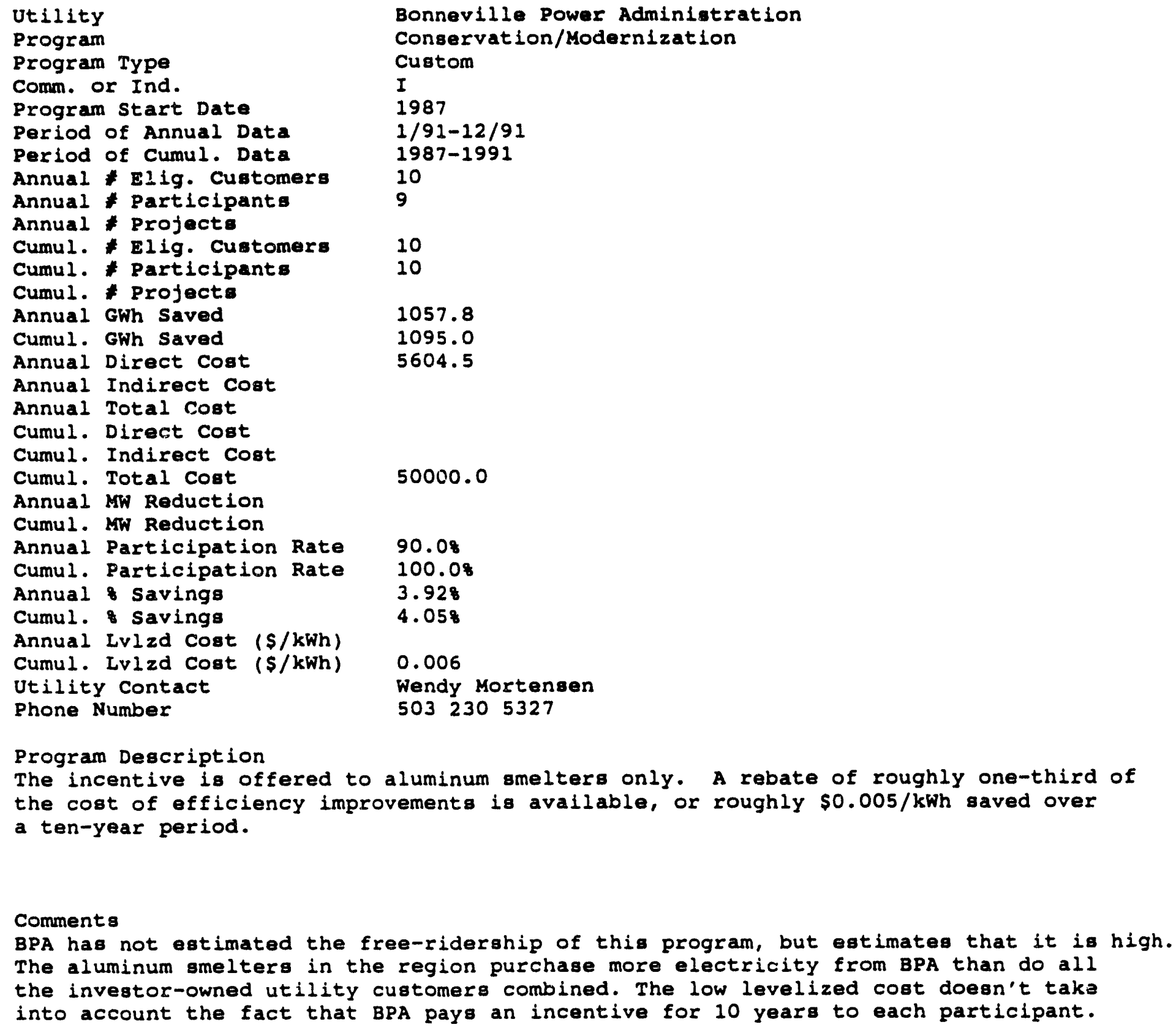

Program Description

The incentive is offered to aluminum smelters only. A rebate of roughly one-third of the cost of efficiency improvements is available, or roughly $\$ 0.005 / \mathrm{kWh}$ saved over a ten-year period.

\section{Comments}

BPA has not estimated the free-ridership of this program, but estimates that it is high. The aluminum smelters in the region purchase more electricity from BPA than do all the investor-owned utility customers combined. The low levelized cost doesn't take into account the fact that BPA pays an incentive for 10 years to each participant. 
Utility

\section{Program}

Program Type

Comm. or Ind.

Start Date

Period of Annual Data

Period of Cumul. Data

Aunual * Elig. Customers

Annual * Participants

Annual * Projects

Cumul. Elig. Customers

Cumul. \# Participants

Cumul. \# Projects

Annual GWh saved

Cumul. GWh Saved

Annual Direct Cost

Annual Indirect Cost

Annual Total Cost

Cumul. Direct Cost

Cumul. Indirect Cost

Cumul. Total Cost

Anrual MW Reduction

- Cumul. MW Reduction

Annual Participation Rate

Cumul. Participation Rate

Annual Savings

Cumul. \& Savings

Annual Lvlzd Cost ( $\$ / k W h$ )

Cumul. Lvlzd Cost ( $\$ / \mathrm{kWh})$

Utility Contact

Phone Number
Bonneville Power Administration

Energy Savings Plan

Custom

I

$10 / 88$

$1 / 91-12 / 91$

$10 / 88-4 / 92$

300

12

300

37

32.0

82.5

704.7

211.4

916.1

2538.7

761.6

3300.3

4.08

12.38

2.158

5.548

0.004

$\therefore .005$

Pat Tawney

5032303973

Program Description

Contractors, vendors, utility custoers, and others are directly involved in the planning, design, and on-going evaluation of this program. The investor-owned utility customers administer the program and BPA funds the program. Participants are paid, on average, \$0.15/1st year kW! savings or 808 of the project's cost, whichever is smaller.

\section{Comments}

In mid-1990, BPA decentralized the program by giving administering power to their member utilities. Since 1990, there is greater emphasis on selling the program through trade allies. 


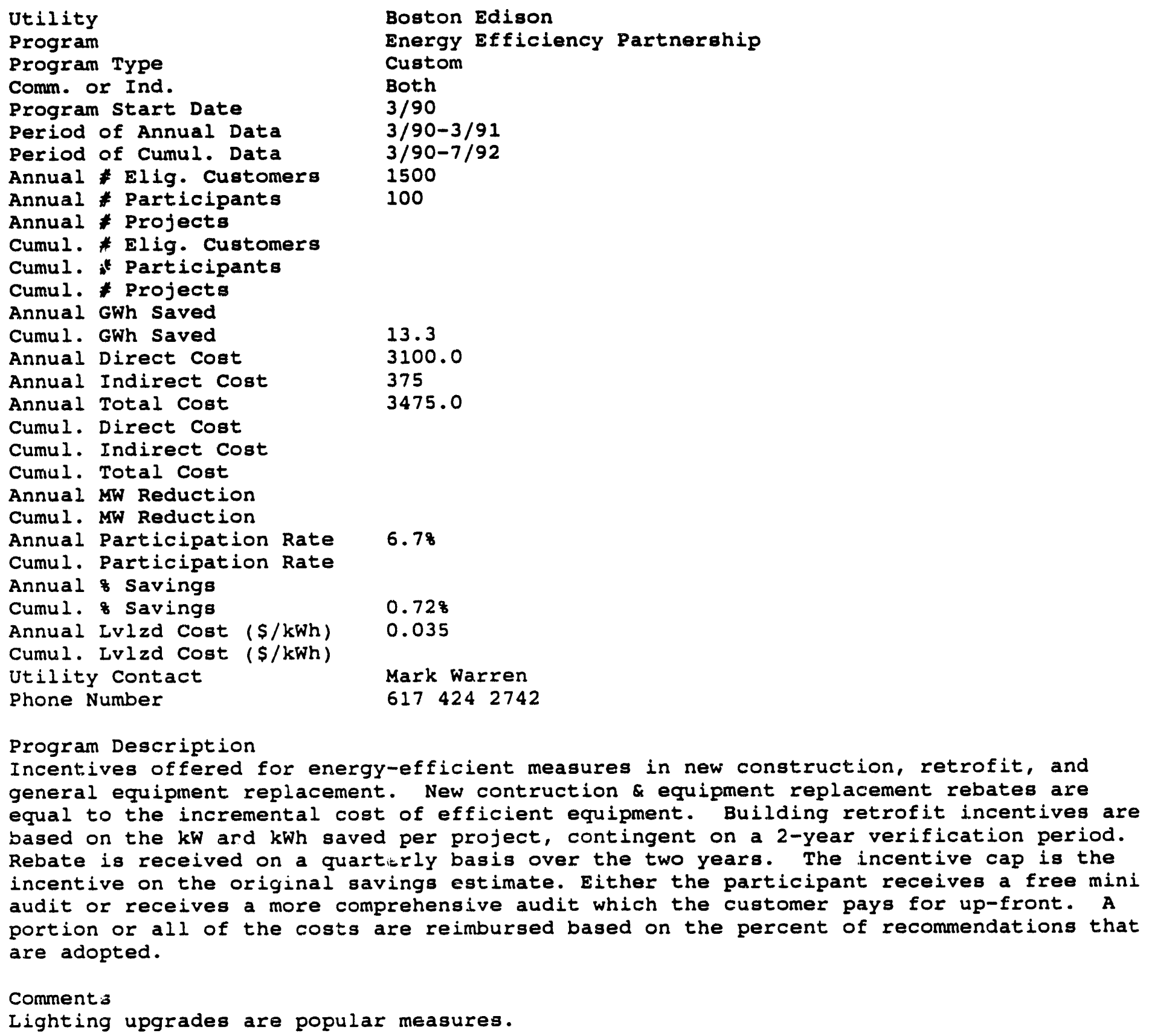


Utility

Program

Program Type

Comm. or Ind.

Program start Date

Period of Annual Data

Period of Cumul. Data

Annual Elig. Customers

Annual * Participants

Annual * Projects

Cumul. * Elig. Customers

Cumul. * Participants

Cumul. * Projects

Annual GWh saved

Cumul. GWh Saved

Annual Direct Cost

Annual Indirect Cost

Annual Total cost

Cumul. Direct Cost

Cumul. Indirect Cost

Cumul. Total cost

Annual MW Reduction

Cumul. MW Reduction

Annual Participation Rate

Cumul. Participation Rate

Annual \& Savings

Cumul. \& Savings

Annual Lvlzd Cost ( $\$ / k W h$ )

Cumul. I.vlzd Cost ( $\$ / k W h$ )

Utility Contact

Phone Number
British Columbia Hydro

Power Smart: Bonus Partners

Custom

I

$8 / 90$

$3 / 91-4 / 92$

$8 / 90-4 / 92$

5000

84

5000

105

45.2

56.0

816.0

144

960.0

1105.0

195.0

1300.0

1.78

2.18

0.238

$0.28 \%$

0.004

0.003

John Hesson

6046852206

Program Description

Customers propose energy-conserving, process-related projects to BC Hydro. Qualifying projects receive either financing options or cash grants. If an approved project saves less than $200 \mathrm{MWh} / \mathrm{yr}$, the participant generally receives an incentive which brings the project's payback period down to no less than 2 yrs. For larger projects, the utility and customer negotiate an incentive, taking into account the effects of the project on maintenance costs, productivity, product quality, equipment reliability, etc. 


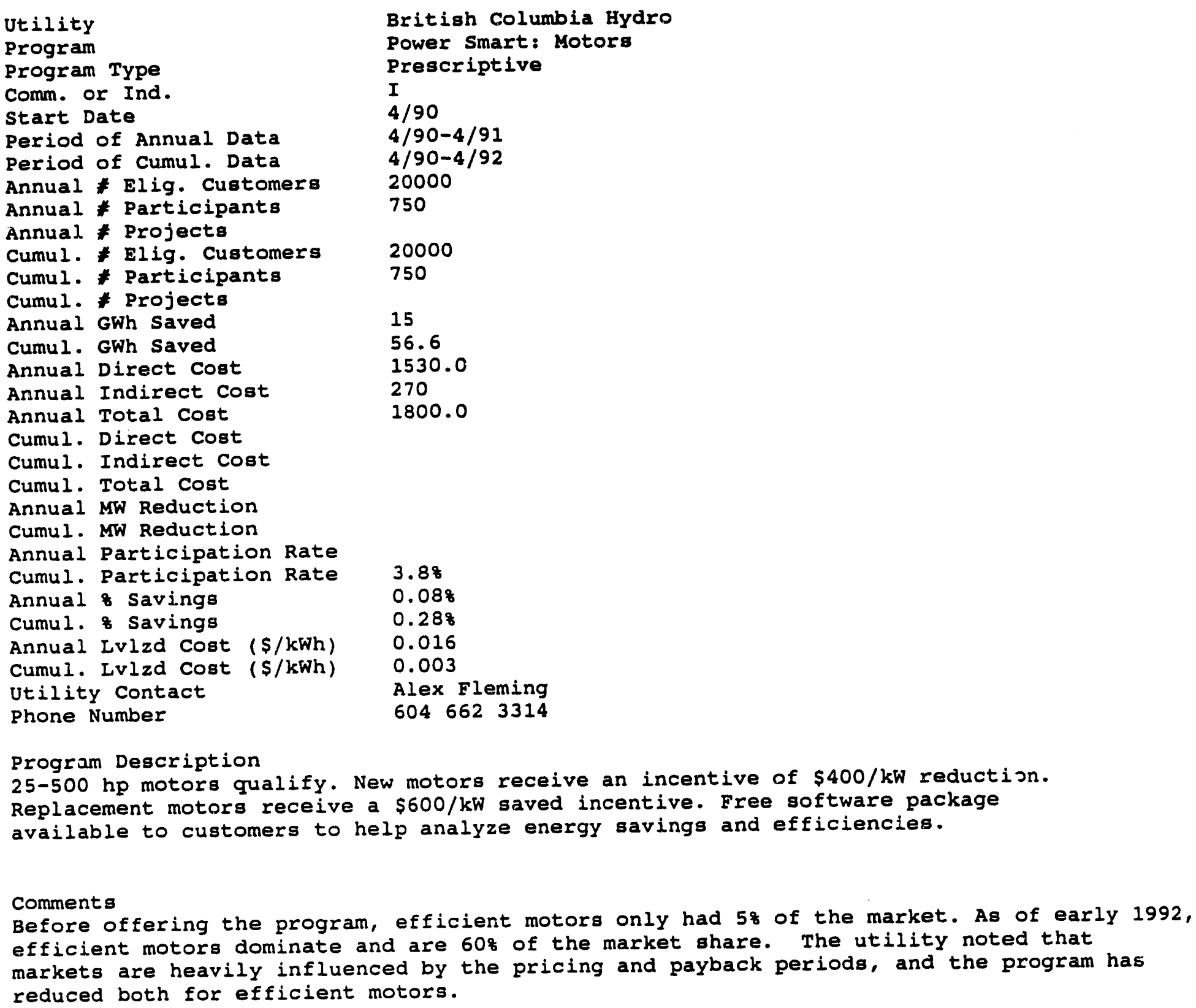

Program Description

25-500 hp motors qualify. New motors receive an incentive of $\$ 400 / \mathrm{kW}$ reduction.

Replacement motors receive a $\$ 600 / \mathrm{kW}$ saved incentive. Free software package

available to customers to help analyze energy savings and efficiencies.

Comments

Before offering the program, efficient motors only had $5 \%$ of the market. As of early 1992 , efficient motorg dominate and are 608 of the market share. The utility noted that markets are heavily influenced by the pricing and payback periods, and the program has reduced both for efficient motors. 
Utility

Program

Program Type

Comm. or Ind.

start Date

Period of Annual Data

Period of Cumul. Data

Annual * Elig. Customers

Annual * Participants

Annual * Projects

Cumul. * Elig. Customers

Cumul. * Participants

Cumul. \# Projects

Annual GWh saved

Cumul. GWh Saved

Annual Direct Cost

Annual Indirect Cost

Annual Total cost

Cumul. Direct Cost

Cumul. Indirect Cost

Cumul. Total Cost

Annual MW Reduction

Cumul. MW Reduction

Annual Participation Rate

Cumul. Participation Rate

Annual \& Savings

Cumul. \& Savings

Annual Lvlzd cost ( $\$ / \mathrm{kWh}$ )

Cumul. Lvlzd Cost ( $\$ / k W h)$

Utility contact

Phone Number

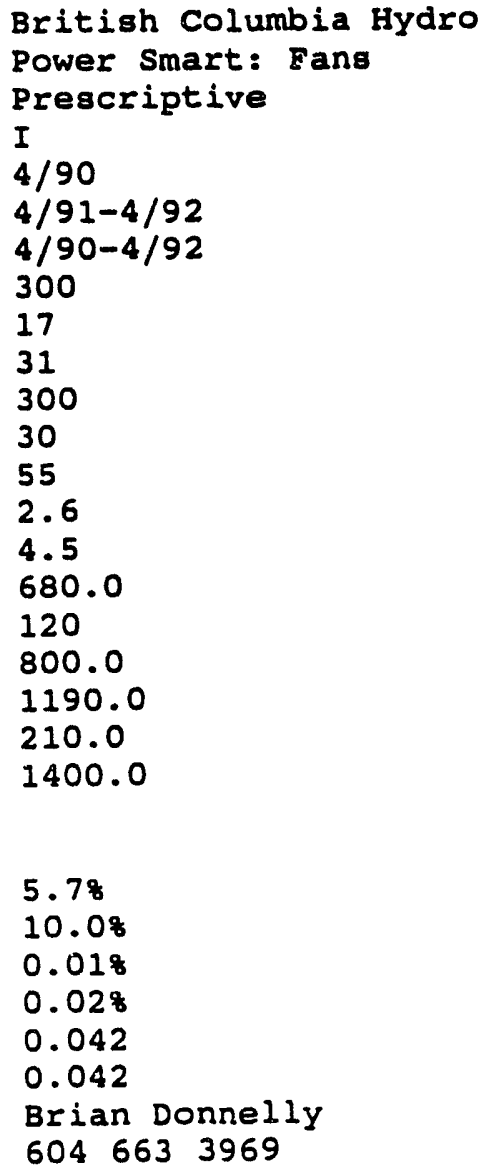

Program Description

Program primarily installs ASDs on fans in lumber drying kilns. Incentive buys down payback period to 2 years. An ASD software package is available for analyzing energy savings and payback information. Incentives are provided after the measure is installed.

Comments

The program is still in its infancy, according to the utility. The utility plan is to take a few case study installations and promote the program through these case studies. The utility is considering expanding the program to the cement industry soon. 


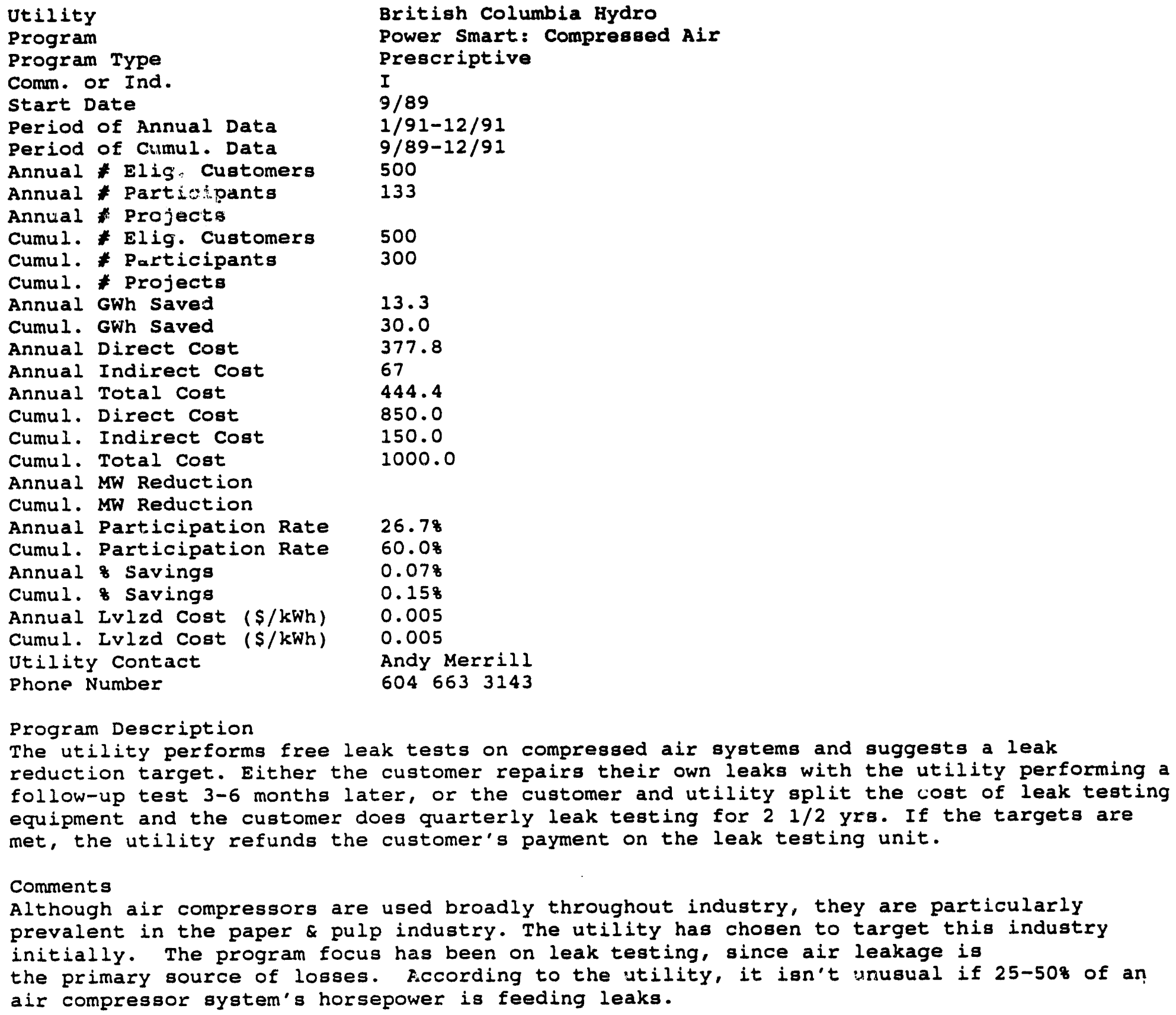


Utility

Program

Program Type

Comm. or Ind.

Start Date

Period of Annual Data

Period of Cumul. Data

Annual * Elig. Customers

Annual * Participants

Annual * Projects

Cumul. \# Elig. Customers

Cumul. * Participants

Cumul. * Projects

Annual GWh Saved

Cumul. GWh saved

Annual Direct Cost

Annual Indirect cost

Annual Total cost

Cumul. Direct Cost

Cumul. Indirect Cost

Cumul. Total Cost

Annual MW Reduction

Cumul. MW Reduction

Annual Participation Rate

Cumul. Participation Rate

Annual \& Savings

Cumul. \& Savings

Annual Lvizd Cost ( $\$ / \mathrm{kWh}$ )

Cumul. Lvizd Cost ( $\mathbf{S / k W h}$ )

Utility Contact

Phone Number
British Columbia Hydro

Power Smart: Pumping Profitg

Prescriptive

I

$9 / 90$

$3 / 91-4 / 92$

$9 / 90-4 / 92$

112

5

112

6

1.0

1.2

340.0

60

400.0

425.0

75.0

500.0

4. $3 \%$

5.48

$0.005 \%$

0.018

0.057

0.057

Marty Ahad

6046633282

Program Description

Utility first hires consultant to do audit of pump systems. If customer implements recommendations, an incentive is earned which buys down payback period.

Comments

Like the fan program, this program is still in its infancy. The utility looks at pump systems in process applications. Pulp mills and refineries have the largest pump systems in their service territory and these customers are the focus of the program. 


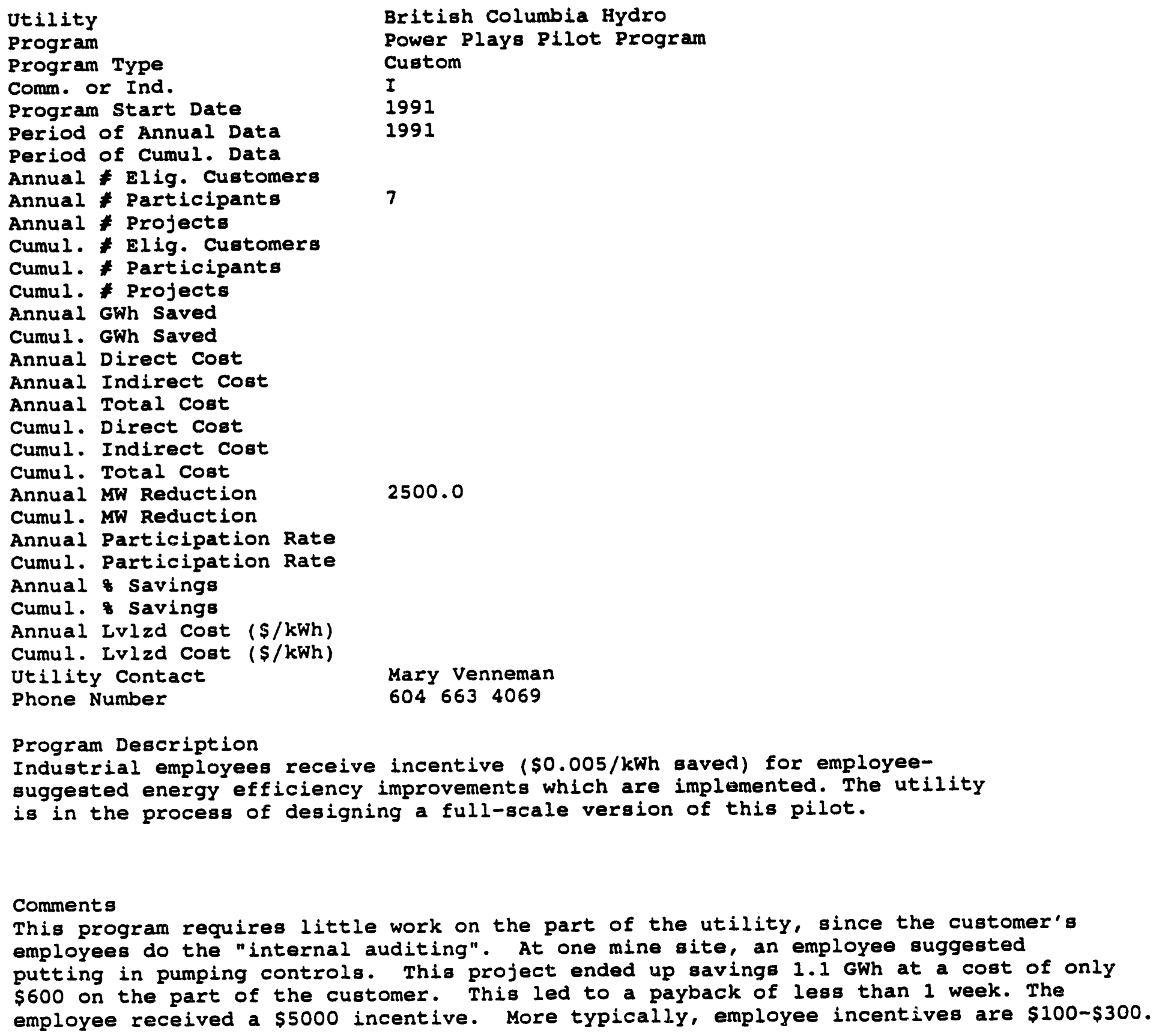


Utility

Program

Program Type

comm. or Ind.

Program Start Date

Period of Annual Data

Period of Cumul. Data

Annual \# Elig. Customers

Annual * Participants

Annual * Projects

Cumul. * Elig. Customers

Cumul. * Participants

Cumul. * Projects

Annual GWh Saved

Cumul. GWh Saved

Annual Direct Cost

Annual Indirect Cost

Annual Total Cost

Cumul. Direct Cost

Cumul. Indirect cost

Cumul. Total cost

Annual MW Reduction

Cumul. MW Reduction

Annual Participation Rate

Cumul. Participation Rate

Annual savings

Cumul. \& Savings

Annual Lvlzd Cost ( $\$ / \mathrm{kWh}$ )

Cumul. Lvlzd Cost ( $\$ / \mathrm{kWh})$

Utility Contact

Phone Number
Carolina P\&L

Industrial Audits

Audit

I

1983

1983-1989

200

75

Skip Welker

$919546 \quad 6311$

Program Description

Free in-depth audits are provided for new and existing industrial facilities. Audits are fuel-blind; water uses are audited as well. The auditors generally recommend measures with a 2 year payback or less; however, in a few cases measures with up to a 7-year payback are recommended.

Comments 


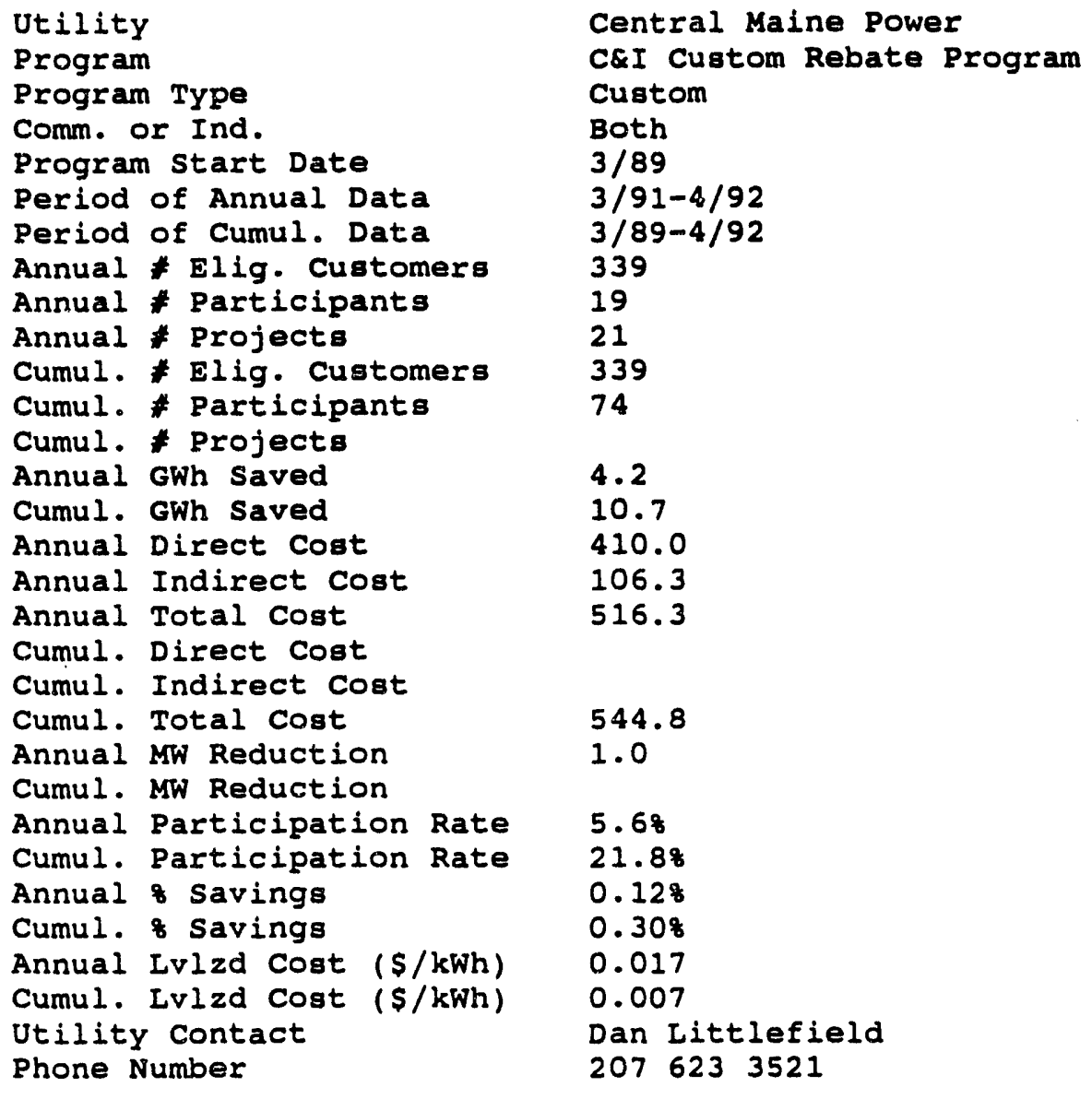

Program Description

Technical and financial assistance is offered for energy-efficient retrofits not falling within the lighting and motor rebate programs. Until recently, rebates were $\$ 0.01 / \mathrm{kWh}$ saved over the lifetime of the project, capped at $90 \%$ of the project's material costs (excluding labor). In 1992, the incentive cap was changed to $80 \%$ of a project's total costs Recently, the utility has begun negotiating incentives with customers.

\section{Comments}

Cumulative data are rough estimates derived from utility data. For \# of cumulative participants, the $1991^{\prime}$ ' of rebates/customer' ratio was used for deriving cumulative total participants. The 1991 ratio of 'industrial participants/total participants' was used to derive the approximate * of cumulative industrial participants. A similar approach was used for deriving cumulative savings. Total cumulative utility expenditures were derived from a latility estimate of a total program cost of $\$ .051 / \mathrm{kWh}$ and cumulative savings values. ASDs, sensors, and energy management systems are frequently installed.. 


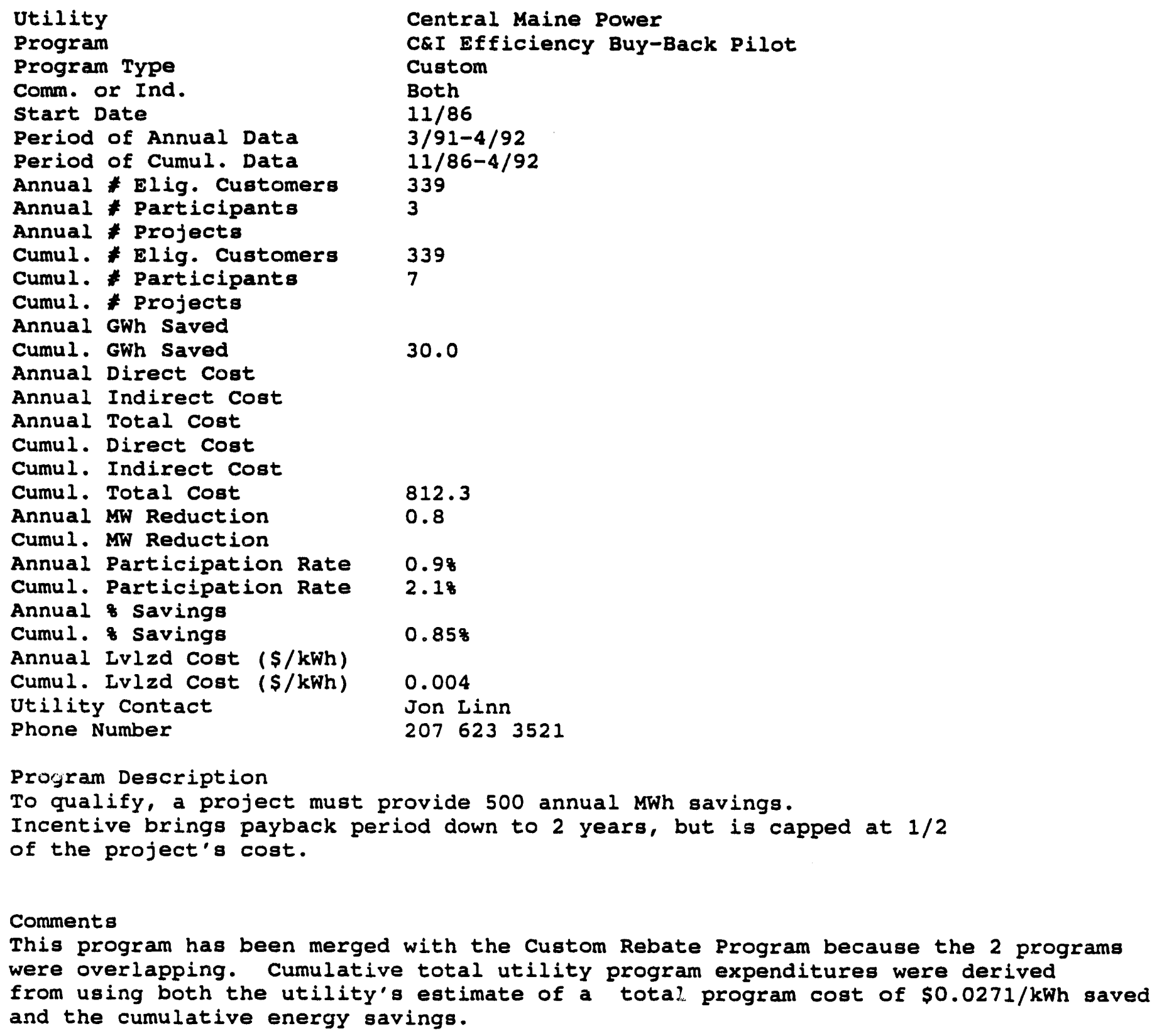




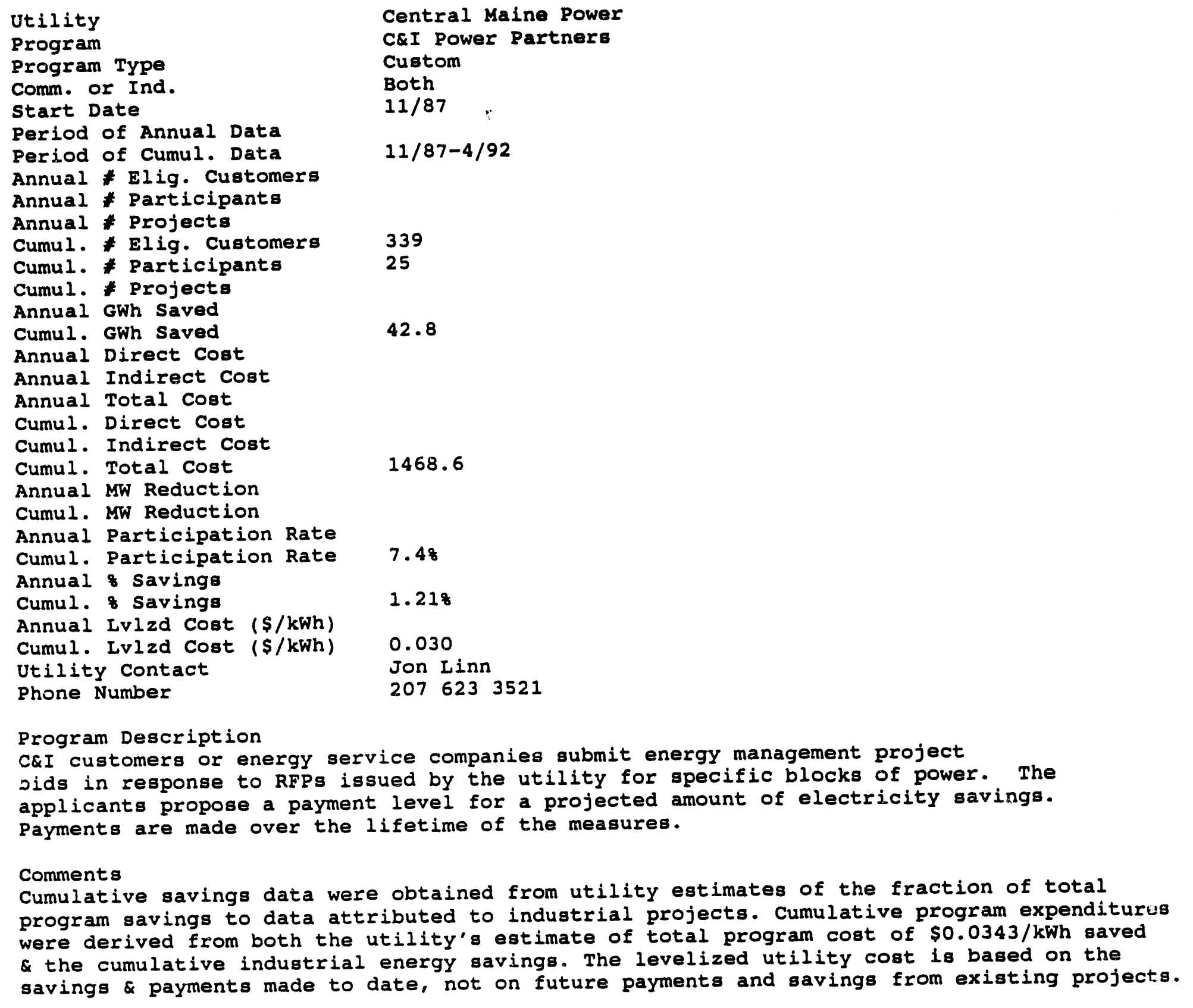




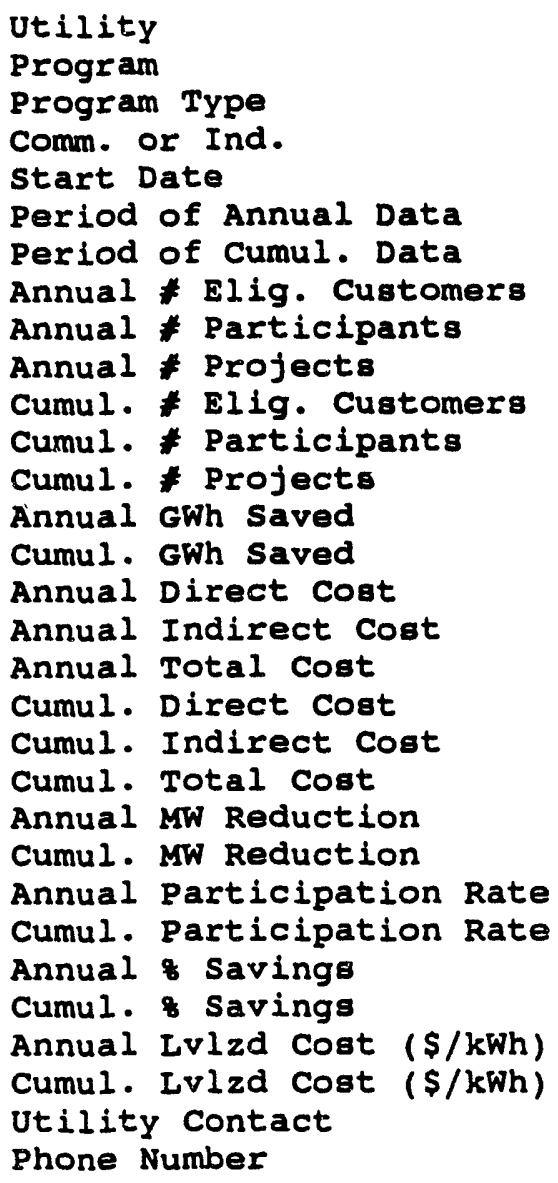

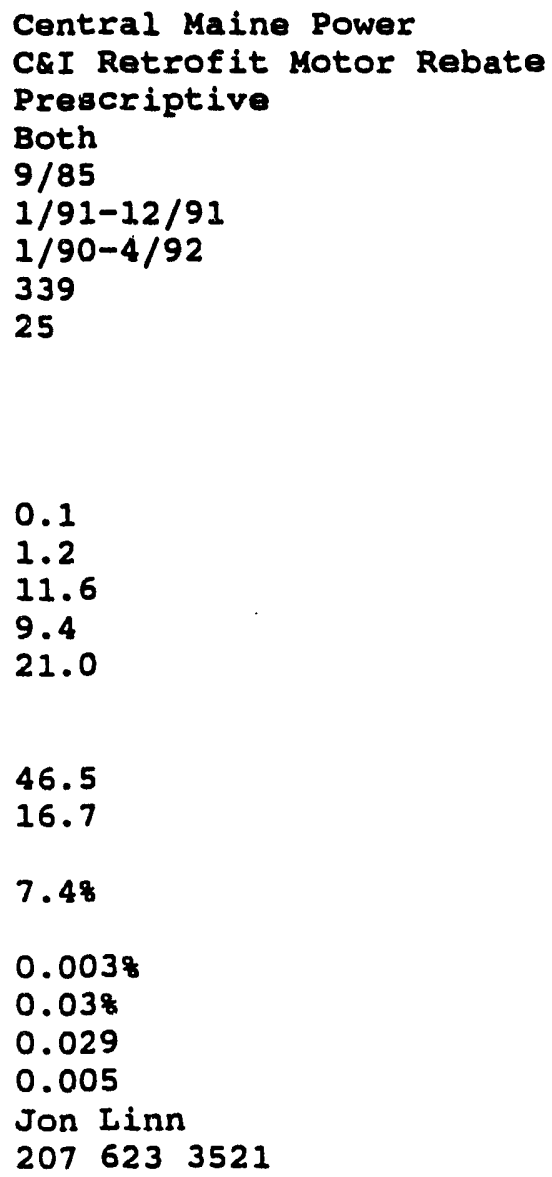

46.5

16.7

7.48

$0.003 \%$

$0.03 \%$

0.029

0.005

Jon Linn

2076233521

Program Description

Rebates offered for motor replacement with motors meeting CMP's efficiency standards. 5-75 hp motors apply. Rebates approximately cover incremental cost of going from a standard to high-efficiency motor.

Comments

Please refer to CMP's Custom Rebate Program "Comments" section for a degcription of the methods used for calculating cumulative results. 


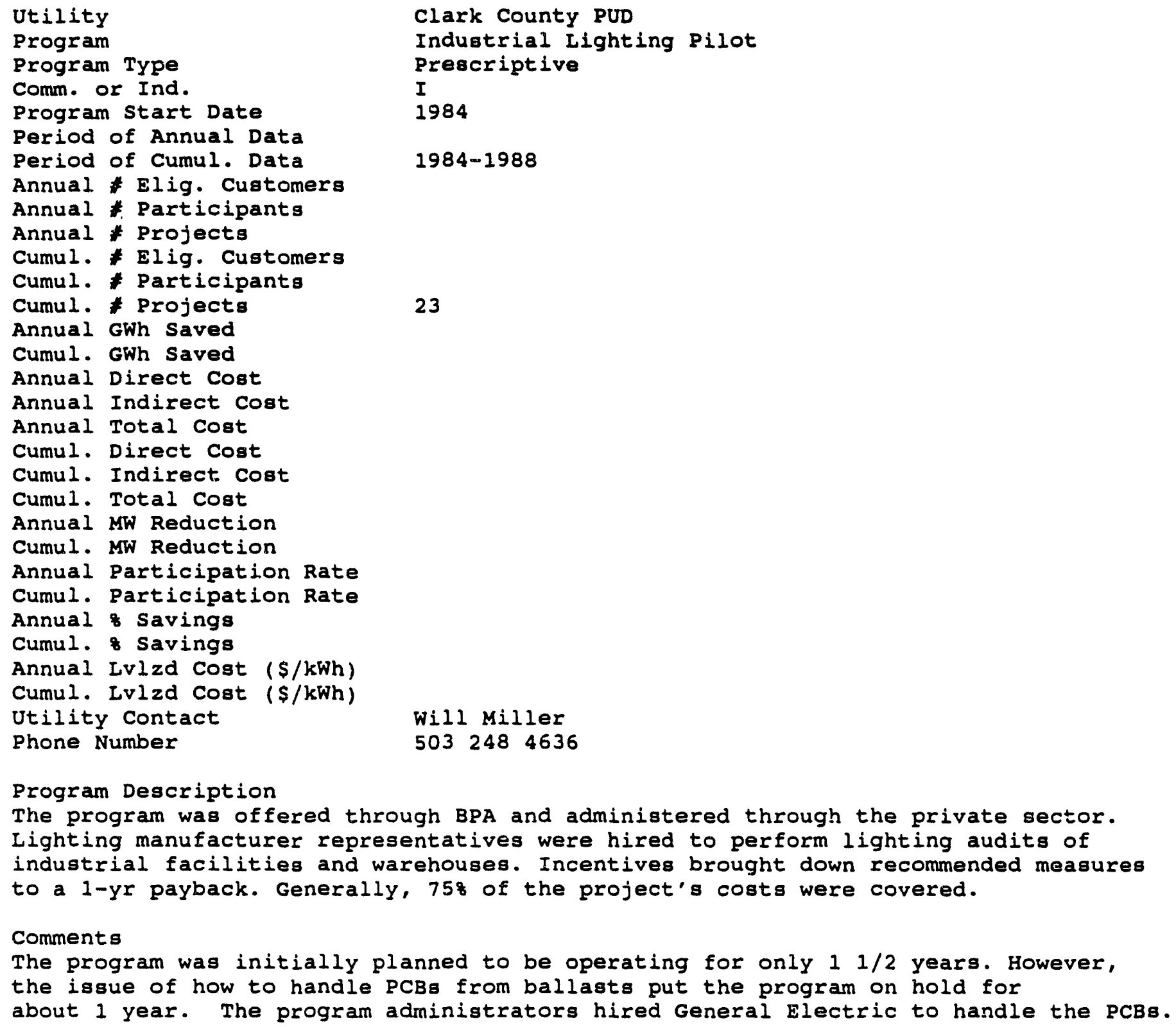


Utility

Program

Program Type

Comm. or Ind.

Program start Date

Period of Annual Daca

Period of Cumul. Data

Annual * Elig. Customers

Annual * Participants

Annual * Projects

Cumul. Elig. Customers

Cumul. * Participants

Cumul. * Projects

Annual GWh saved

Cumul. GWh Saved

Annual Direct Cost

Annual Indirect Cost

Annual Total Cost

Cumul. Direct Cost

Cumul. Indirect Cost

Cumul. Total cost

Annual MW Reduction

Cumul. MW Reduction

Annual Participation Rate

Cumul. Participation Rate

Annual Savings

Cumul. Savings

Asnual Lvlzd Cost ( $\$ / k W h$ )

Cumul. Lvlad Cost ( $\$ / \mathrm{kWh})$

Utility Contact

Phone Number
Commonwealth Edison

High-Efficiency Motor Incentive Program

Prescriptive

Both

Jerry Hill

3122942764

Incentive Description

NEMA high-efficiency motors between 5-200 hp are eligible. Limit of 10 rebates per customer. Motors must operate at least $1000 \mathrm{hrs} / \mathrm{yr}$. 


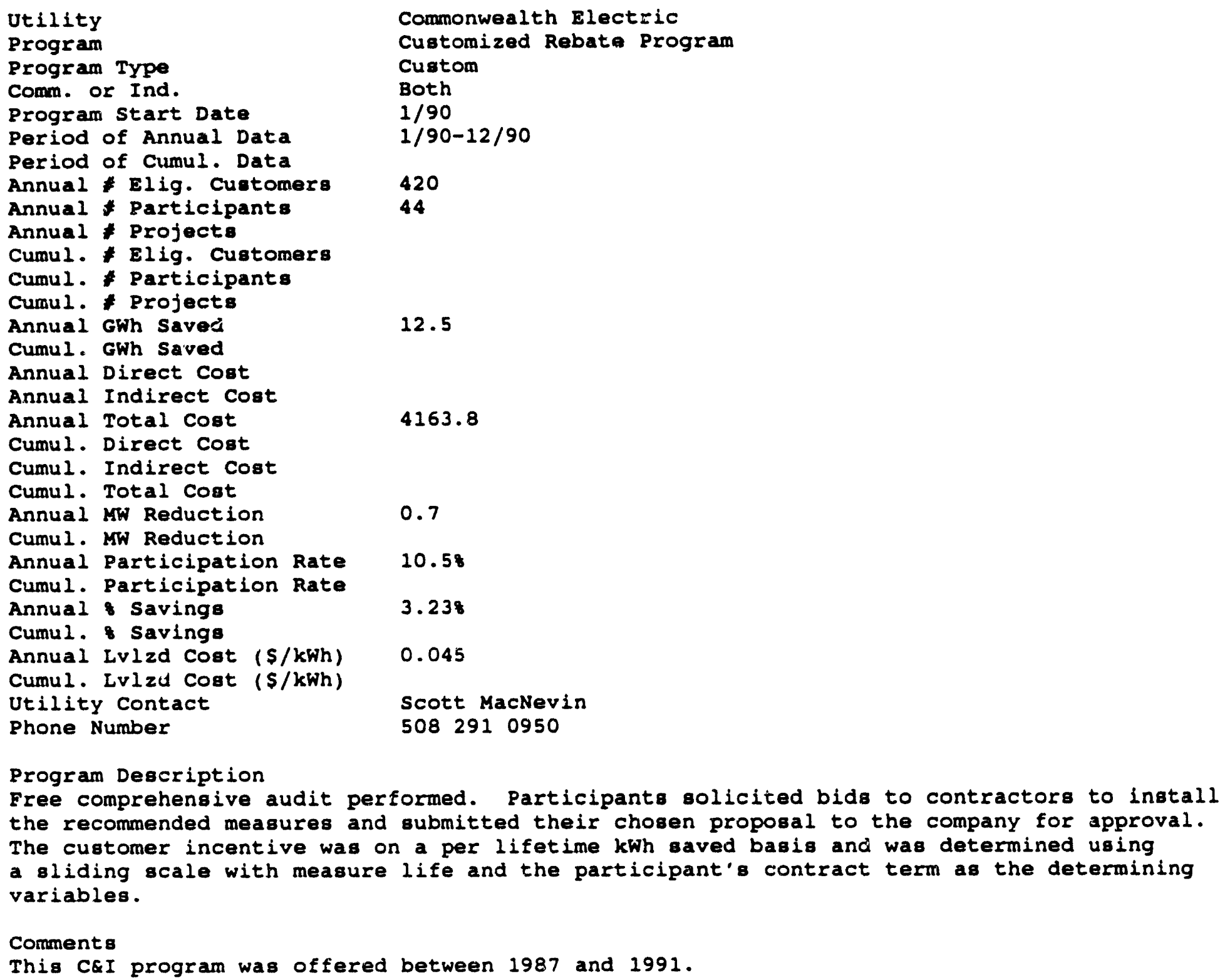




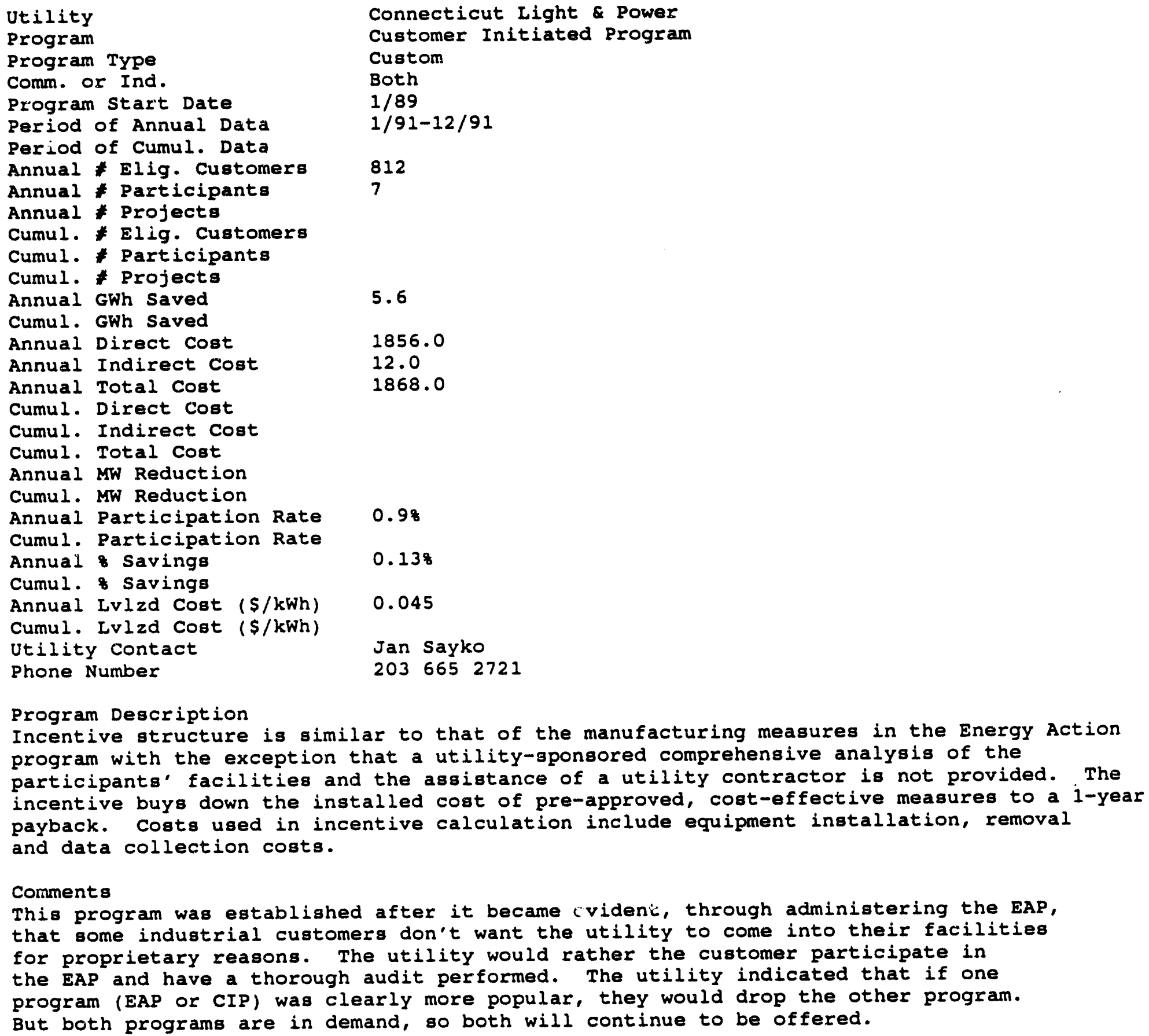

Program Description

Incentive structure is similar to that of the manufacturing measures in the Energy Action program with the exception that a utility-sponsored comprehensive analysis of the participants' facilities and the assistance of a utility contractor is not provided. The incentive buys down the installed cost of pre-approved, cost-effective measures to a $1-y e a r$ payback. Costs used in incentive calculation include equipment installation, removal and data collection costs.

Comments

This program was established after it became cvideni, through administering the EAP, that some indugtrial customers don't want the utility to come into their facilities for proprietary reasons. The utility would rather the customer participate in the EAP and have a thorough audit performed. The utility indicated that if one program (EAP or CIP) was clearly more popular, they would drop the other program. But both programs are in demand, so both will continue to be offered. 


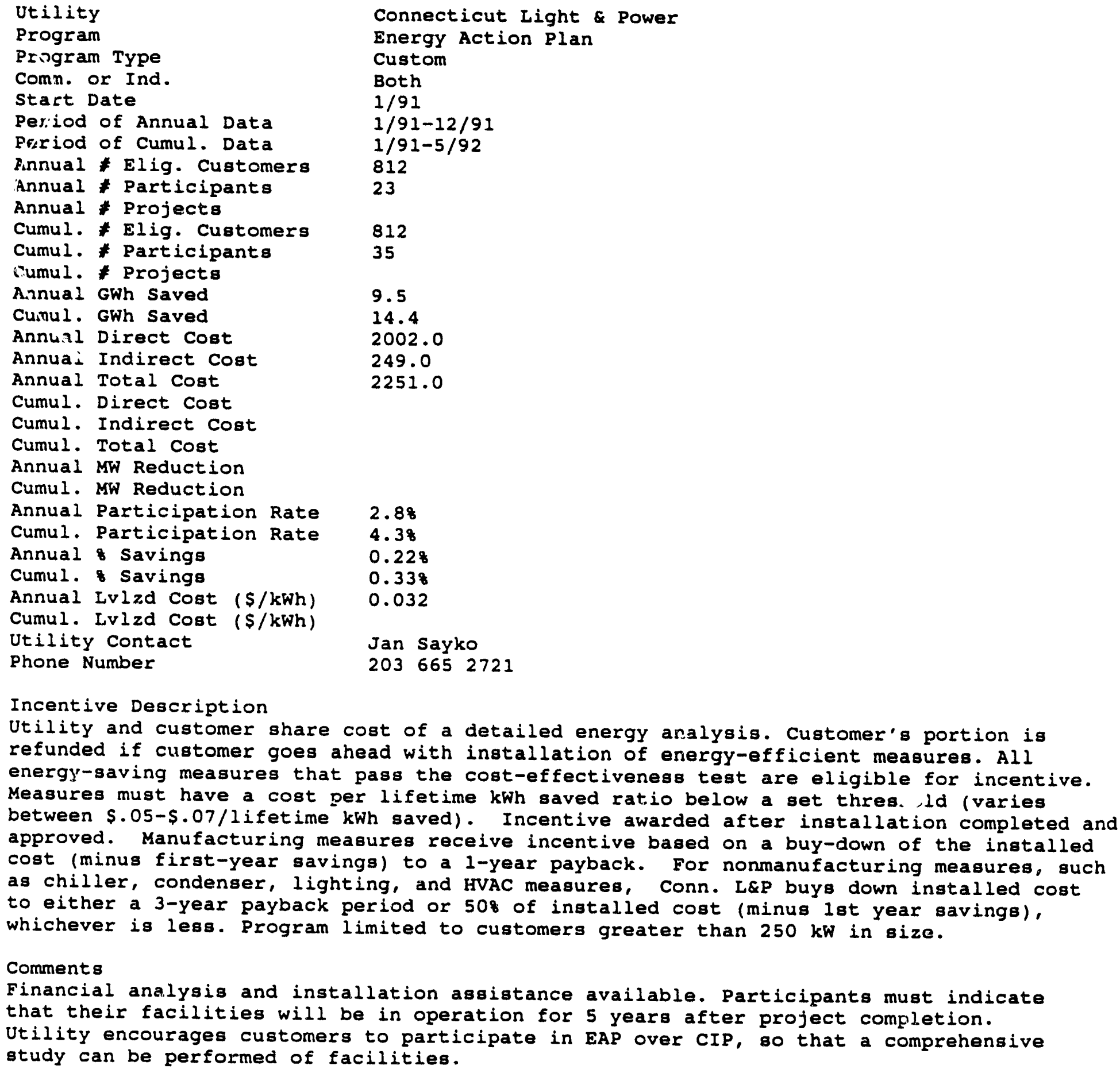




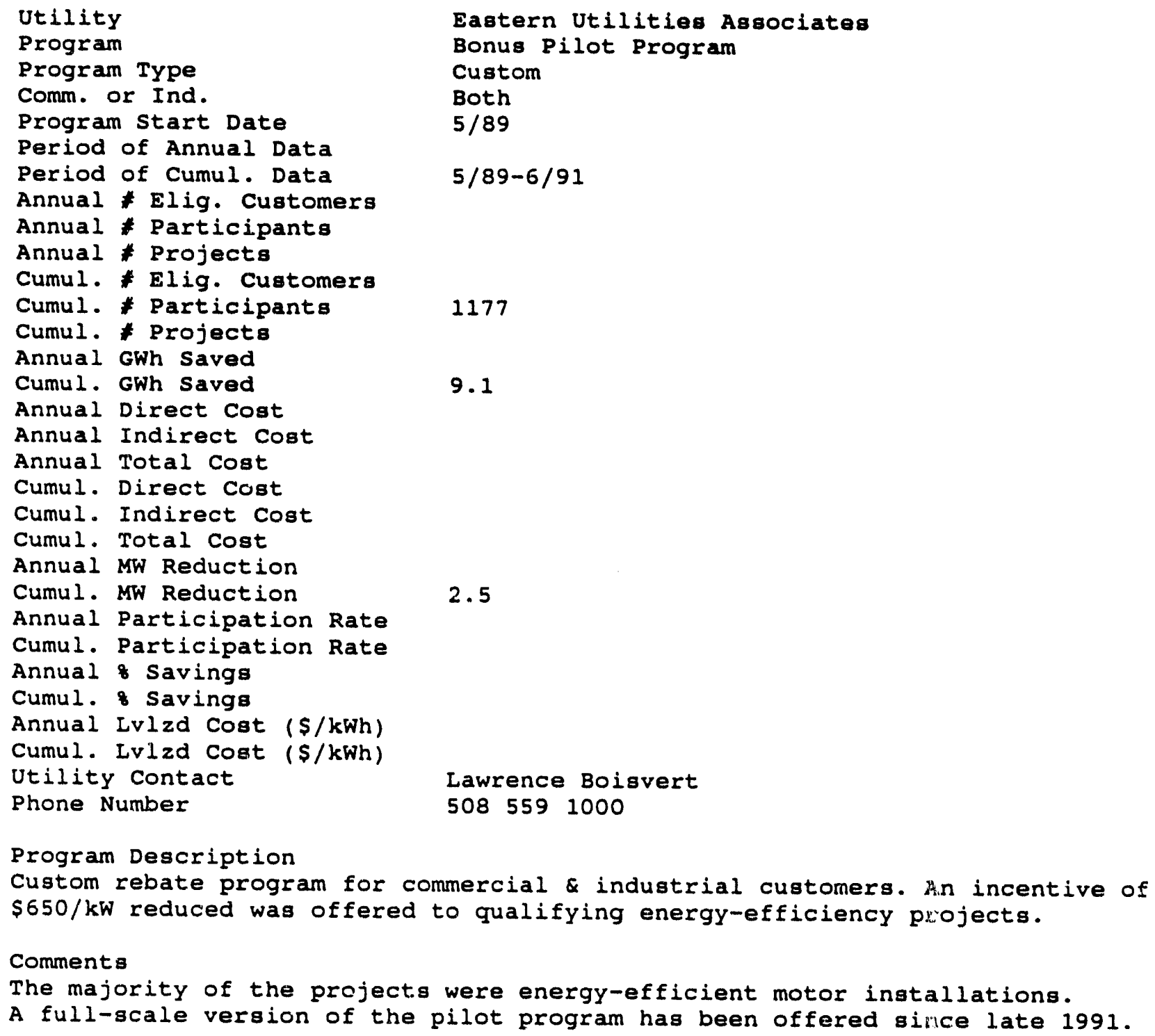




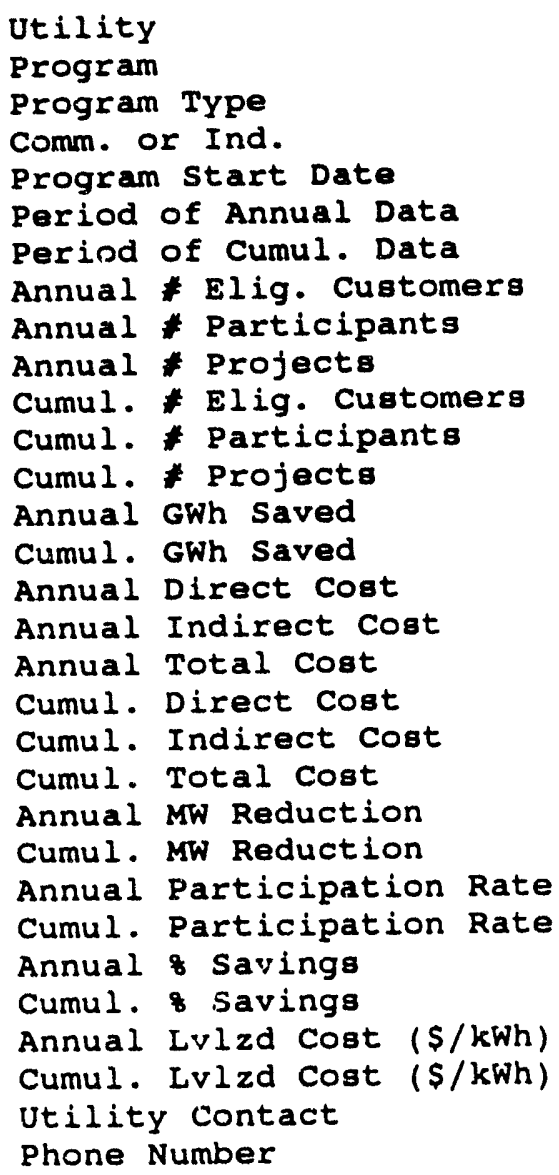

Green Mountain Power

Large C\&I Retrofit Program

Custom

Both

1992

Program Description

A free energy audit is offered. Incentives reduce qualifying measures' payback periods to 2 years. All C\&I customers using more than $12.5 \mathrm{MWh} / \mathrm{month}$ are eligible.

Comments
Measures which fuel switch away from electric heating can be considered for an incentive. 


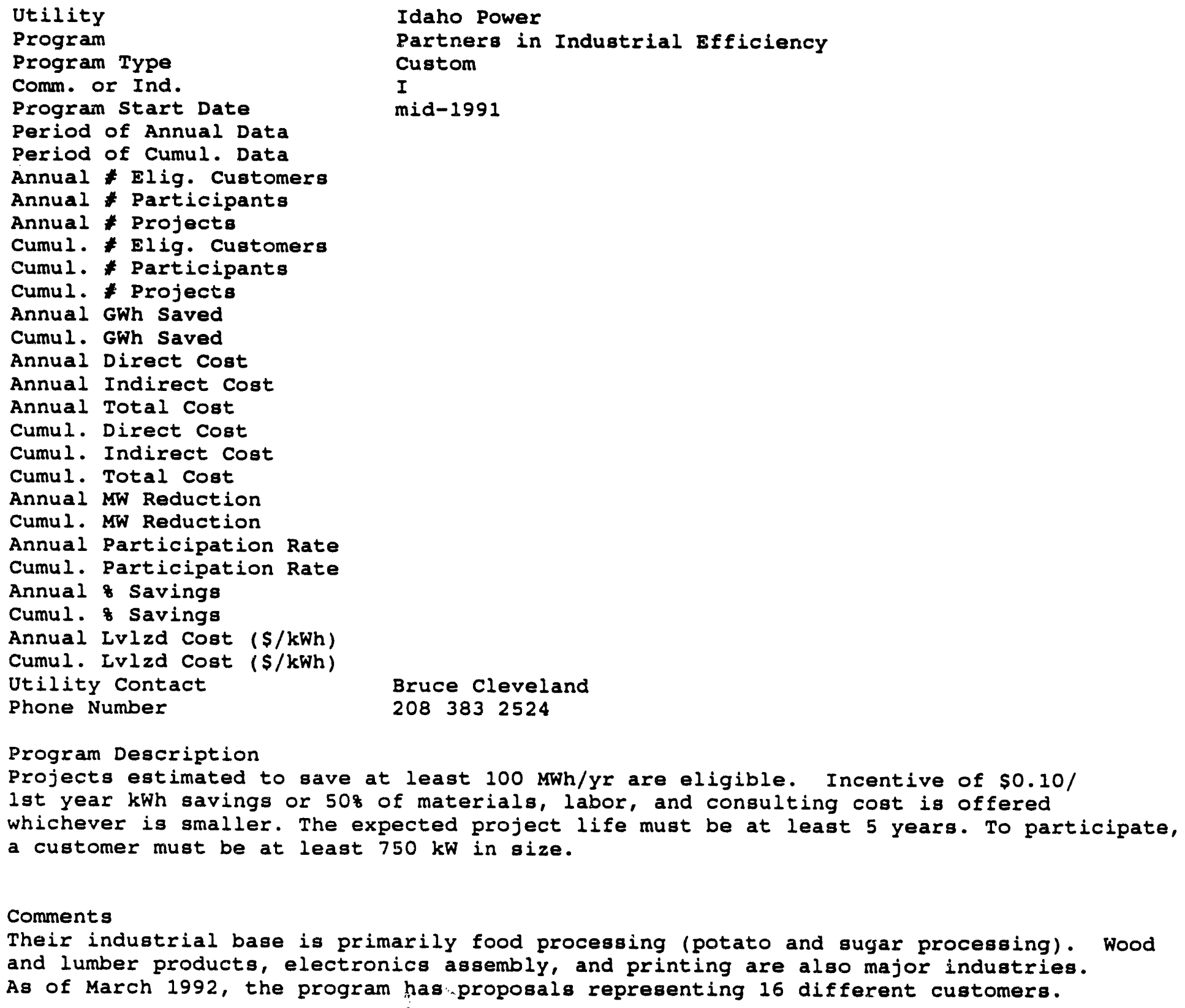

Program Description

Projects estimated to save at least $100 \mathrm{MWh} / \mathrm{yr}$ are eligible. Incentive of $\$ 0.10 /$ lst year kWh savings or 508 of materials, labor, and consulting cost is offered whichever is smaller. The expected project life must be at least 5 years. To participate, a customer must be at least $750 \mathrm{~kW}$ in size.

Comments

Their industrial base is primarily food processing (potato and sugar processing). Wood and lumber products, electronics assembly, and printing are also major industries. As of March 1992, the program has proposals representing 16 different customers. 


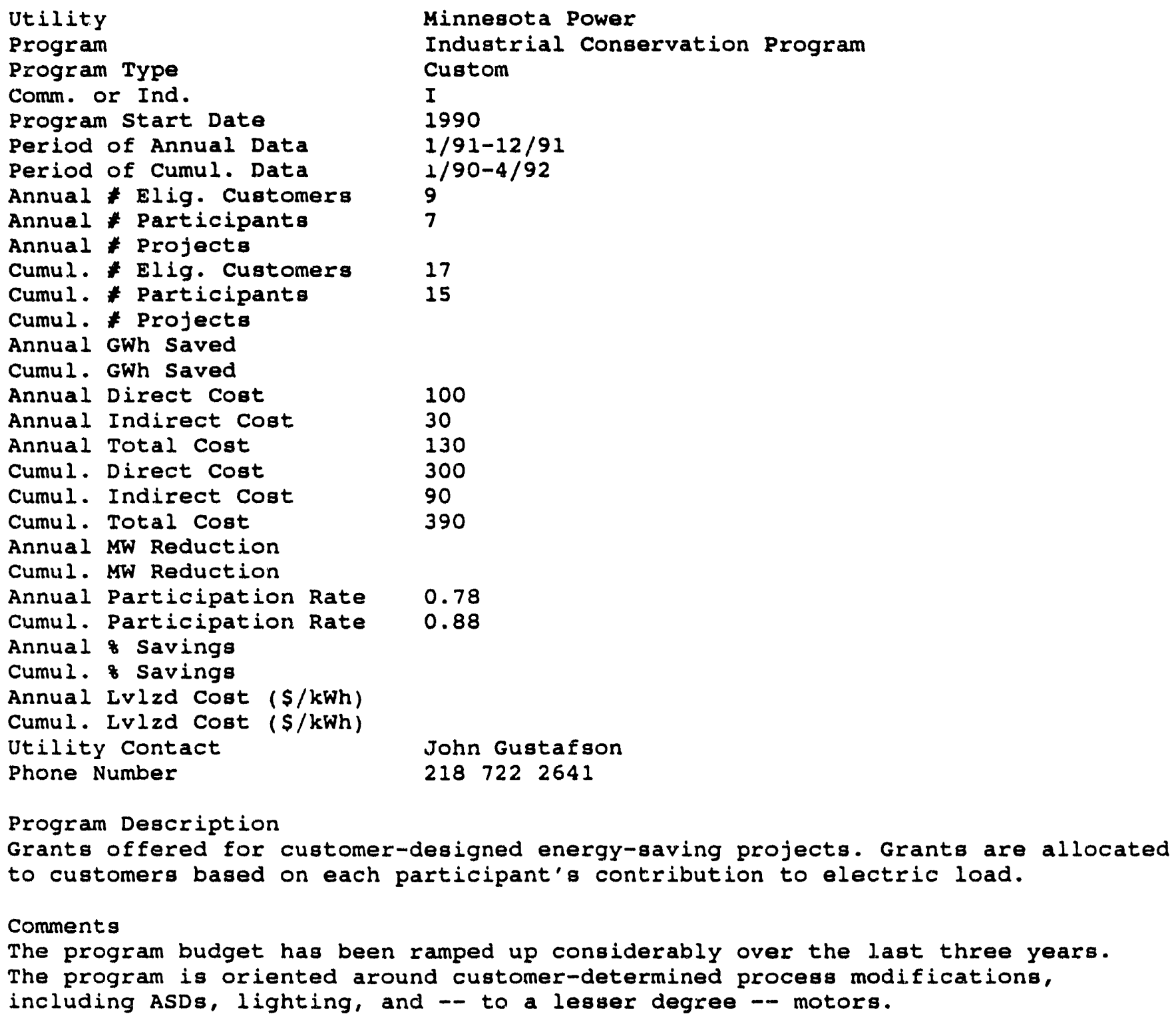

Program Description

Grants offered for customer-designed energy-saving projects. Grants are allocated to customers based on each participant's contribution to electric load.

Comments

The program budget has been ramped up considerably over the last three years. The program is oriented around customer-determined process modifications, including ASDs, lighting, and -- to a lesser degree -- motors. 


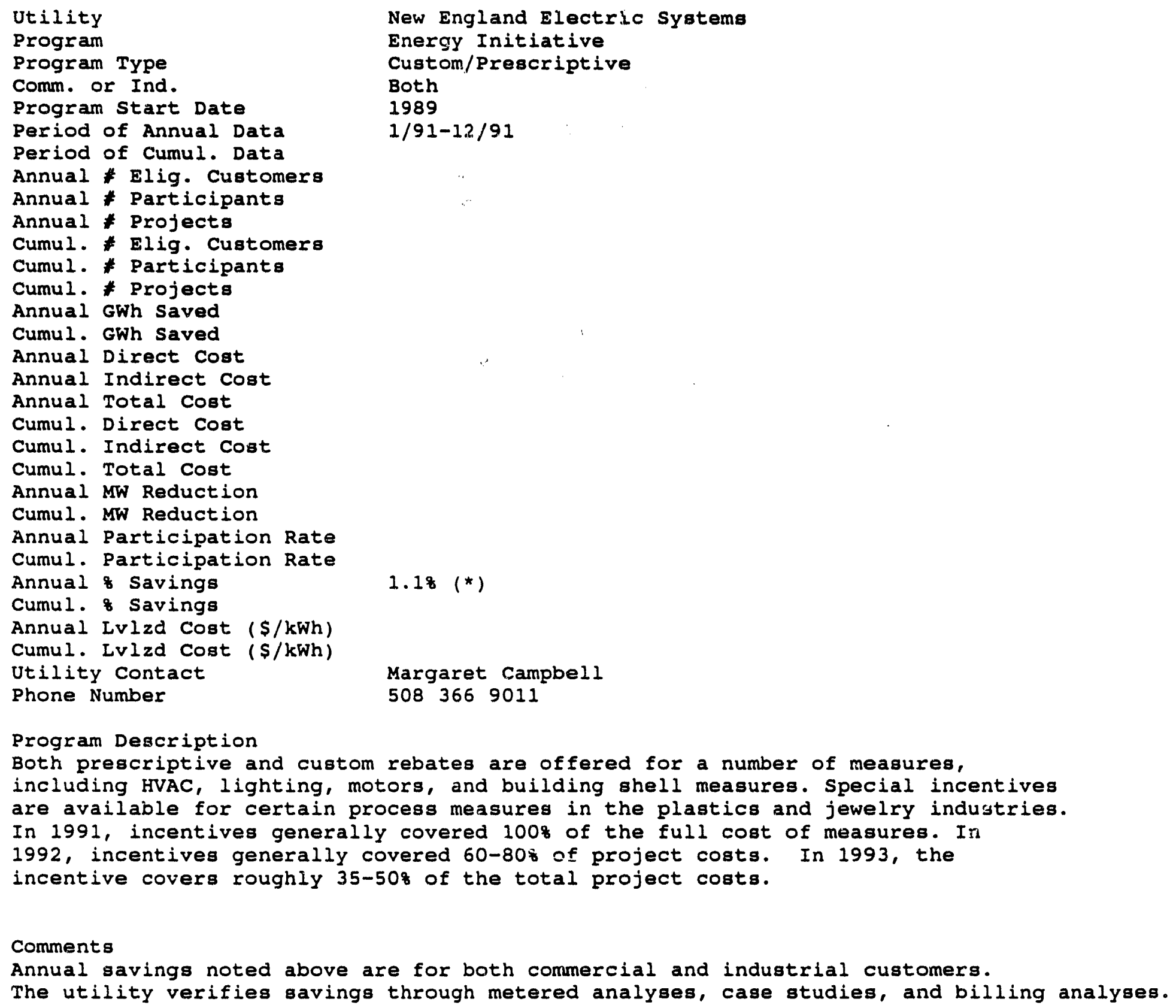




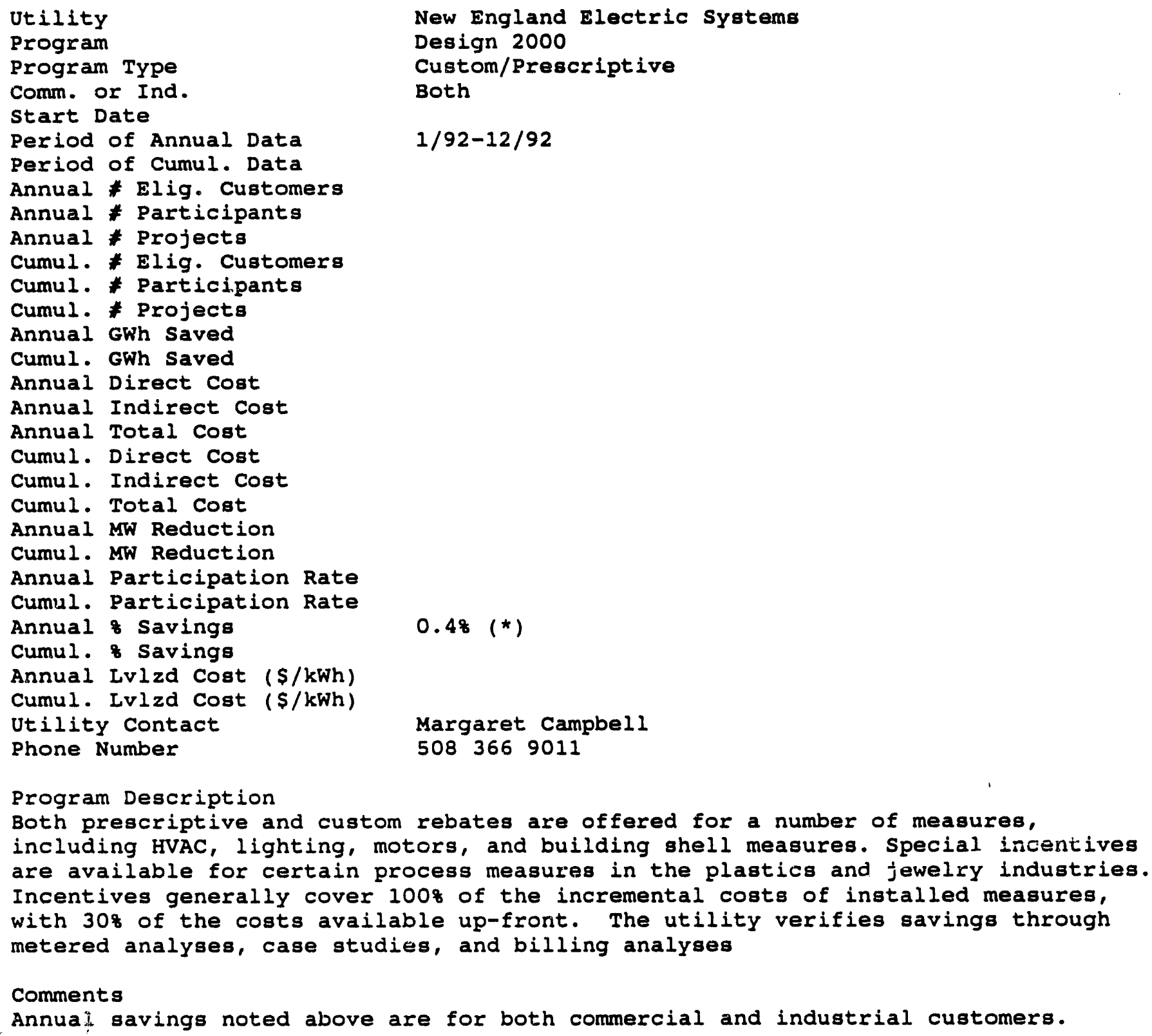




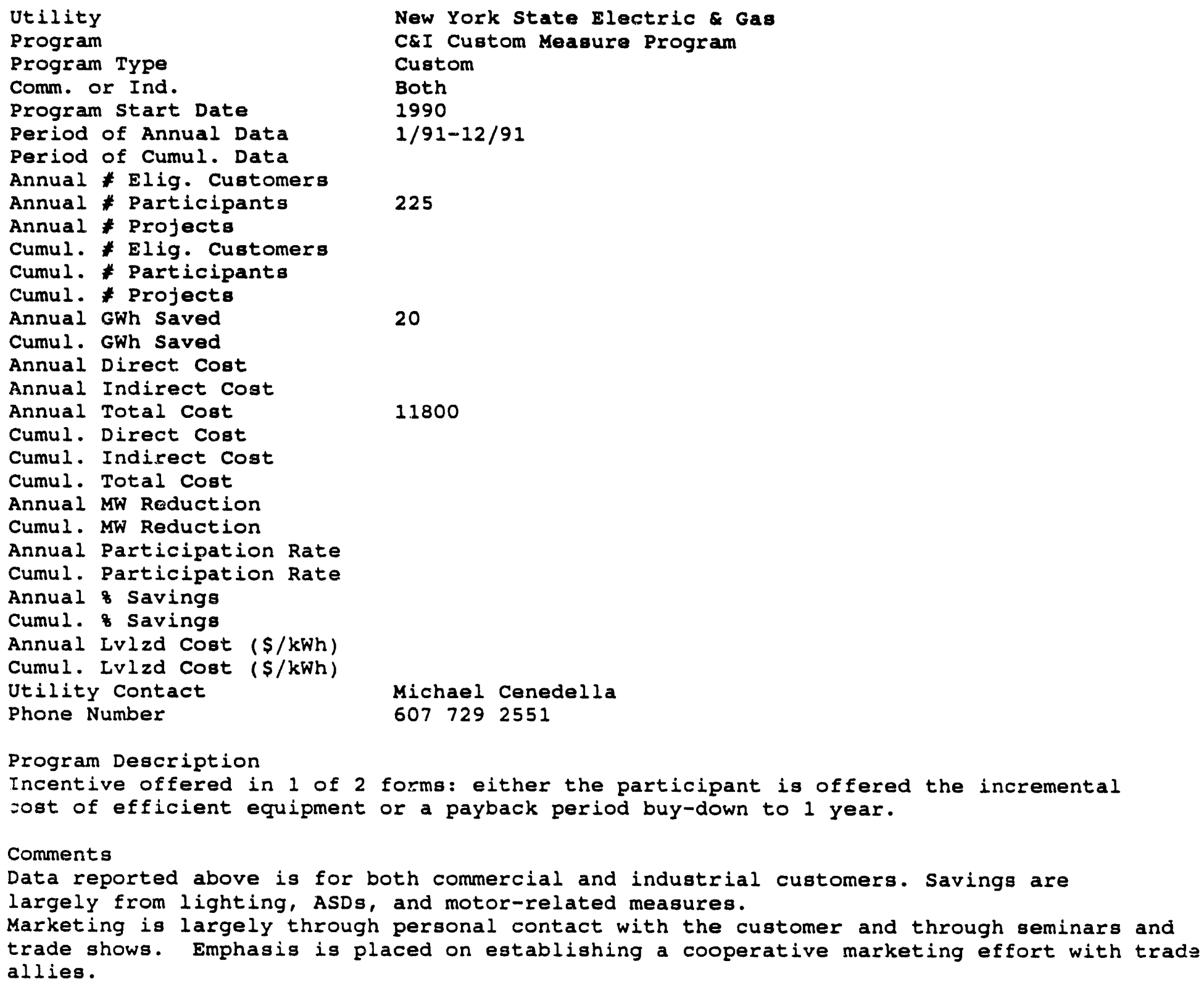




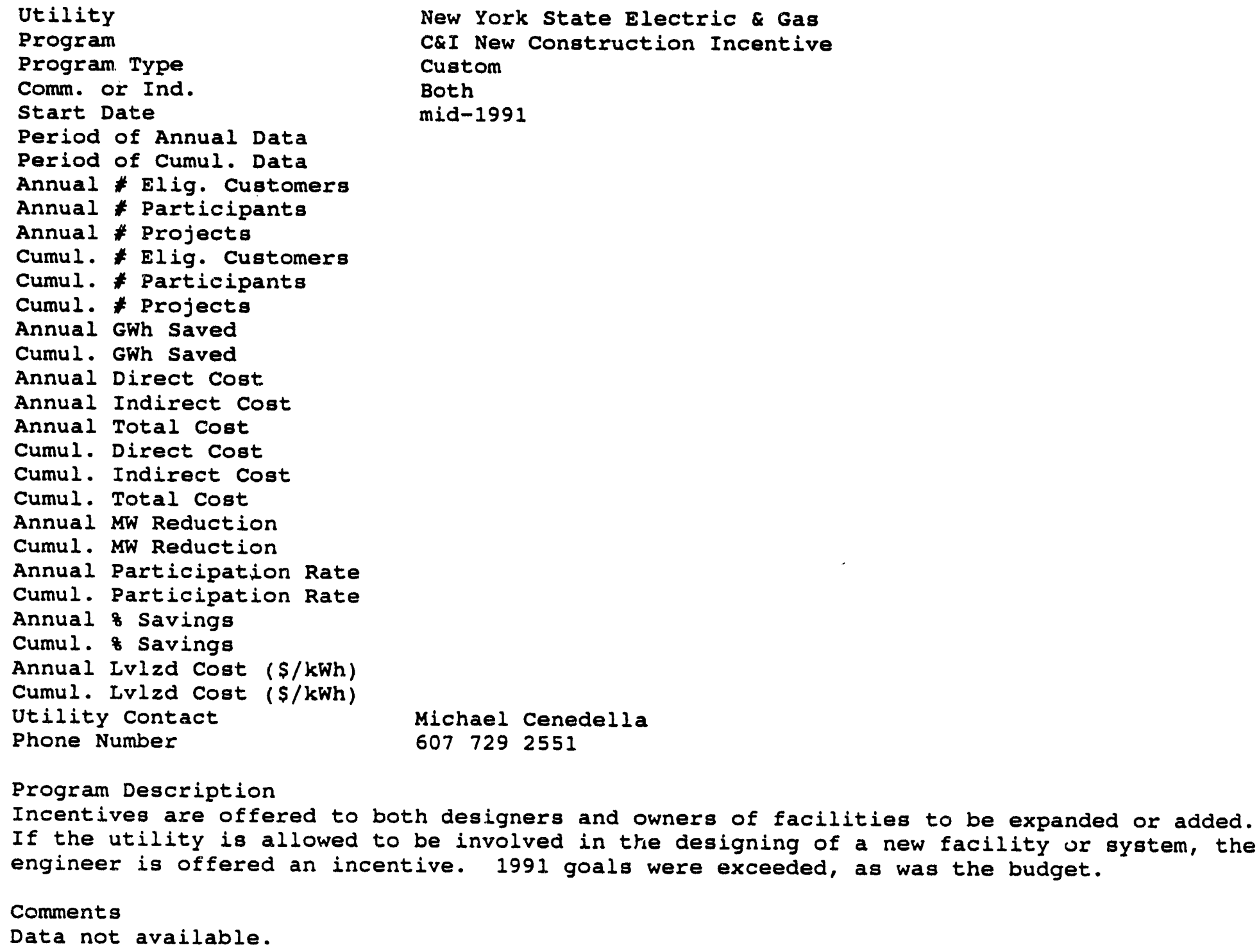




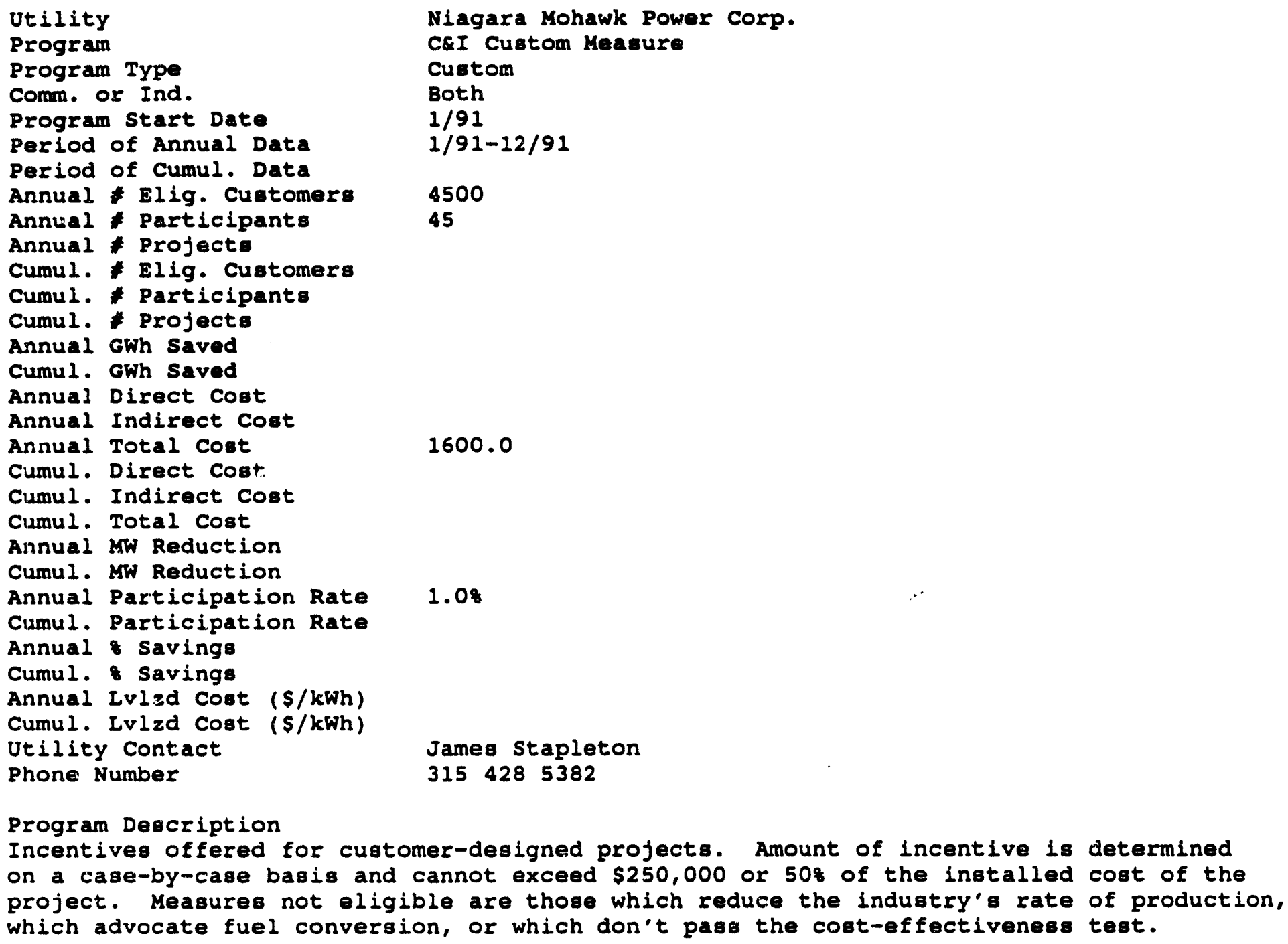

Program Description

Incentives offered for customer-designed projects. Amount of incentive is determined on a case-by-case basis and cannot exceed $\$ 250,000$ or 508 of the installed cost of the project. Measures not eligible are those which reduce the industry's rate of production, which advocate fuel conversion, or which don't pass the cost-effectiveness test.

Comments

Number of eligible customers and number of participants were estimated by the utility. HVAC upgrades and installations of ASDs are commonly performed measures. 
Utility

Program

Program Type

comm. or Ind.

start Date

Period of Annual Data

Period of Cumul. Data

Annual Elig. Customers

Annual * Participants

Annual * Projects

Cumul. Elig. Customers

Cumul. * Participants

Cumul. Projects

Annual GWh saved

Cumul. GWh saved

Annual Direct Cost

Annual Indirect Cost

Annual Total cost

Cumul. Direct Cost

Cumul. Indirect Cost

Cumul. Total cost

Annual MW Reduction

Cumul. MW Reduction

Annual Participation Rate

Cumul. Participation Rate

Annual \& Savings

Cumul. \& Savings

Annual Lvizd cost ( $\$ / k W h$ )

Cumul. Lvlzd Cost ( $\$ / k W h$ )

Utility contact

Phone Number
Niagara Mohawk Power Corp.

C\&I Motors \& Drives Program

Prescriptive

Both

$1 / 91$

$1 / 91-12 / 91$

3600

110

9.6

728.0

312.0

1040.0

\subsection{8}

0.088

0.015

James Stapleton

$315428 \quad 5382$

Program Description

Customers receive incentives for replacing motors with qualifying energy-efficient models and for installing ASDs. The ASD incentives generally pay for 50-758 of the drive installation costs.

Comments

The utility exceeded their 1991 goals 500\%. Trade allies are trained on how to market their products with this program. 
Utility

Program

Program Type

Comm. or Ind.

start Date

Period of Annual Data

Period of Cumul. Data

Annual * Elig. Customers

Annual Participanta

Annual Projects

Cumul. Elig. Customers

Cumul. Participanta

Cumul. Proje ito

Annual GWh Saved

Cumul. GWh Savea

Annual Direct Coet

Annual Indirect Cost

Annual Total Cost

Cumul. Direct Cost

Cumul. Indirect Cost

Cumul. Total Cost

Annual MW Reduction

Cumul. MW Reduction

Annual Participation Rate

Cumul. Participation Rate

Annual Savings

Cumul. Savings

Annual Lvizd Cost ( $\$ / k W h$ )

Cumul. Lvlzd Cost ( $/ / \mathrm{kWh}$ )

Phone Number
Northern State Power - Minnesota

Motor Rebate Program

prescriptive

Both

1990

Program Description

The utility offers both customer \& vendor incentives for purchase of energy-efficient motors. The customer incentive depends on the size of the motor. The vendor incentive is $\$ 0.50 / \mathrm{hp}$. In 1993, ASD incentives have been added.

Comments

Vendor incentives were added in 1990. 


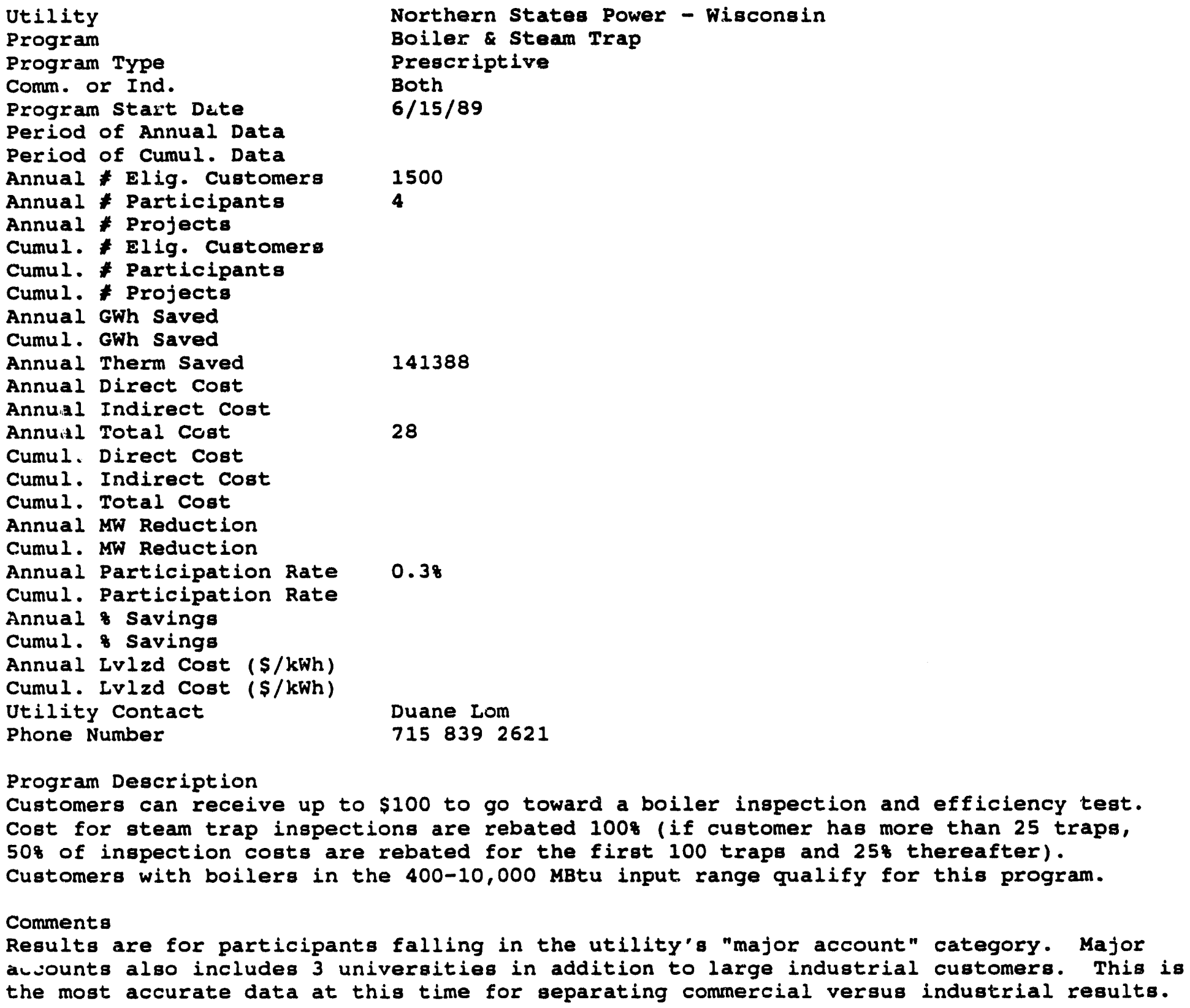

Program Description

Customers can receive up to $\$ 100$ to go toward a boiler inspection and efficiency tegt. Cost for steam trap inspections are rebated 1008 (if customer has more than 25 traps, 508 of inspection costs are rebated for the first 100 traps and 258 thereafter). Customers with boilers in the 400-10,000 MBtu input range qualify for this program.

Comments

Results are for participants falling in the utility's "major account" category. Major ausounts also includes 3 universities in addition to large industrial customers. This is the most accurate data at this time for separating commercial versus industrial results. 


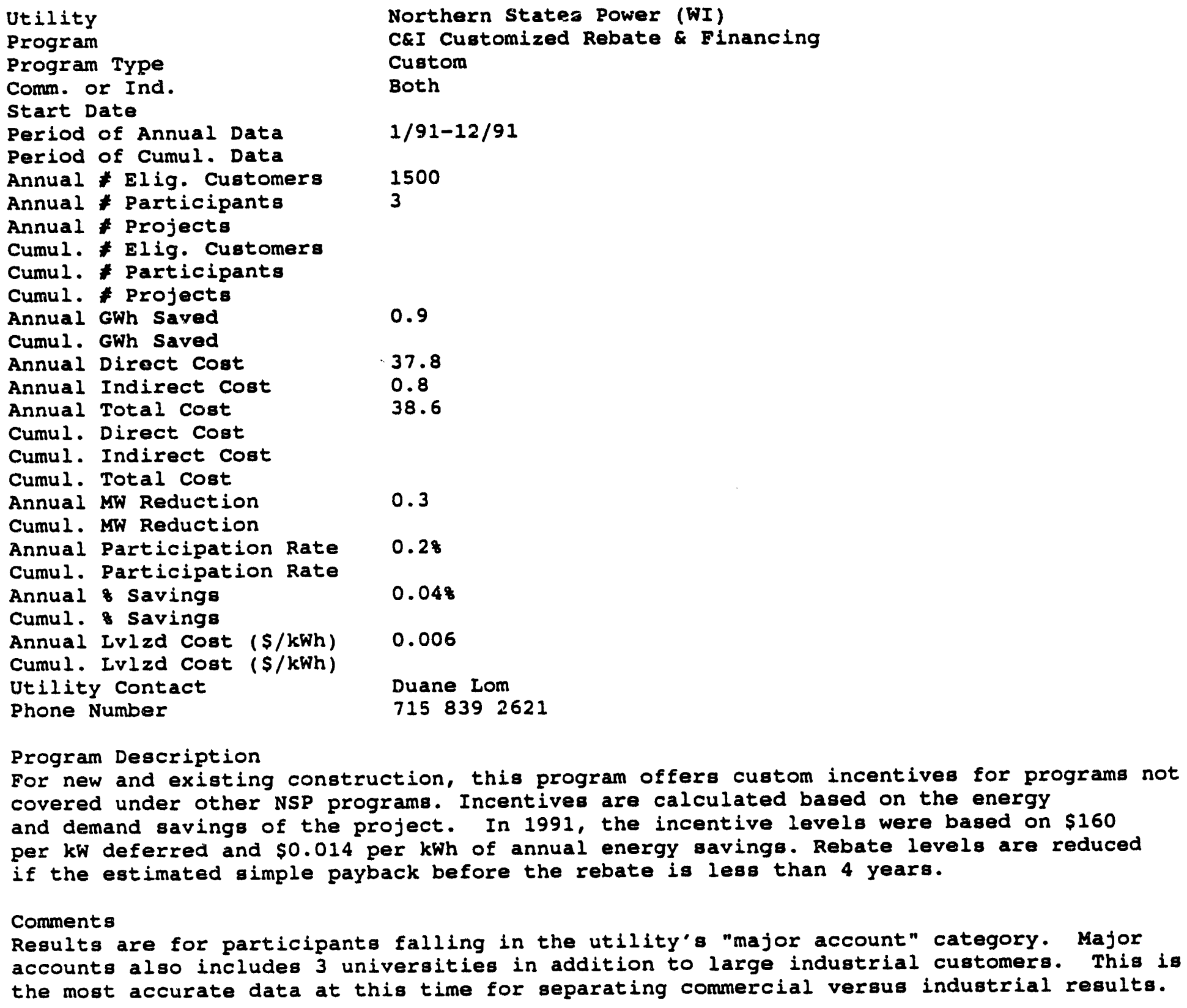


Utility

Program

Program Type

Comm. or Ind.

start Date

Period of Annual Data

Period of Cumul. Data

Annual * Elig. Customers

Annual * Participants

Annual * Projects

Cumul. Elig. Customerg

Cumul. * Participanta

Cumul. * Projects

Annual GWh Saved

Cumul. GWh saved

Annual Direct Cost

Annual Indirect Cost

Annual Total Cost

Cumul. Direct cost

Cumul. Indirect Cost

Cumul. Total Cost

Annual MW Reduction

Cumul. MW Reduction

Annual Participation Rate

Cumul. Participation Rate

Annual \& Savings

Cumul. \& Savings

Annual Lvizd Cost ( $\$ / \mathrm{kWh}$ )

Cumul. Lvizd Cost ( $\$ / k W h$ )

Utility Contact

Phone Number
Northern States Power (WI)

C\&I Motor Effic. Improvement

Prescriptive

Both

$1 / 91$

$1 / 91-12 / 91$

1500

49

\section{2}

66.2

34.2

100.4

0.5

3.38

0.168

0.004

Duane Lom

$\begin{array}{lll}715 & 839 & 2621\end{array}$

Program Description

Customers who install energy-efficient motors can receive rebates between $\$ 30-200 /$ motor. customers who install ASDs can receive rebates of $\$ 20 / \mathrm{hp}$. Motor rebate depends upon how many hourg per day a motor runs, its load, and other factors.

Comments accounts also includes 3 universities in addition to large industrial customers. This is the most accurate data at this time for separating commercial versus industrial results. 


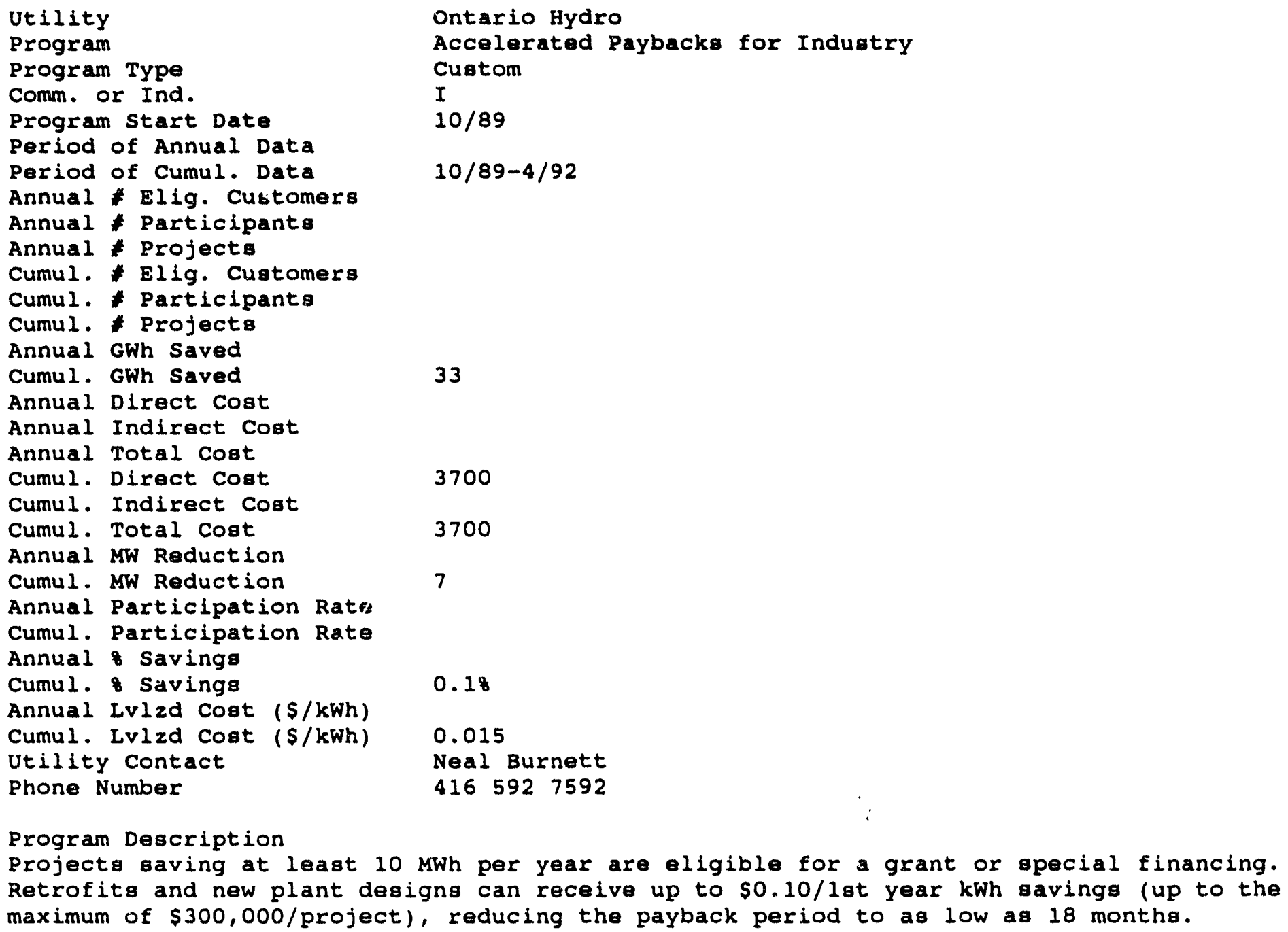


Utility
Program
Program Type
Comm. or Ind.
Start Date

Period of Annual Data

Period of Cumul. Data

Annual * Elig. Customers

Annual \# Participants

Annual * Projects

Cumul. \# Elig. Customers 90000

Cumul. * Participants 1260

Cumul. * Projects

Annual GWh Saved

Cumul. GWh Saved

Annual Direct Cost

Annual Indirect Cost

Annual Total Cost

Cumul. Direct cost

Cumul. Indirect cost

Cumul. Total Cost

Annual MW Reduction

Cumul. MW Reduction

Annual Participation Rate

Cumul. Participation Rate

Annual o Savings

Cumul. Savings

Annual Lvlzd Cost ( $\$ / \mathrm{kWh}$ )

Cumul. Lvlzd Cost $(\$ / \mathrm{kWh})$

Utility contact

Phone Number
Ontario Hydro

High Efficiency Motors Plan

Prescriptive

Both

10/15/89

$10 / 89-4 / 92$

4050

4050

8

1.48

Neal Burnett

$416592 \quad 7592$

Program Description

New and replacement motors from 1-500 hp which exceed utility's Motor Efficiency Levels qualify for a $\$ 12 / \mathrm{hp}$ cash rebate. There is no limit on number the number of rebates per customer allowed.

\section{Comments}

In 1991, a vendor incentive was added. The utility is presently working on getting a better handle on the program's participants. The utility's MW peak reduction goal is $500 \mathrm{MW}$ by the year 2000 in the industrial sector. About $200 \mathrm{MW}$ of this is planned to be captured through load-shifting. 


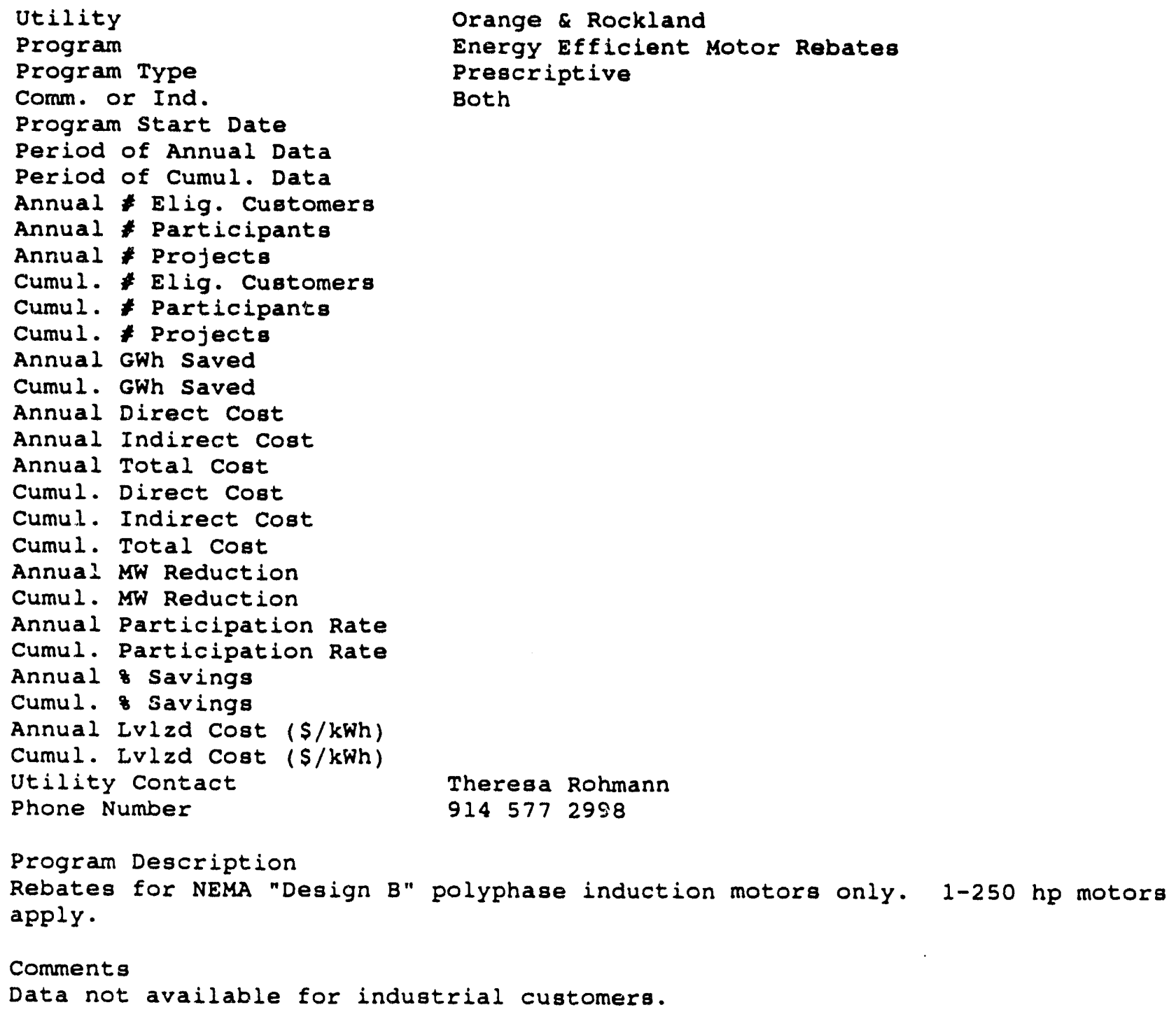




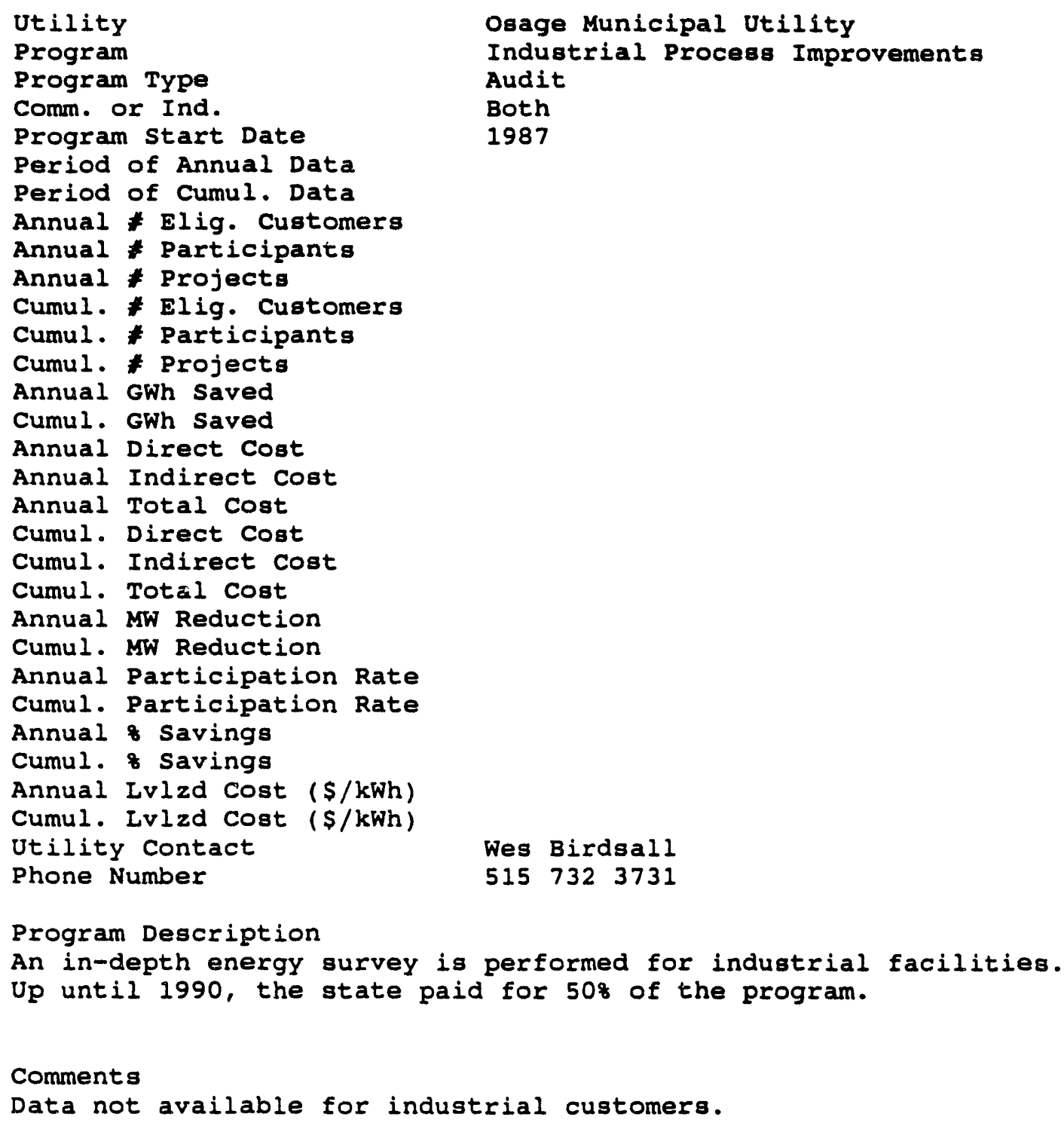

Program Description

An in-depth energy survey is performed for industrial facilities.

Up until 1990, the state paid for $50 \%$ of the program.

Data not available for industrial customers. 
Utility

Program

Program Type

Comm. or Ind

Start Date

Period of Annual Data

Period of Cumul. Data

Annual * Elig. Customers

Annual * Participants

Annual * Projects

Cumul. * Elig. Customers

Cumul. * Participants

Cumul. Projects

Annual GWh saved

Cumul. GWh Saved

Annual Direct Cust

Annual Indirect cost

Annual Total Cost

Cumul. Direct Cost

Cumul. Indirect cost

Cumul. Total Cost

Annual MW Reduction

Cumul. MW Reduction

Annual Participation Rate

Cumul. Participation Rate

Annual \& Savings

Cumul. \& Savings

Annual Lvlzd Cost ( $\$ / \mathrm{kWh}$ )

Cumul. Lvlzd Cost ( $\$ / \mathrm{kWh})$

Utility contact

Phone Number
Otter Tail power

Industrial Energy saver Grant

Custom

I

1989

Program Description

Custom rebates are available to customers for installing energy-efficient motors, AsDs, energy management systems, refrigeration compressors, cold thermal storage, etc.

Equipment and/or system can be new or retrofit of existing installations. The customer submits a grant application; the utility determines the incentive on a case-by-case basis.

Comments 


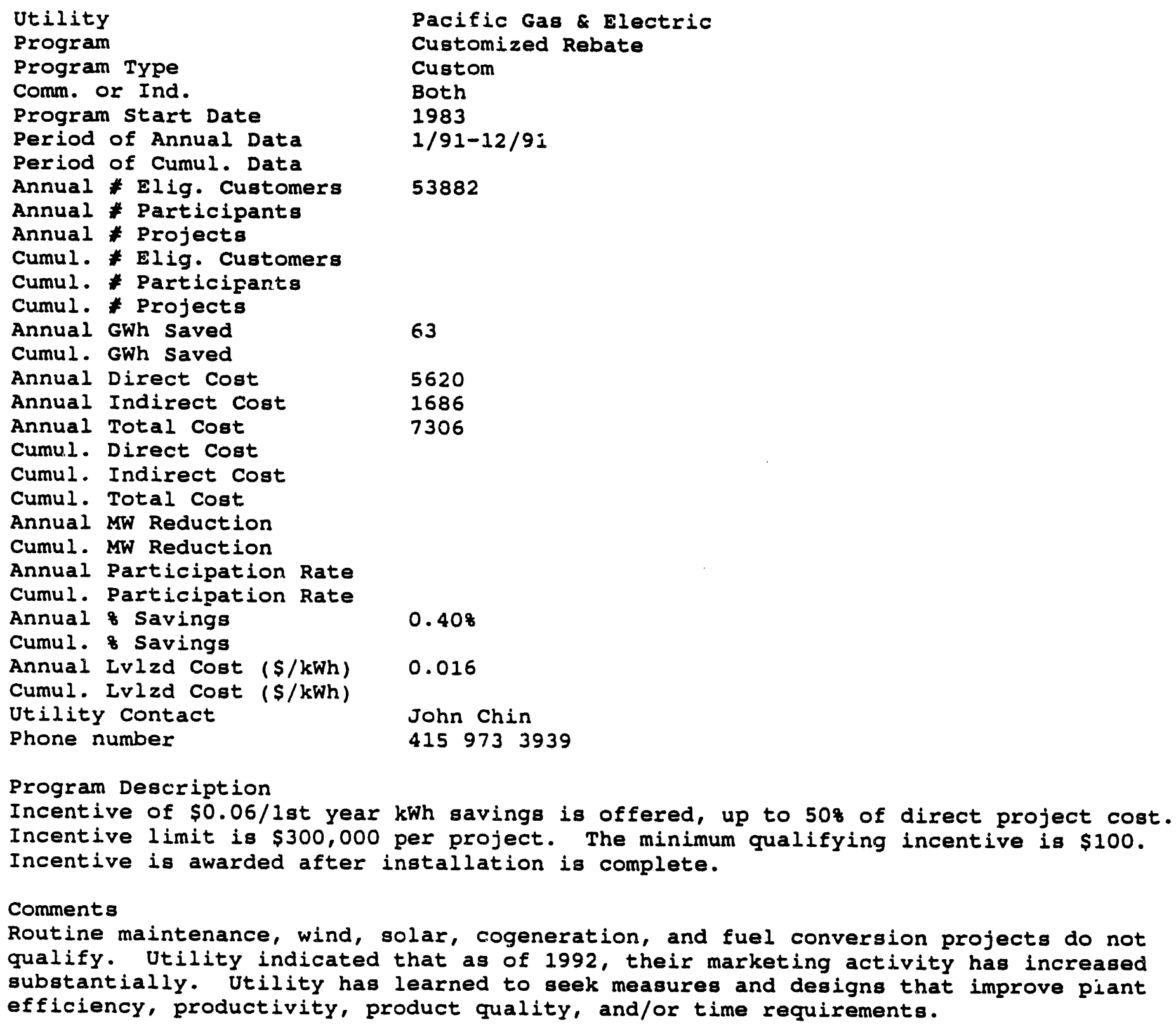




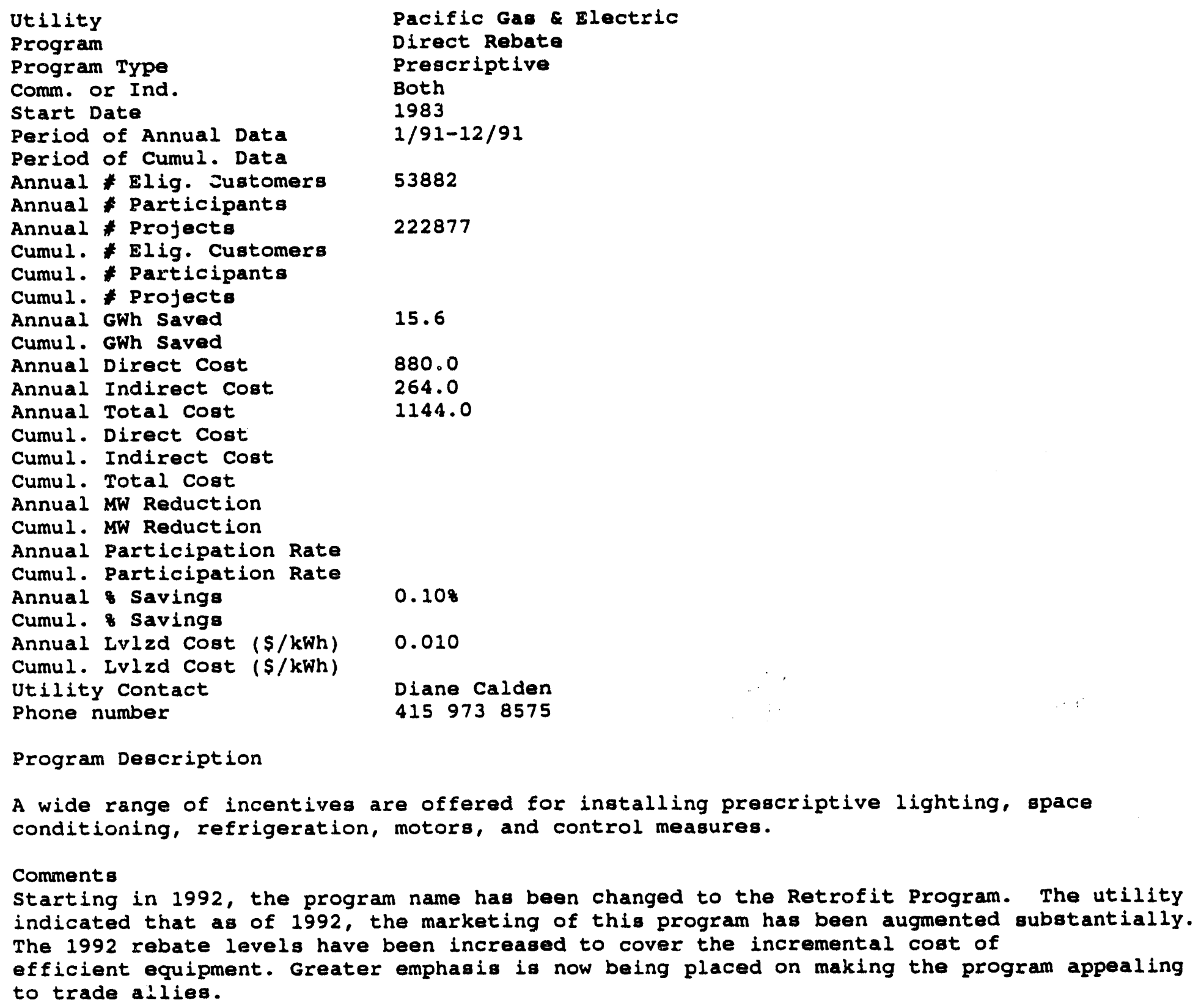




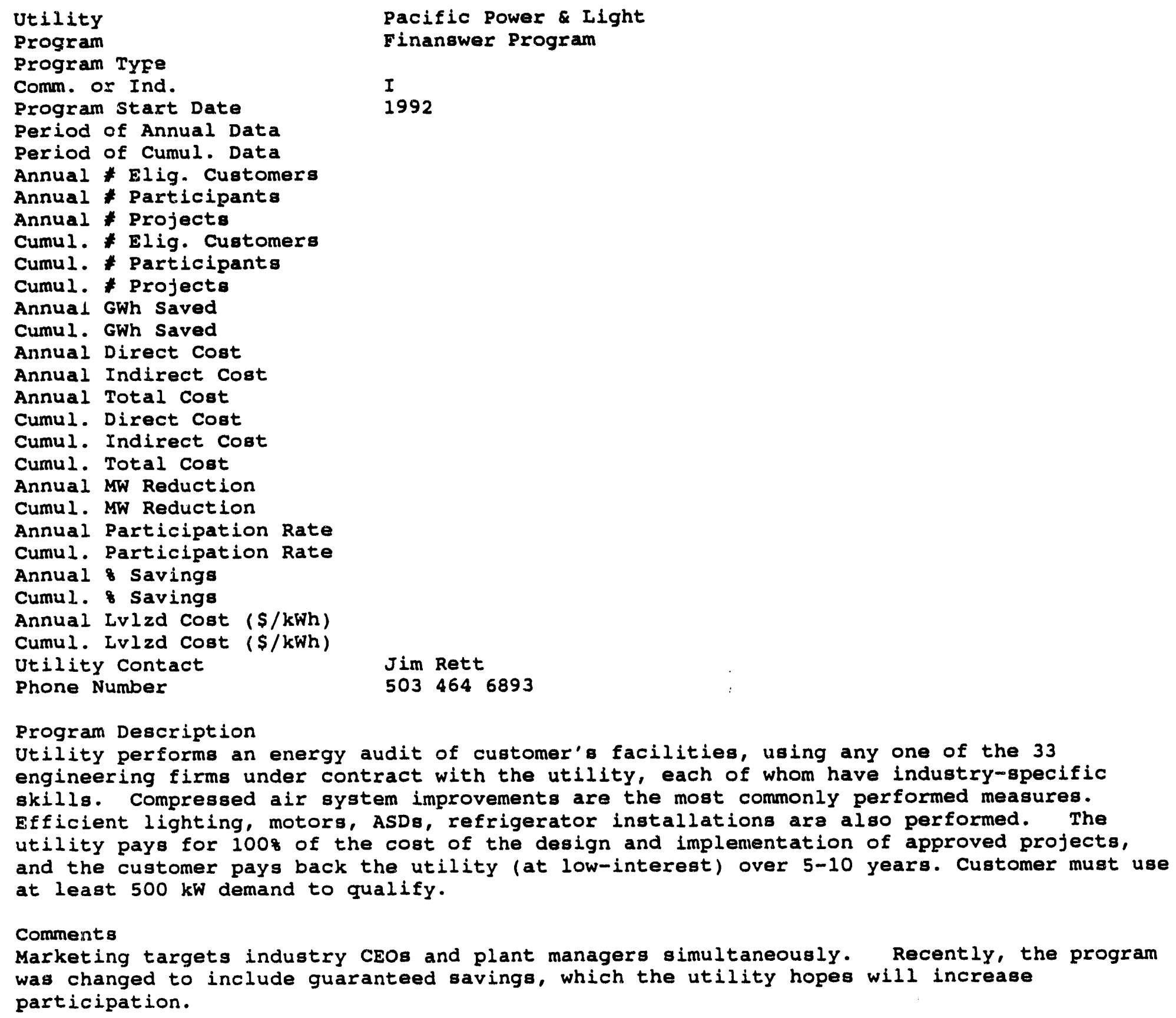




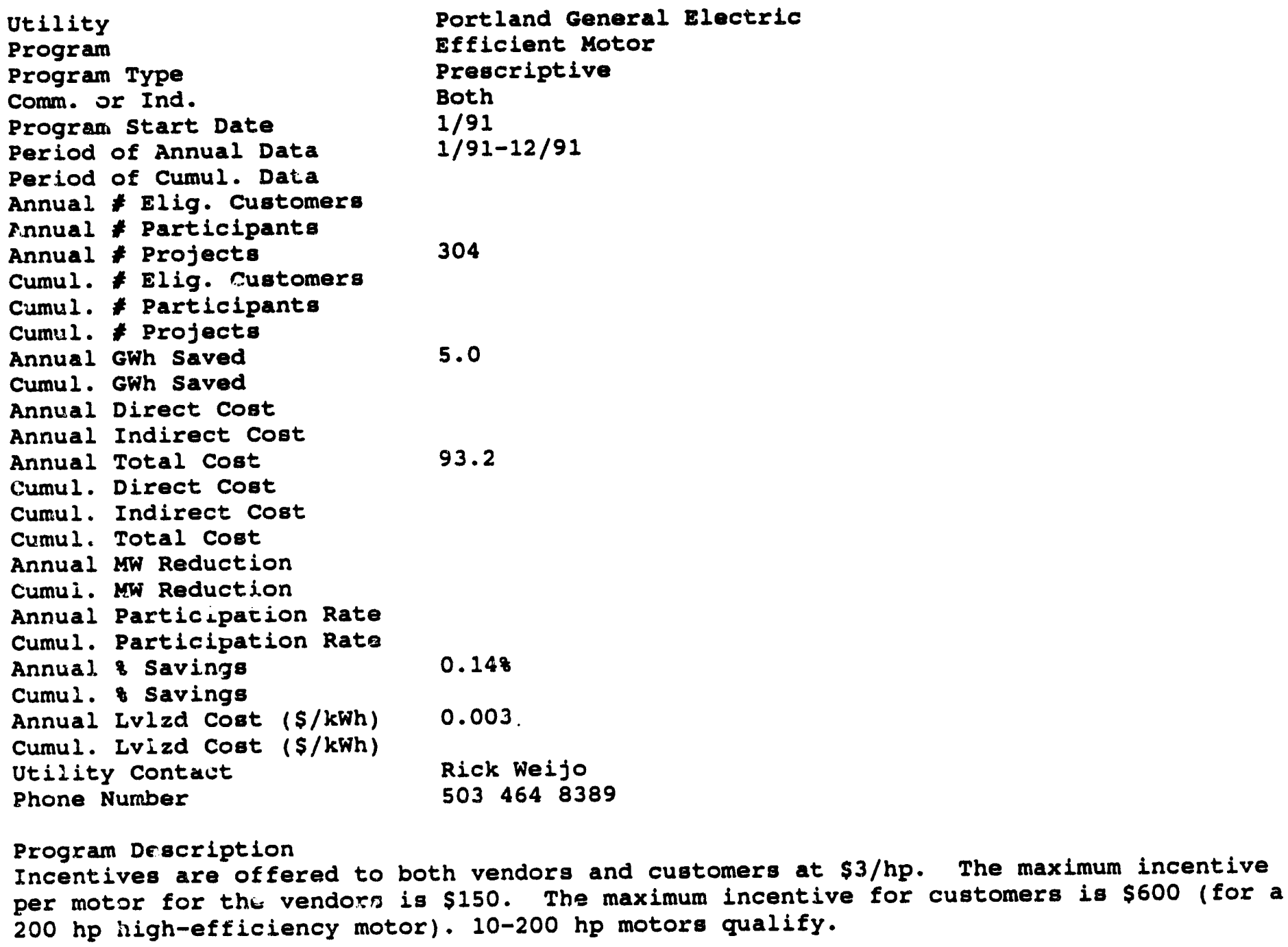

Program Description

Incentives are offered to both vendorg and customers at $\$ 3 /$ hp. The maximum incentive per motor for the vendors is $\$ 150$. The maximum incentive for customers is $\$ 600$ (for a $200 \mathrm{hp} \mathrm{high-ef(iciency}$ motor). 10-200 hp motors qualify. 


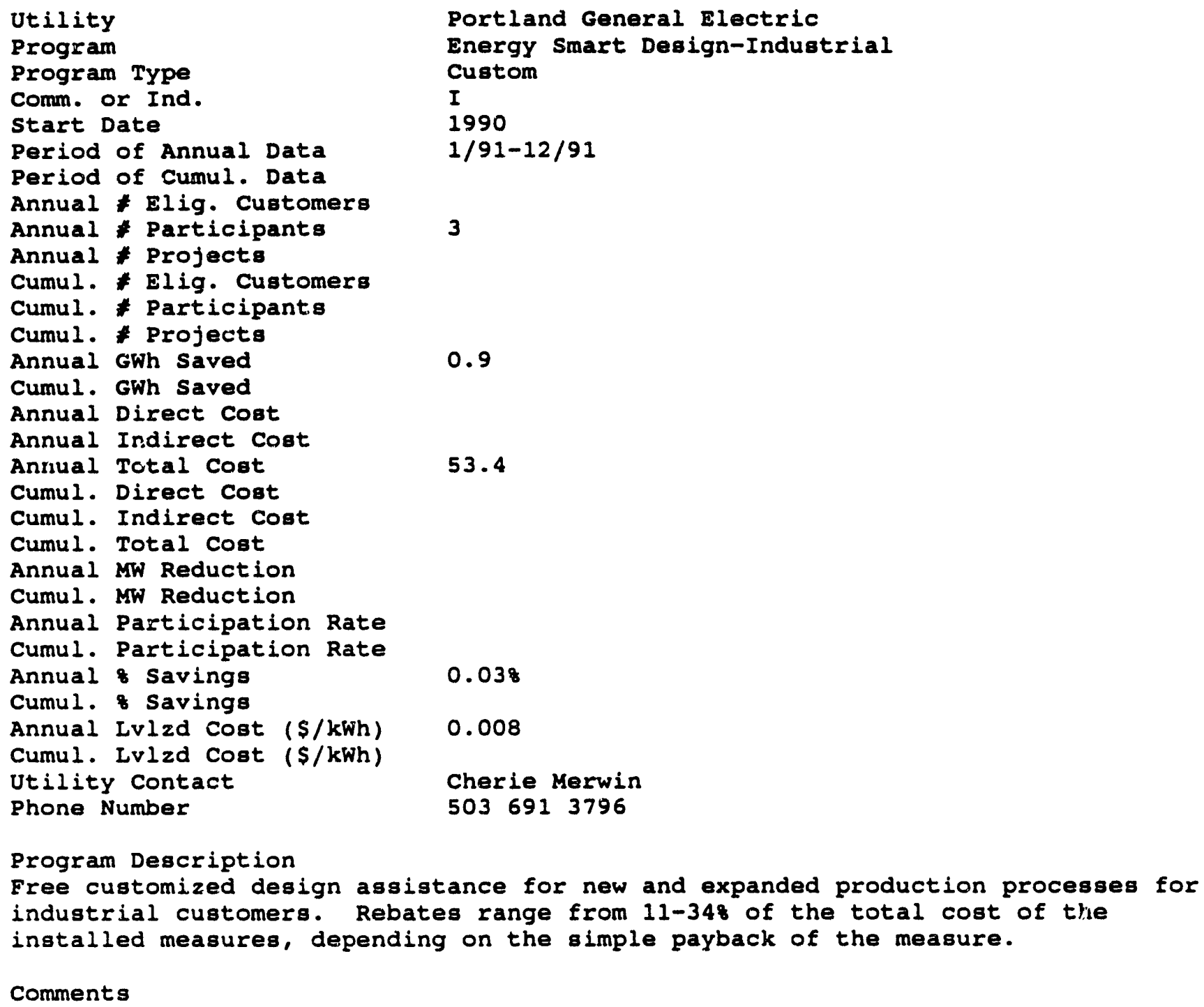

Comments 


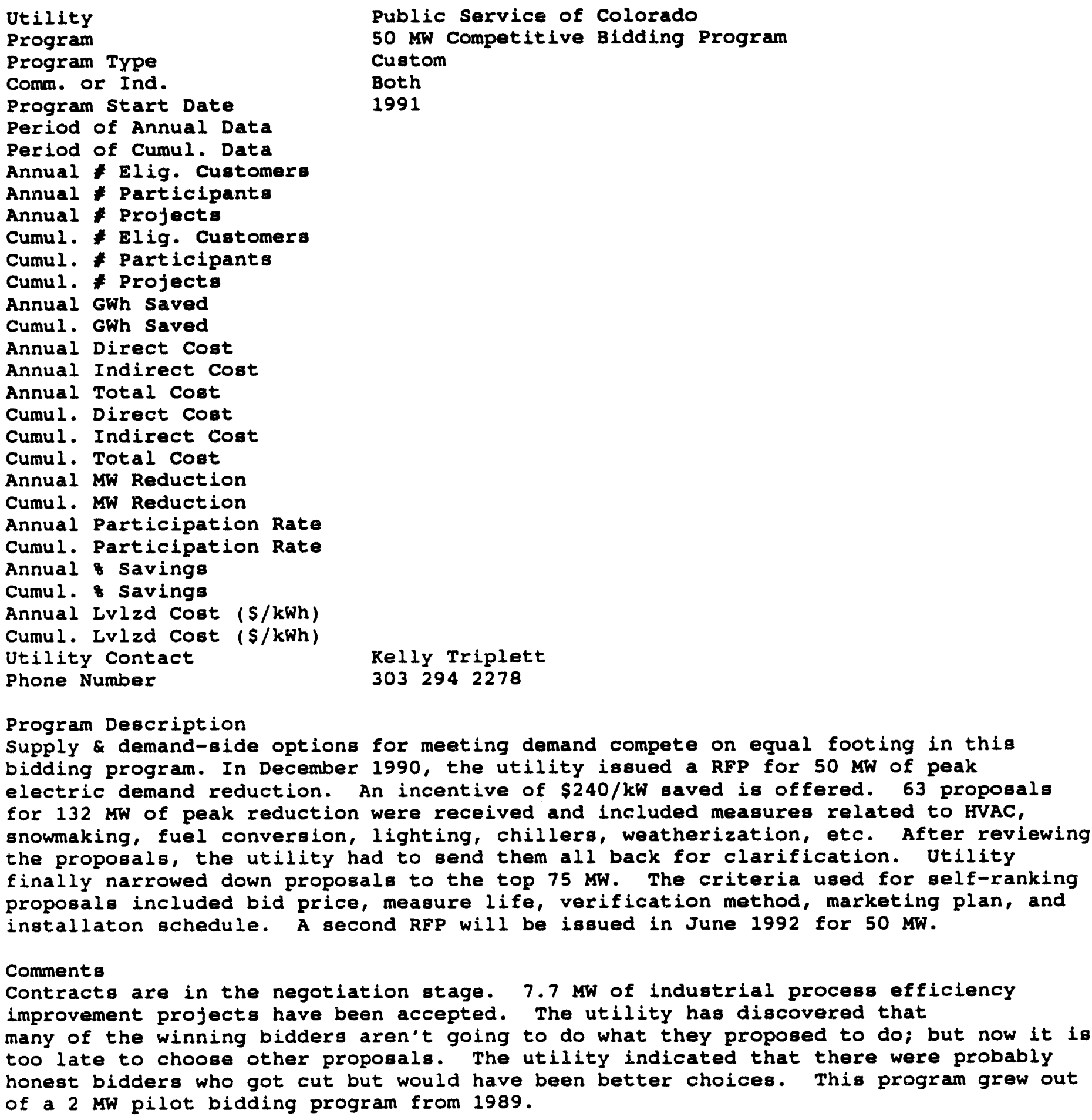




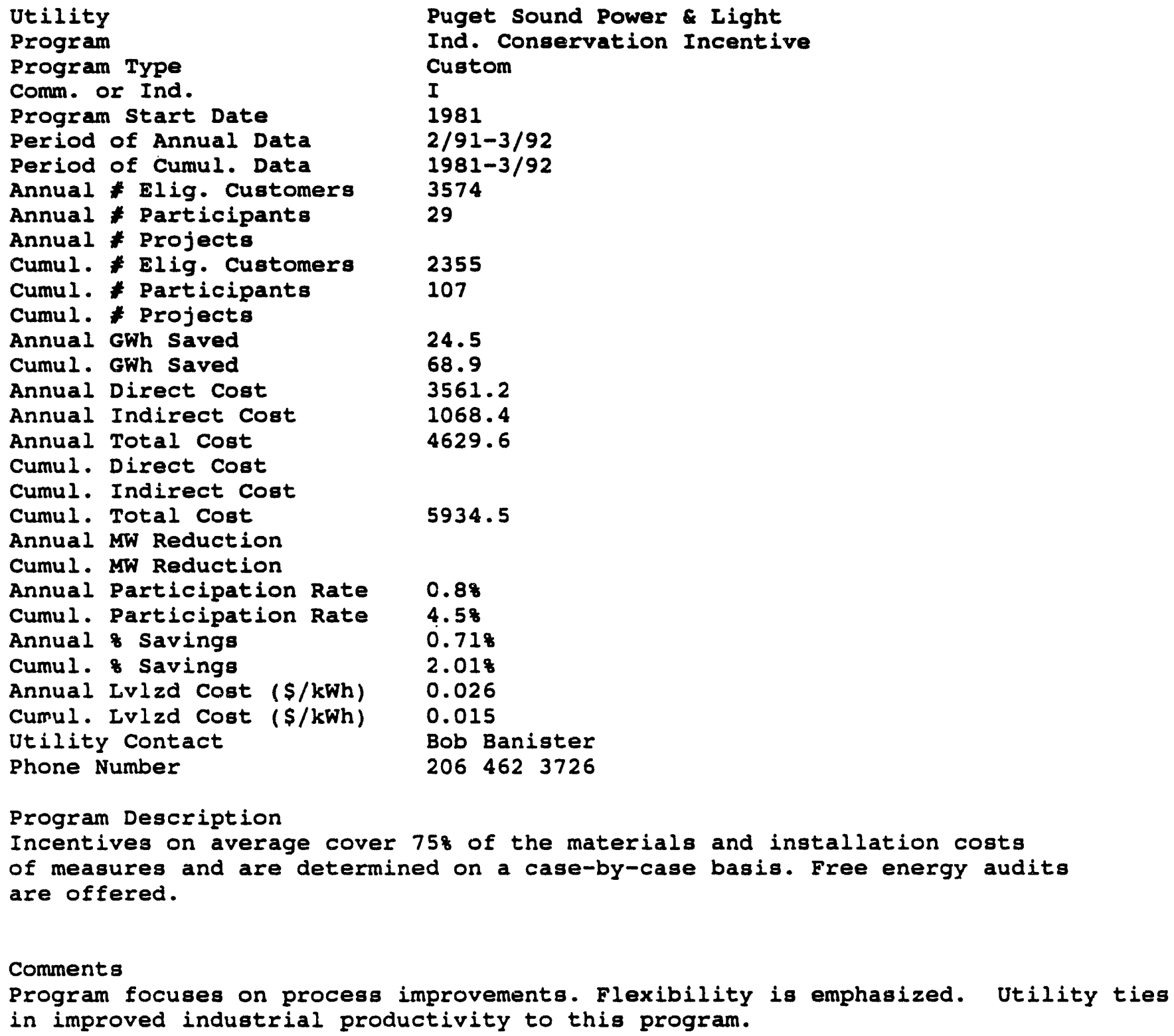




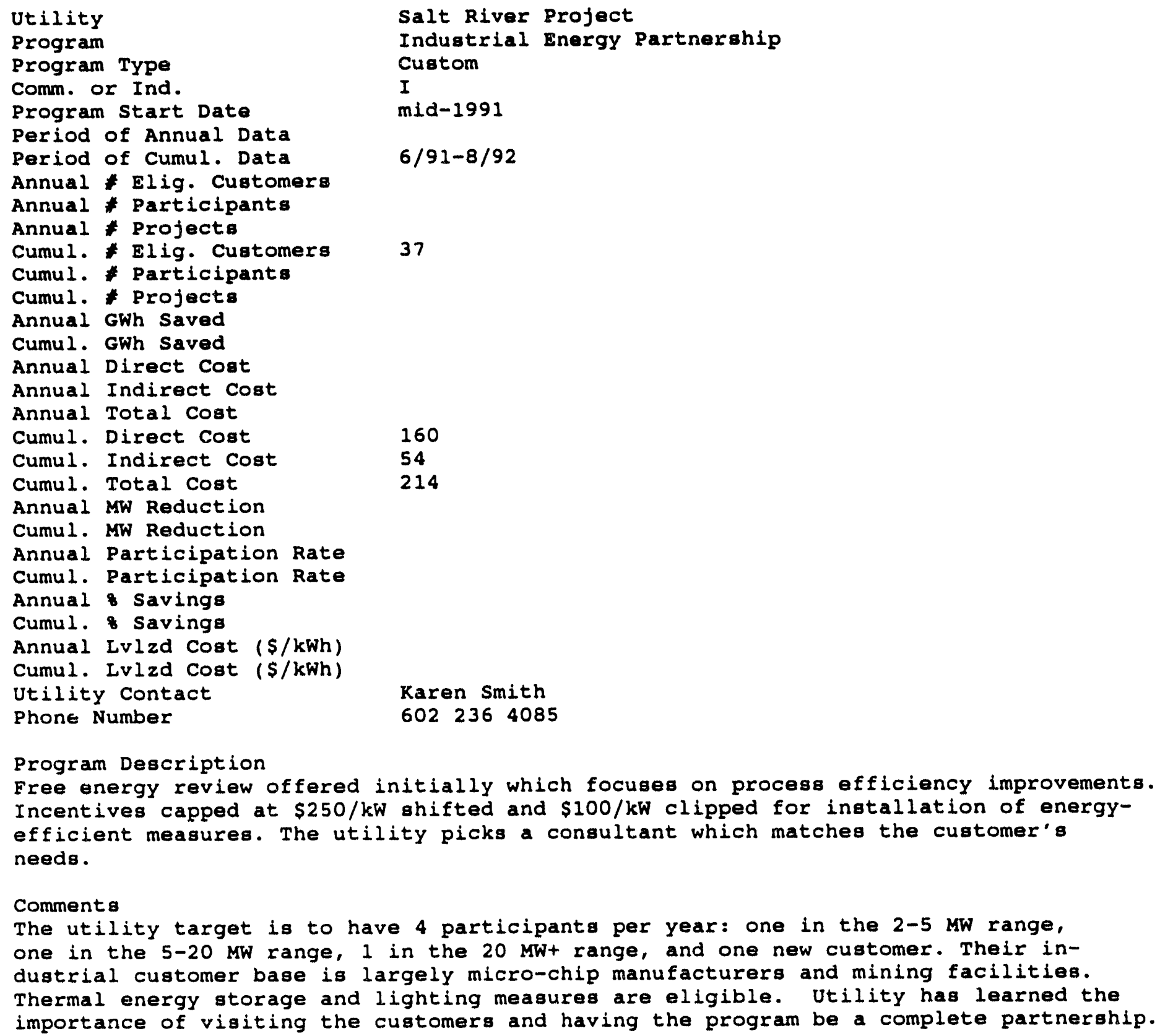




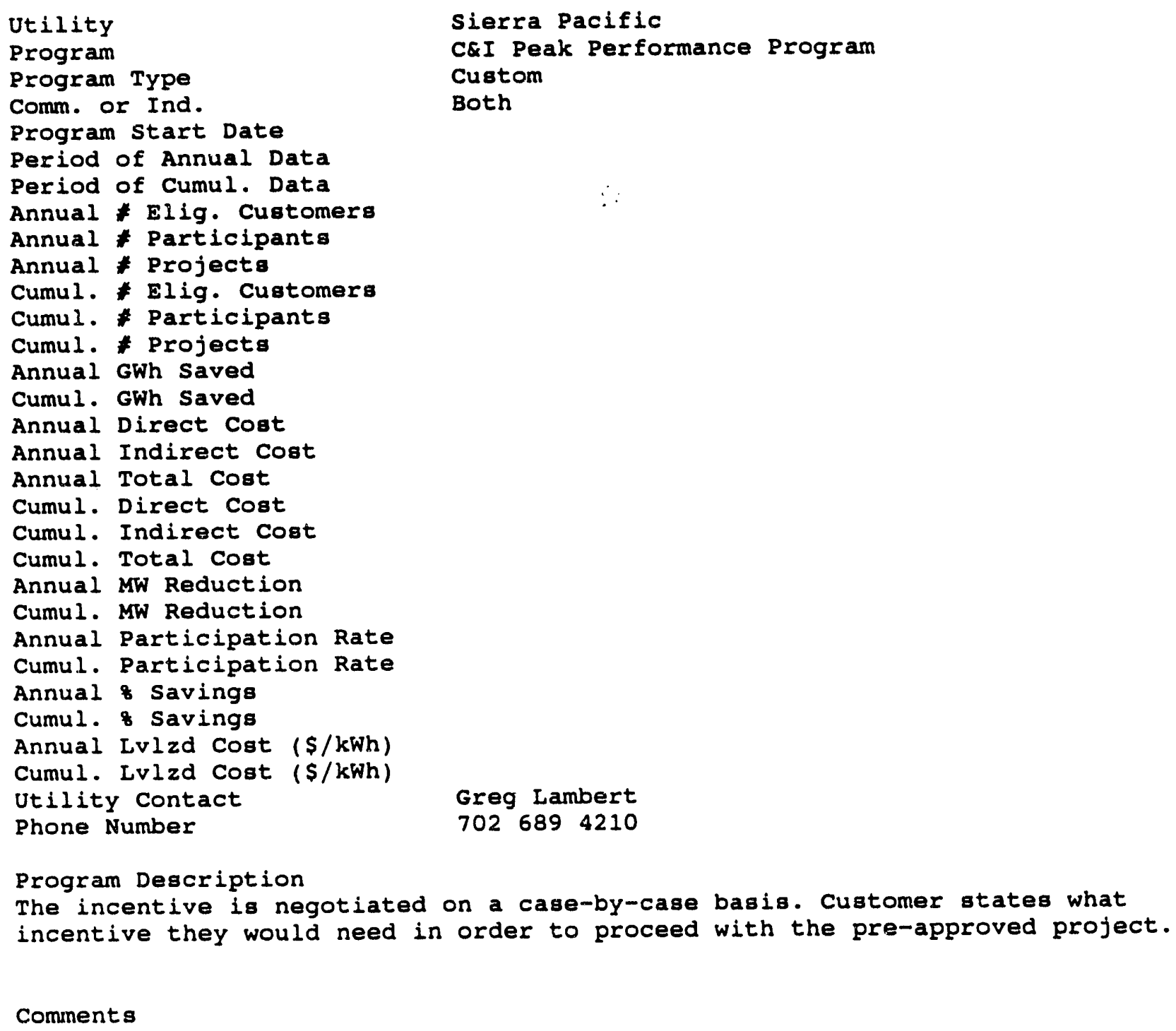

Comments 


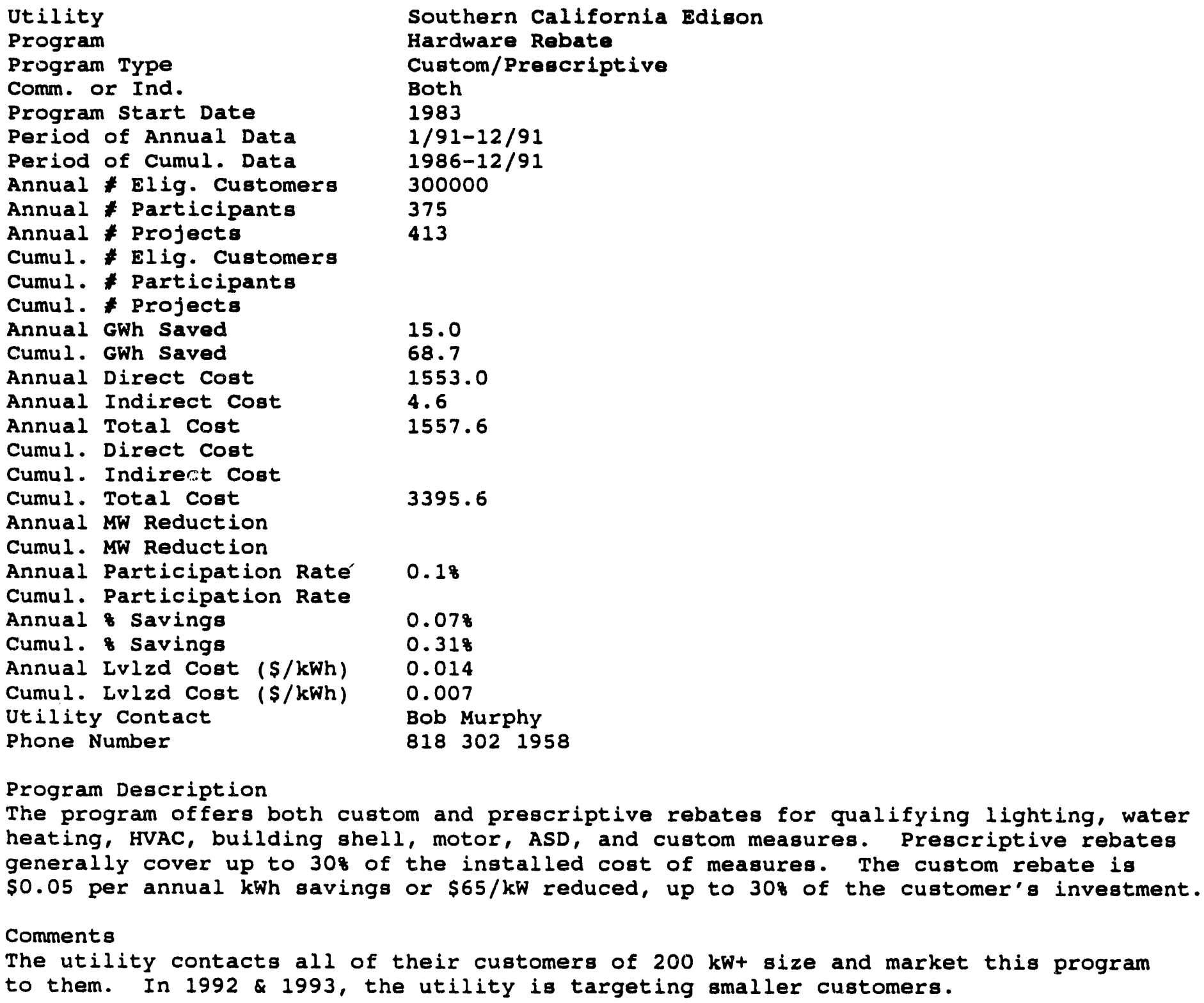

Program Description

The program of fers both custom and prescriptive rebates for qualifying lighting, water heating, HVAC, building shell, motor, ASD, and custom measures. Prescriptive rebates generally cover up to 308 of the installed cost of measures. The custom rebate is $\$ 0.05$ per annual $\mathrm{kWh}$ savings or $\$ 65 / \mathrm{kW}$ reduced, up to $30 \%$ of the customer's investment.

Comments

The utility contacts all of their customers of $200 \mathrm{~kW}+$ size and market this program to them. In 1992 \& 1993, the utility is targeting smaller customers. 
Utility

Program

Program Type

Comm. or Ind.

Program start Date

Period of Annual Data

Period of Cumul. Data

Annual * Elig. Customers

Annual * Participanto

Annual * Projects

Cumul. * Elig. Customers 20000

Cumul. * Participants

Cumul. * Projects

Annual GWh saved

Cumul. GWh saved

Annual Therm Saved

Cumul. Therm Saved

Annual Direct Cost

Annual Indirect cost

Annual Total cost

Cumul. Direct Cost

Cumul. Indirect Cost

Cumul. Total cost

Annual MW Reduction

Cumul. MW Reduction

Annual Participation Rate

Cumul. Participation Rate

Annual \& Savings

Cumul. \& Savings

Annual Lvizd Cost ( $\$ / \mathrm{kWh}$ )

Cumul. Lvizd Cost ( $\$ / \mathrm{kWh}$ )

Utility contact

Phone Number

I

1990

293

4169

6439

$1.5 \%$
Southern California Gas

Industrial Equipment Replacement/Heat Recovery Program

Custom/Prescriptive

$3 / 91-2 / 92$

$3 / 90-2 / 92$

Dan Gladen

$213 \quad 244 \quad 3652$

Program Description

The utility pays up to 508 of the cost of an audit. space heater, boiler, dryer, furnace, kiln, oven, and process cooking equipment upgrades are eligible for prescriptive incentives Custom rebates of $\$ 2.65 /$ MBtu saved are available for qualifying projects. The heat recovery portion of the program offers a rebate of 508 of the installation costs of a project, or $\$ 0.50 /$ therm saved (whichever is less) for heat recovery projects.

Comments

Fuel switching measures are not eligible due to the regulator's concerns about fuel wars. In Heat Recovery program, economizers and recuperators are the most frequently installed and rebated measures. 


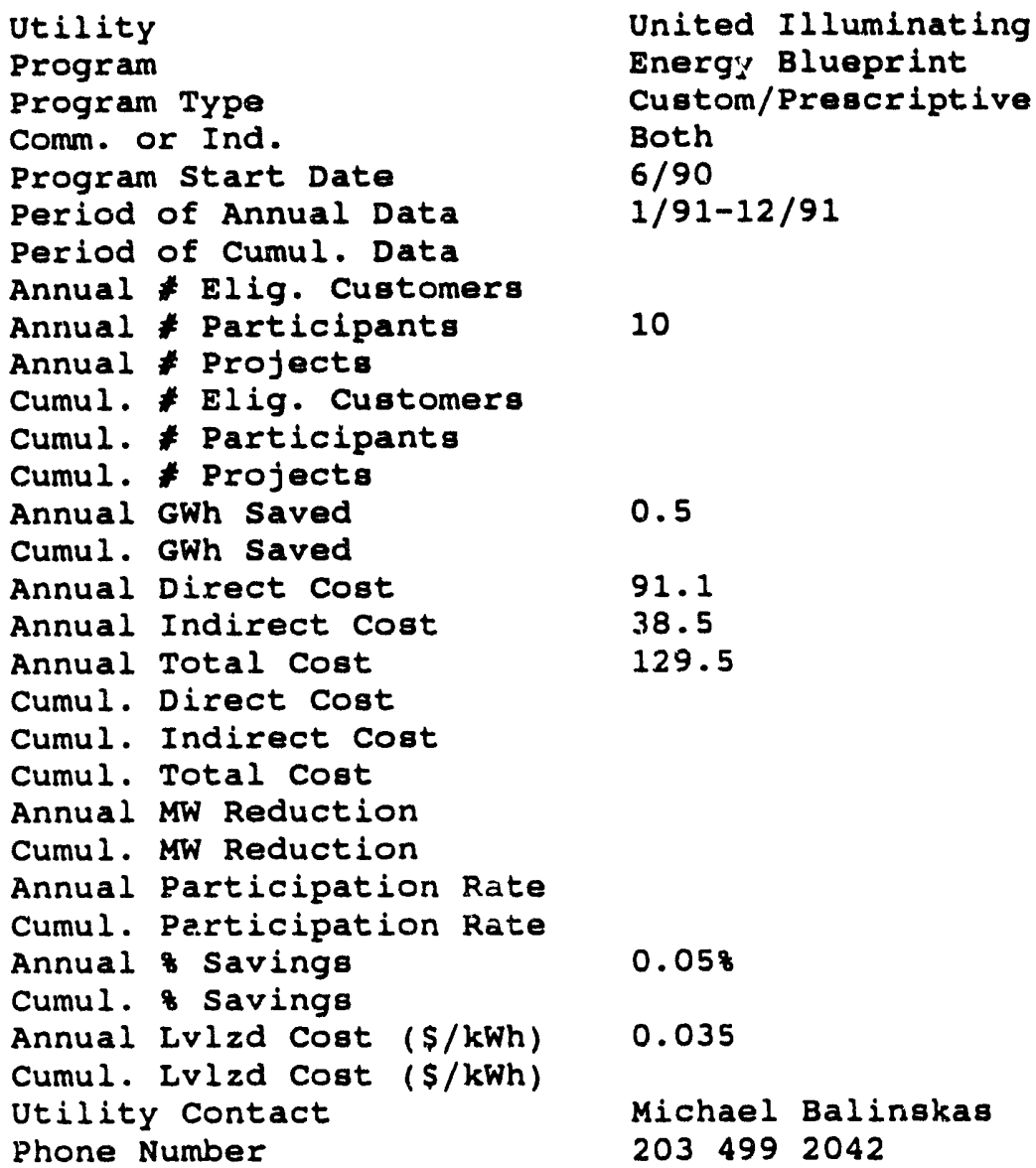

Program Description

Incentives are offered for energy-saving projects in c\&I new construction.

Prescriptive rebates are available for installation of high-efficiency motors, lighting, building envelope, HVAC, and heat recovery equipment. Custom rebates based on kw saved are offered for measures not fitting into any precriptive rebate. Design grants are also available to architects and engineers and is calculated using UI's sliding scale and multiplying it by the affected square footage.

Comments

While the program was offered in 1990 and 1991, the industrial portion was not experiencing much participation. Therefore, in 1992 a larger industrial incentive was offered which was 308 larger than the commercial incentive. Cooling

and lighting measures have brought the largest savings to date. No incentives are given for fuel conversion measures, but the utility will give recommendations of fuel switching to gas when appropriate. 


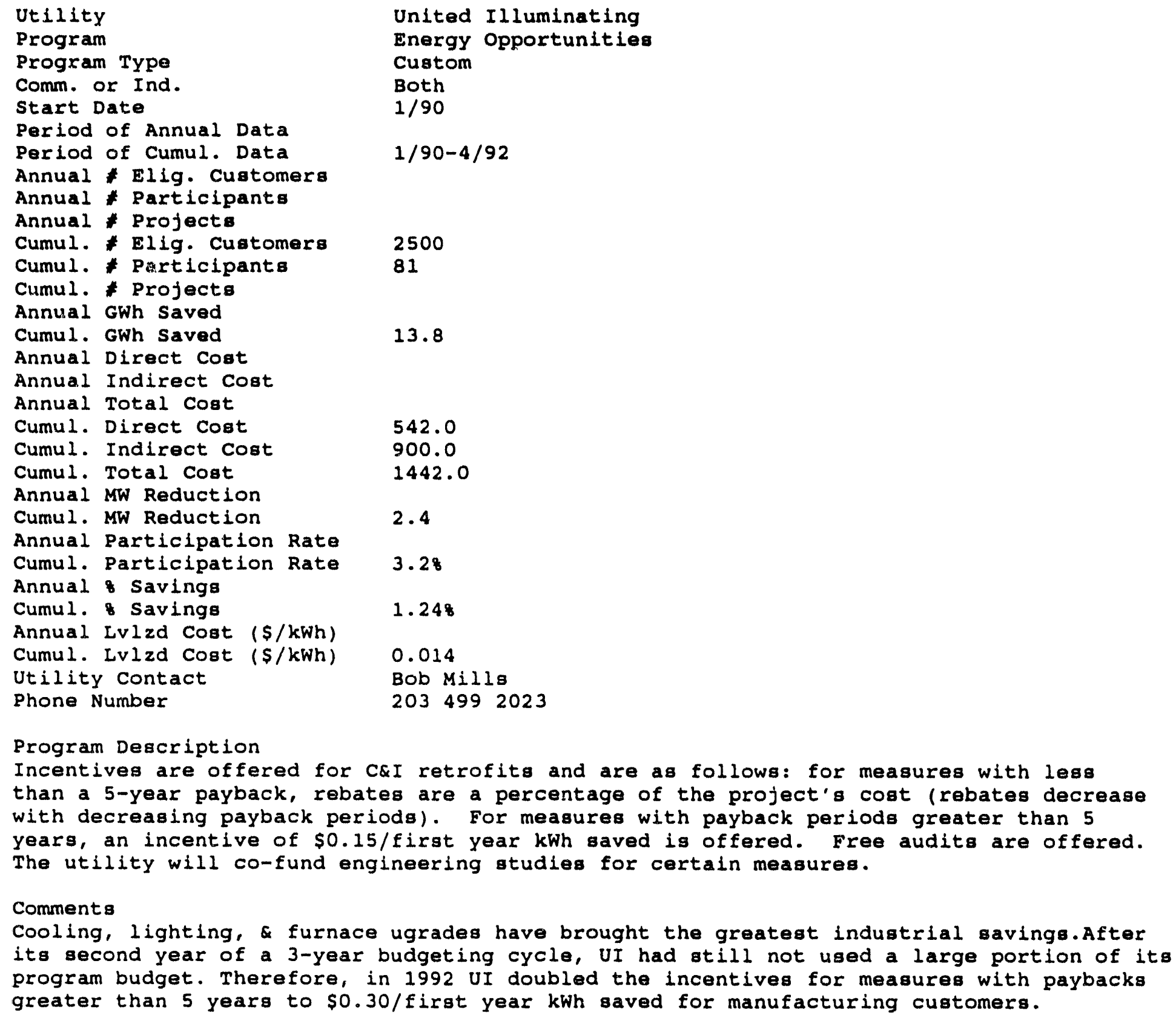




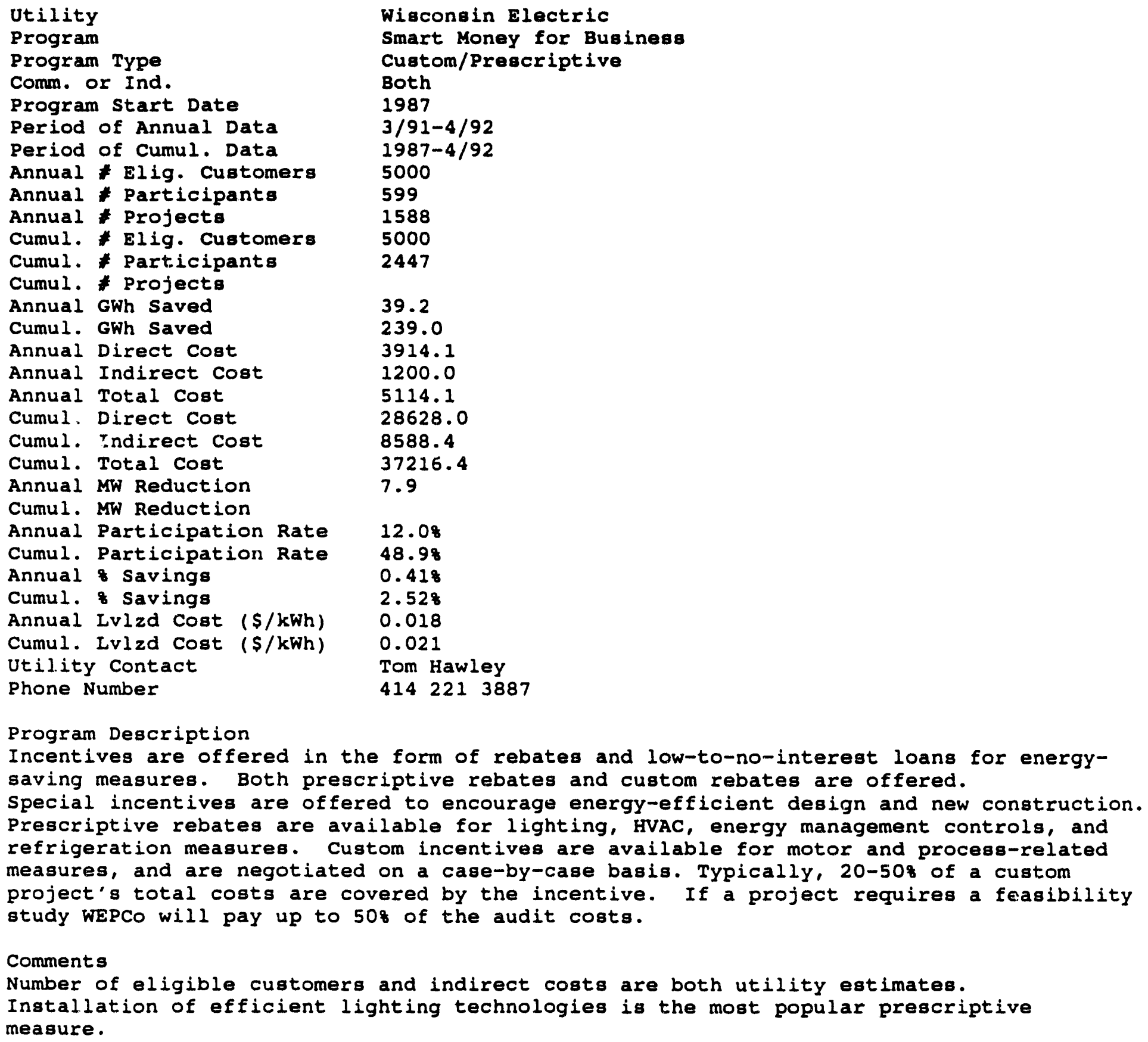


Utility

Program

Program Type

Comm. or Ind.

Program start Date

Period of Annual Data

Period of Cumul. Data

Annual * Elig. Customers

Annual * Participants

Annual * Projects

Cumul. * Elig. Customers

Cumul. * Participants

Cumul. * Projecta

Annual GWh saved

Cumul. GWh Saved

Annual Therm Saved

Cumul. Therm Saved

Annual Direct Cost

Annual Indirect Cost

Annual Total cost

Cumul. Direct Cost

Cumul. Indirect Cost

Cumul. Total Cost

Annual MW Reduction

Cumul. MW Reduction

Annual Participation Rate

Cumul. Participation Rate

Annual \& Savings

Cumul. \& Savings

Annual Lvizd Cost ( $\$ / \mathrm{kWh}$ )

Cumul. Lvizd Cost ( $\$ / \mathrm{kWh}$ )

Utility Contact

Phone Number
Wisconsin Fuel \& Light

Heating/Processing Burner Tune-up

Prescriptive

I

Tom Bosey

4146822541

Program Description

An incentive is offered for tune-ups of process heating burner equipment. The incentive is 758 of the cost of the tune-up.

Comments 


\author{
Utiity \\ Program \\ Program Type \\ Comm. or Ind. \\ Program start Date \\ Period of Annual Data \\ Period of Cumul. Data \\ Annual * Elig. Customers \\ Annual * Participants \\ Annual * Projects \\ Cumul. Elig. Customers \\ Cumul. * Participants \\ Cumul. \# Projects \\ Annual GWh saved \\ Cumul. GWh Saved \\ Annual Therm Saved \\ Cumul. Therm Saved \\ Annual Direct Cost \\ Annual Indirect Cost \\ Annual Total Cost \\ Cumul. Direct Cost \\ Cumul. Indirect cost \\ Cumul. Total Cost \\ Annual MW Reduction \\ Cumul. MW Reduction \\ Annual Participation Rate \\ Cumul. Participation Rate \\ Annual Savings \\ Cumul. \& Savings \\ Annual Lvizd Cost ( $\$ / \mathrm{kWh}$ ) \\ Cumul. Lvizd Cost $(\$ / \mathrm{kWh})$ \\ Utility Contact \\ Phone Number
}

Tom Bosey

4146822541

Wisconsin Fuel \& Light

Efficient Gas Furnace Rebate Program

Prescriptive

I

Program Description

Incentives are offered for the installation of $908+$ efficient gas furnaces.

The incentive equals 108 of a qualifying project's materials \& installation costs.

Comments 


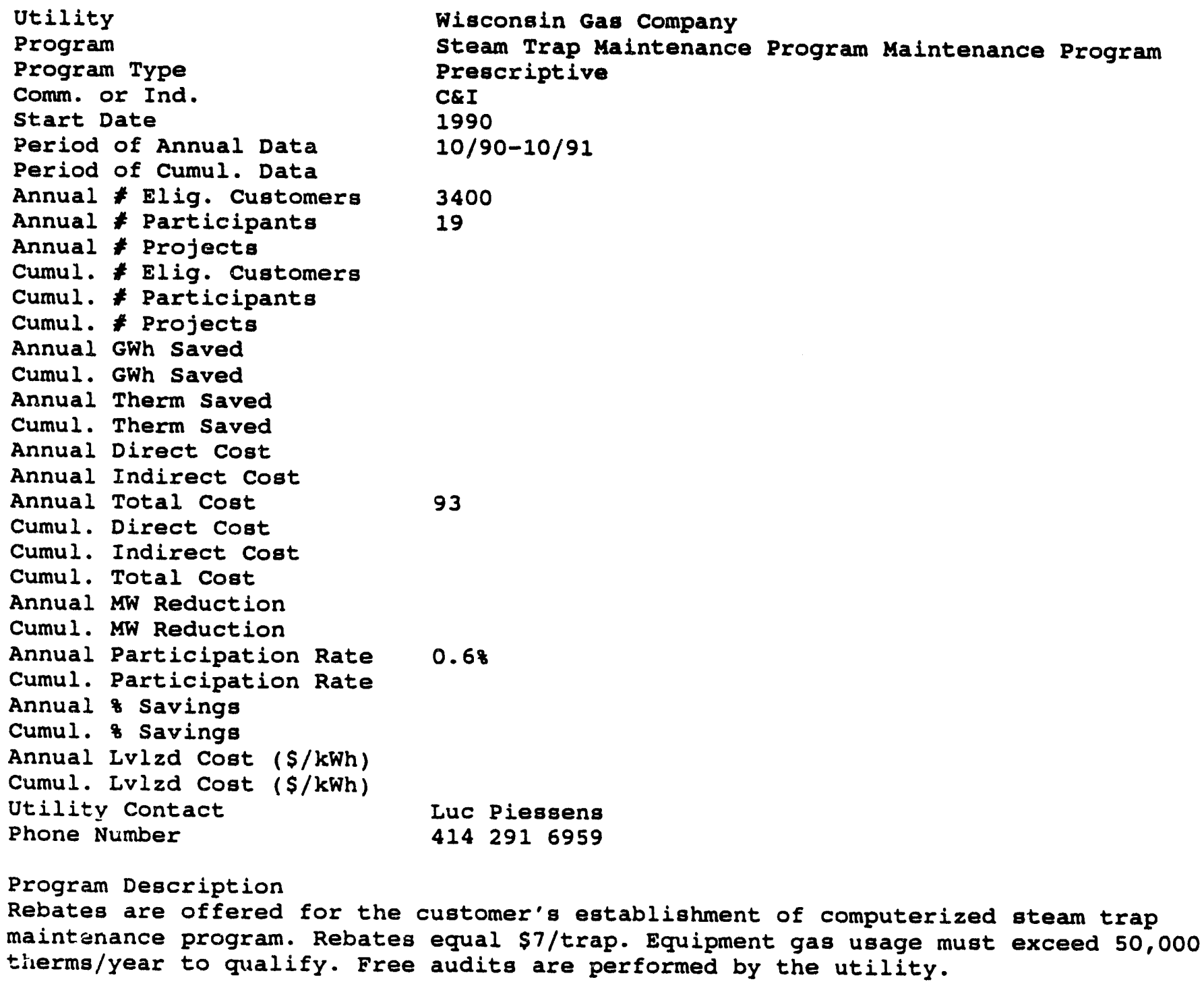

Comments 


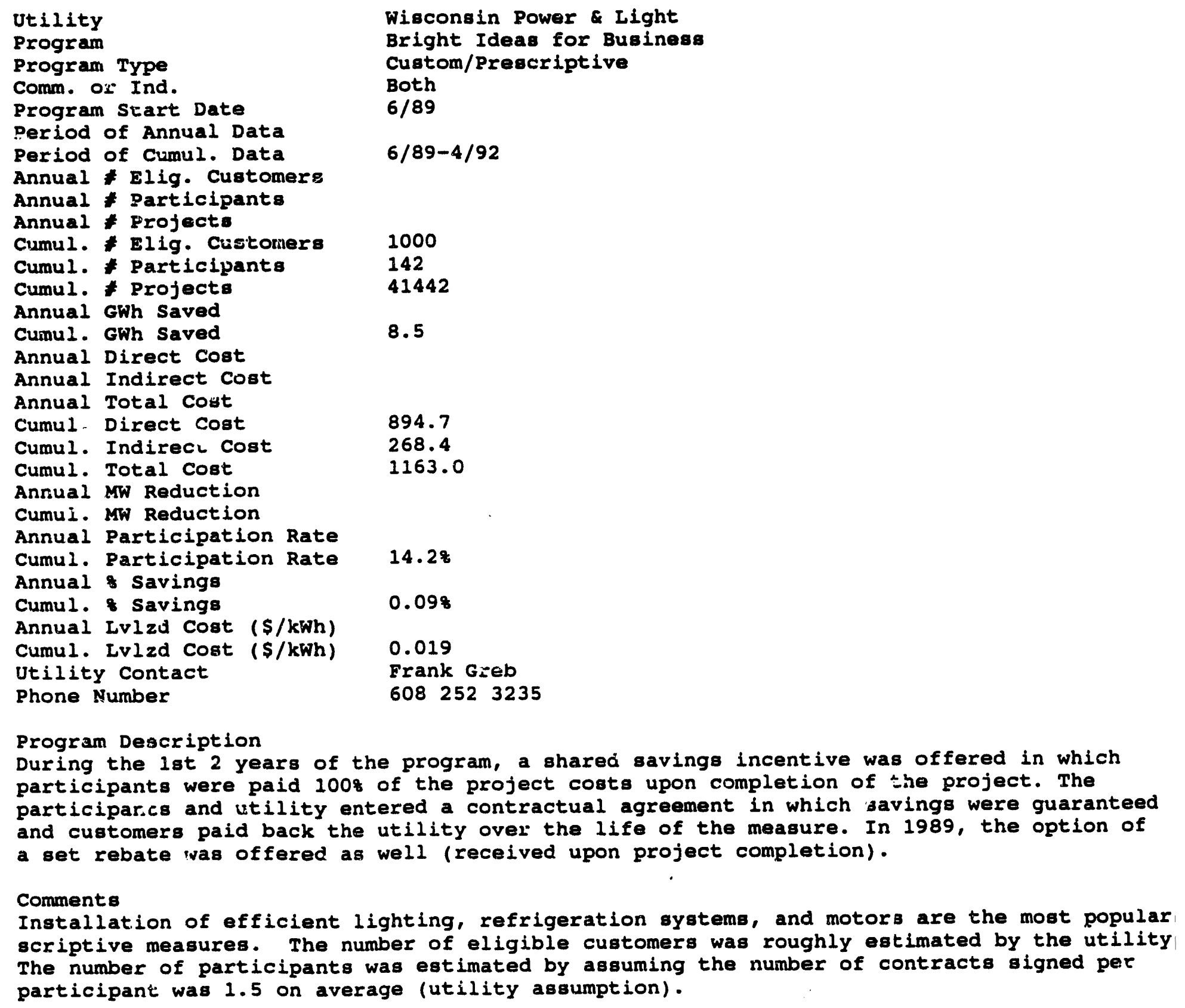

Program Description

During the $18 t 2$ years of the program, a shared savings incentive was offered in which participants were paid $100 \%$ of the project costs upon completion of the project. The participar.cs and utility entered a contractual agreement in which savings were guaranteed and customers paid back the utility over the life of the measure. In 1989 , the option of a set rebate was offered as well (received upon project completion).

Comments

Installation of efficient lighting, refrigeration systems, and motors are the most popular scriptive measures. The number of eligible customers was roughly estimated by the utility The number of participants was estimated by assuming the number of contracts signed per participant was 1.5 on average (utility assumption). 


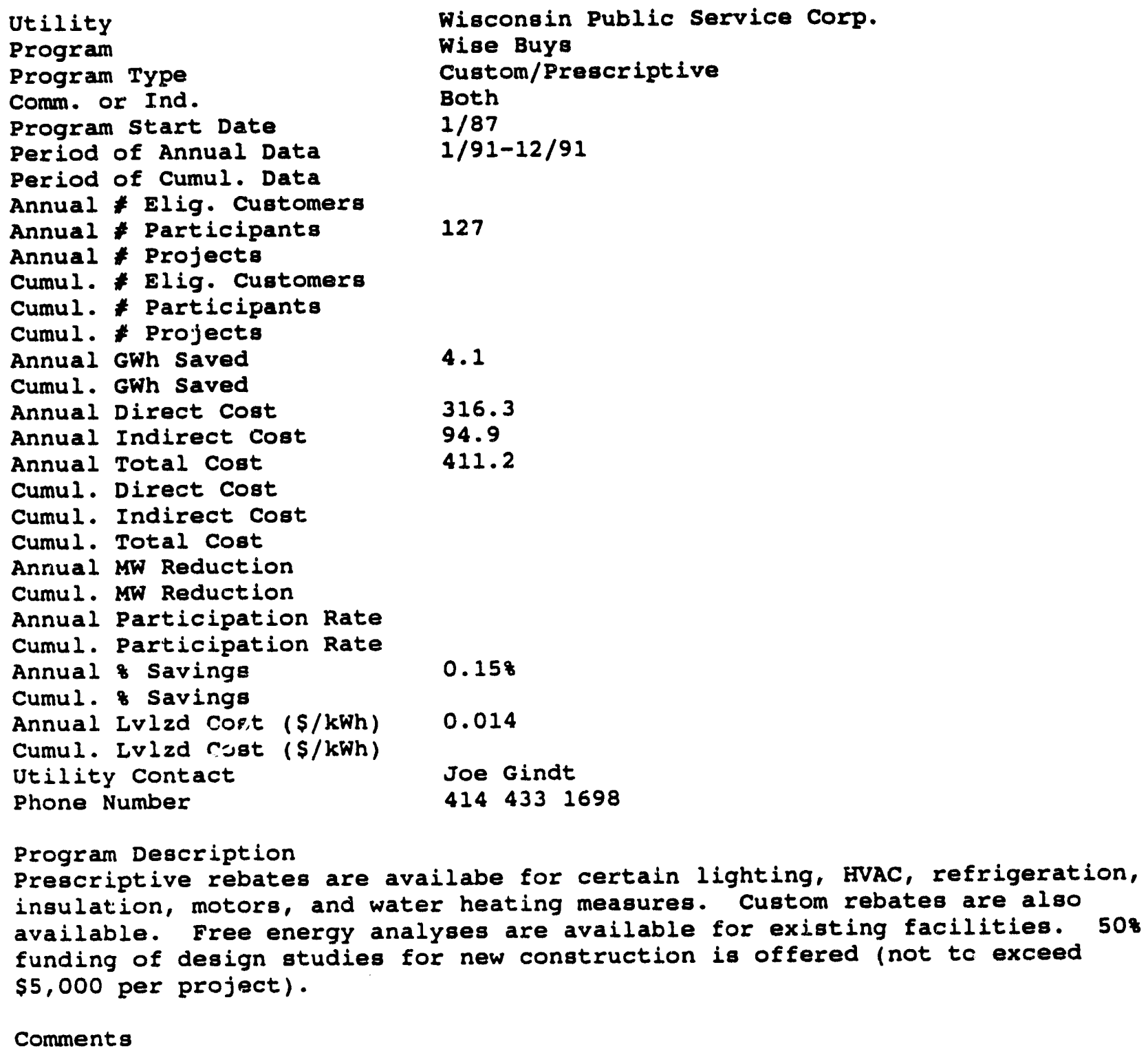

Commentg 


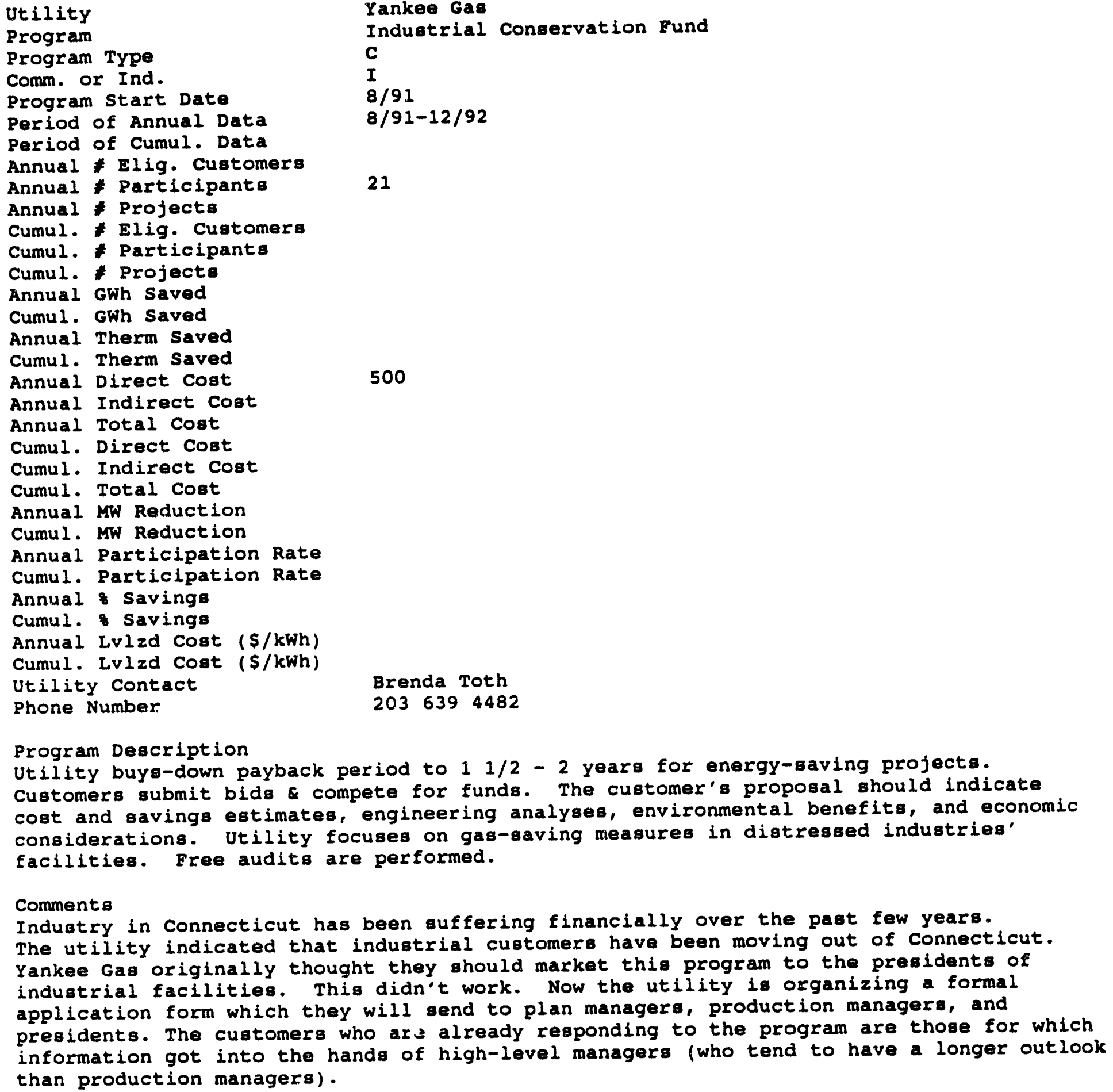




\section{$\Gamma$}
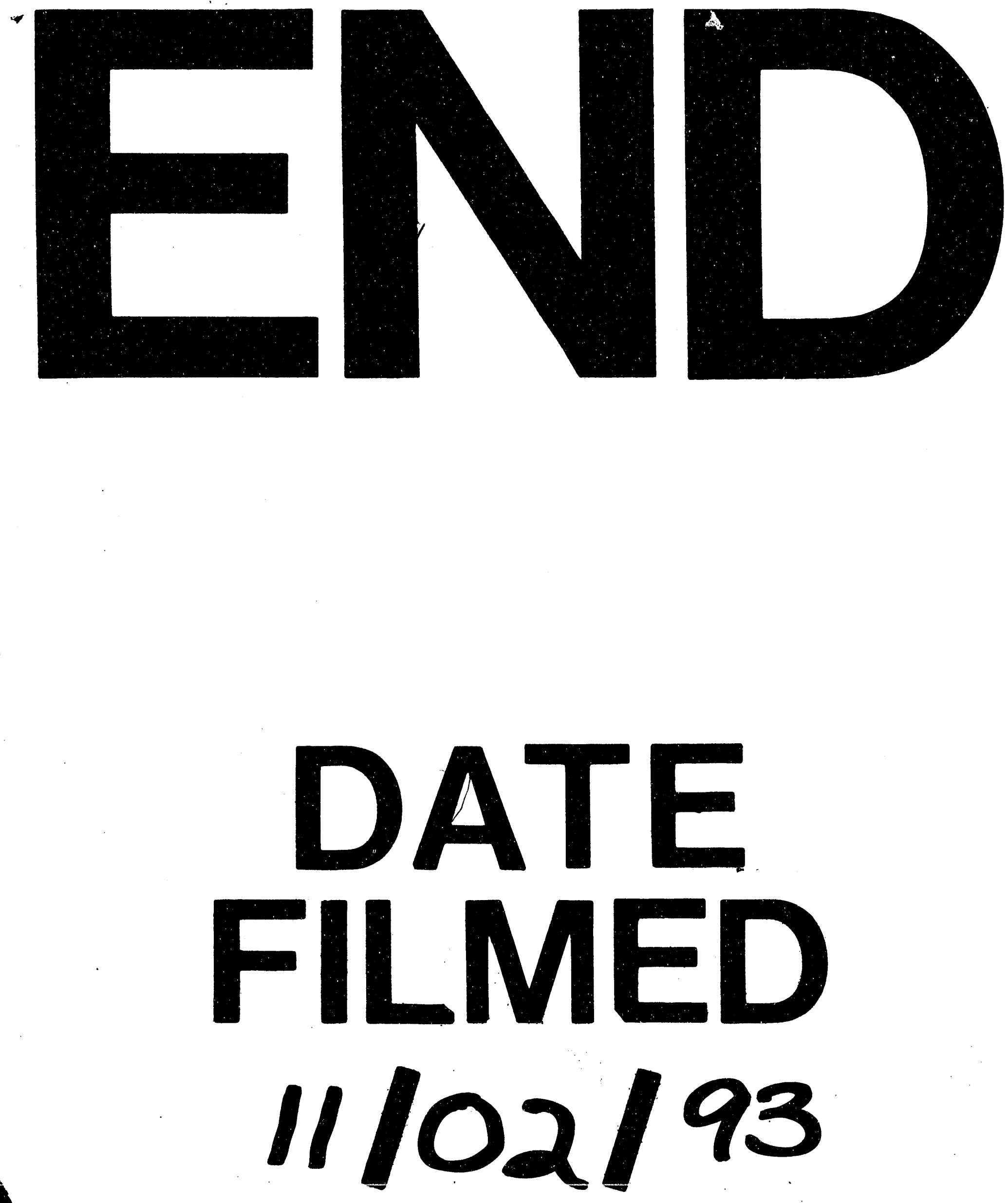

1 
